Fig. 3. Zahlreiche „Übergänge" zwischen Tubuli und L a nge r h a $\mathrm{n}$ s scher Insel. Methylgrün-Pyroninfärbung. Okul. 2, Obj. 6.

Fig. 4. "Insel" aus Insel- und Tubuluszellen fast gleichmäßig zusammengesetzt. MethylgrünPyroninfärbung. Okul. 1, Obj. 6 .

\title{
XXI. \\ Über die pathologische Histologie der syphilitischen Aortitis mit besonderer Berücksichtigung des Vorkommens von Plasmazellen.
}

(Aus dem Pathologischen Institut der Universität Berlin.)

Von

Dr. M. Fuku sh i (Tokio),

Volontärassistenten am Institut.

(Hierzu Taf. VIII.)

Während im Jahre 1885 die erste Arbeit D o e h les über die syphilitische Aortitis zunächst wenig Beachtung gefunden hatte, ist die Diskussion über die syphilitische Genese des von ihm beschriebenen Krankheitsbildes seit dem Kongreß in München im Jahre 1899 nicht verstummt, die Zahl seiner zunächst nur sehr vereinzelten Anhänger ständig gewachsen. Vor allem hatte sich auf diesem Kongreß $\mathrm{B}$ a u m garten gegen die Doehle-Heller sche Ansicht gewandt, indem er hervorhob, daß er bei einem großen, in Königsberg untersuchten Material niemals bei Paralytikern und Syphilitikern an der Aorta arteriitische Veränderungen gesehen habe, die er von der gewöhnlichen Arteriosklerose abgrenzen und als spezifisch syphilitisch hätte ansehen können. Nach $\mathrm{P}$ o n f i c $\mathrm{k}$ sollte der chronische Alkoholismus diese Veränderungen hervorbringen können, nach $\mathrm{Zi}$ e $\mathrm{g} l$ er sich das von D o e h l e beschriebene Krankheitsbild auch bei Infektionen mit Streptokokken und Staphylokokken finden. v. H. a s e m a n n behauptete, die Lokalisation des Prozesses im oberen Teil der Aorta sei kein Charakteristikum für die Spezifität der Erkrankung, da er im unteren Teil der Aorta ein zweifellos syphilitisches Aneurysma gesehen habe.

Standen ganz im Anfang nur B o lli ing er und B e ne ke auf D o e h les Seite, so schlossen sich ihm bald $\mathrm{Straub}, \mathrm{Backhaus,} \mathrm{Simon,} \mathrm{Moll}$ und I s e $\mathrm{n} \mathrm{b}$ er $\mathrm{g}$ an, und die um das Jahr 1903 herum zahlreich erscheinenden Arbeiten, die sich mit dieser Frage beschäftigten, nahmen höchstens eine abwartende oder zweifelnde Haltung an, wie das auch auf der Kasseler Naturforscherversammlung (1903) zum Ausdruck kam. Hier berichteten $\mathrm{Ch}$ i a r i und $\mathrm{B}$ e n d a 
über den Stand der Frage, ob und wie häufig Gummen in der Aorta vorkommen, dabei wurde nicht einmal das Vorkommen von gummösen Veränderungen allgemein als spezifisch für Syphilis angesehen.

Marehand bringt für die Mehrzahl der Fälle das von D o ehle beschriebene Krankheitsbild mit Syphilis in Beziehung, namentlich bei jüngeren Individuen, doch setzt er Zweifel in die histologische Deutung als spezifisch und gummös. Er hält die Beurteilung der Mesaortitis deshalb für schwierig, weil sie sich öfter bei älteren Individuen mit gewöhnlichen arteriosklerotischen Veränderungen kombiniert und weil sich auch die gewöhnliche Form der Arteriosklerose bei Syphilitischen entwickeln kann. A m en de und B a r d a chzi haben sich dahin ausgesprochen, daß diesen eigenartigen Aortenerkrankungen aller Wahrscheinlichkeit nach ein syphilitischer Ursprung zugrunde liegt. In einer 1904 erschienenen Arbeit erkennt $\mathrm{Fahr}$ die Aortenveränderungen nur dann als spezifisch für Syphilis an, wenn das Bindegewebe, das aus den Granulationsherden der Media hervorgeht, tiefe' Einziehungen der Intima erzeugt, wie die Mehrzahl der Autoren mehr oder weniger übereinstimmend beschreibt.

Im Gegensatz zu den genannten mehrten sich die Fälle, in denen ein $\mathrm{Zu}$ sammentreffen von D o eh le scher Aortitis mit anatomisch sicheren Syphilisbefunden beobachtet wurde oder ihr Auftreten bei Personen, bei denen entweder eine syphilitische Infektion durch die Anamnese sichergestellt war oder die an einer Krankheit litten, deren Zusammenhang mit der Syphilis anerkannt ist, wobei allerdings die Aortenerkrankung von den verschiedenen Autoren verschieden benannt wurde: Mesaortitis productiva ( $\mathrm{Ch}$ iari), syphilitische Aortensklerose ( B enda), Mesaortitis syphilitica ( Heller, Kaufmann), schwielige Aortensklerose (Mö n c k e b e r g), sklerogummöse Aortitis (Malmsten).

So stammen die drei Aorten, an denen Do e h l e die spezifische Krankheit zuerst beschrieb, von sicheren Syphilitikern. Nach B a ck ha us wurden 59 Fälle von sicherer Syphilis obduziert, von denen 16 syphilitische Mesaortitis aufwiesen. S t r a u b fand unter 84 Fällen von progressiver Paralyse 69 mit dieser Erkrankung, allerdings wurden nur 27 Fälle mikroskopisch untersucht. $\mathrm{Ch}$ iari fand die Mesaortitis productiva in $59 \%$ seiner sicher Syphilitischen und in $47 \%$ seiner Paralytiker. Rosenberger fand sie unter 153 sicheren Syphilisfällen 27 mal, also in $17 \%$. $\mathrm{F}$ a h r fand unter 29 Fällen mit $\mathrm{D}$ o e h l e scher Aortitis 12, die in der Anamnese oder nach dem Leichenbefund sichere Syphilis ergaben. Molinari hatte unter 10 Fällen Doehleseher Aortitis 6 , bei denen klinisch oder anatomisch Syphilis sichergestellt war. Gins b u r g fand bei 96 Leichen von Paralytikern $58 \mathrm{mal}$ makroskopische spezische Aortenveränderungen. E i $\mathrm{ch}$ untersuchte 63 Aorten, deren gemeinsames Charakteristikum entzïndliche umschriebene Veränderungen an der Media und Adventitia der Aorta mit entsprechendem makroskopischen Ausdruck bildeten. Darunter waren 10 Fälle mit sicherer Syphilis, 17 Fälle mit metasyphilitischen Erkrankungen, 36 Fälle ohne anatomische oder klinische Beweise für Syphilis.

Dagegen war es Th o r el aufgefallen, dab diese Aortitis gar nicht selten ist, während sich sichere Syphilisbefunde viel seltener bei Sektionen erheben lassen, oft also bei der Aortitis vermiBt werden. Nach W i ed e m a $n \mathrm{n}$ ist es kaum angängig, Prozesse als spezifisch anzusehen, die an anderen Organen nicht als solche gelten und selbst in der Aorta, wenn auch in geringerem Grade, 
bei Arteriosklerose beschrieben worden sind. $\mathrm{Bau} \mathrm{mart}$ en hält es für wahrscheinlich, daB die Fälle der gummösen Aortitis Produkte des syphilitischen Virus sind, kann aber die granulierende oder produktive Mesaortitis ( $\mathrm{Ch}$ iari) nicht so ohne weiteres als syphilitisch anerkennen, da dieselbe sehr häufig auch bei Individuen beobachtet wird, bei welchen jeder Anhaltspunkt für stattgehabte Syphilis fehlt und die Annahme dieser Infektion höchst unwahrscheinlich oder ansgeschlossen ist. $0 \mathrm{rth}$ und $\mathrm{Z}$ i e gler erklären unter Freilassung der Möglichkeit, daB Syphilis die geschilderten Veränderungen hervorrufen könne, daß sie dieselben Erscheinungen auch bei Personen beobachtet hätten, bei denen anamnestisch und anatomisch niehts für eine stattgehabte syphilitische Infektion sprach. Fra en kel fand bei einer 24 jährigen Frau eine auf der Basis eines schweren Gelenkrheumatismus entstandene, der Do ehl e sehen Aortitis völlig gleichartige Veränderung der Aorta. Nach A b r a mow findet sich dieser Prozeß (Wucherung von Granulationsgewebe und Vaskularisation in der Media und Adventitia, Verdickung der Intima) auch häufig bei Personen ohne Anzeichen von Syphilis und ist daher vom anatomischen Standpunkte für diese nicht charakteristisch. Nur gummöse Aortitiden sind anatomisch beweisend. Etwa seit 1905 mehrte sich noch die Załl der Autoren, welche die D o e h l e sche Aortitis bestätigten.

F o à berichtet über 4 Fälle von Aortenaneurysma bei jugendlichen, sicher syphilitischen Individuen. In allen diesen Fällen fand er die Läsion, meist an dem Aortenbogen.

Wi es ner und Bruhns untersuchten die kongenital-syphilitisehe Aorta. Sie meinten, daß anch die Mesaortitis productiva des Erwachsenen durch Syphilis entstehen könne, da die Verärderungen in beiden Fällen ganz gleich wären. $\mathrm{Has} \mathrm{selb} \mathrm{ach} \mathrm{fand} \mathrm{das} \mathrm{gleiche} \mathrm{Resultat.}$

Eich sagt: „Eine vorausgegangene syphilitische Infektion ist für eine große Zahl der Individuen mit Doehle-Hellerscher Aortitis sicher oder wahrscheinlich insgesamt für über $86 \%$."

Steinmeier untersuchte neuerdings einen Fall von syphilitischem Aneurysma und sagt: „Die Aortenveränderungen, wie sie zuerst von D o e hl e und der H elle r schen Schule beschrieben wurden, lassen den sicheren Schluß auf eine stattgehabte luetische Infektion zu."

Es war früher sehr schwer, die Do eh le sche Aortitis und gewöhnliche Arteriosklerose oder Skleratherose voneinander zu unterscheiden, besonders dann, wenn in den übrigen Orgarien, außer der Aorta, keine sichtbaren, syphilitischen Veränderungen sich zeigten. Aber jetzt kann man schon, ungeachtet der großen Ähnlichkeit zwischen D o e h le scher Aortitis und gewöhnlicher Arteriosklerose, durch gewisse besondere Merkmale diese beiden Erkrankungen in manchen Fällen unterscheiden, wenn auch bei geringen Veränderungen, oder wenn das Erkrankungsbild nicht typisch ist, die Entscheidung sehr schwierig sein kann. (Ich werde später zeigen, daß es auch hier möglich ist, mikroskopisch eine Differentialdiagnose zu stellen.) Die bis jetzt bekannten Unterscheidungsmerkmale sind folgende:

Bei Arteriosklerose oder Skleratherose erkrankt nicht nur die Aorta, sondern es leiden auch die Arterien. In den Intimaverdickungen besteht große Neigung zu regressiven Veränderungen (fettige Degeneration, atheromatöse Veränderung, Kalkablagerung). Der primäre Herd liegt in der Intima. Wenn auch zuweilen Entzändungsherde in der Media und Adventitia vorkommen, so zeigen sie doch kaum eine derartige Ausdehnung und so starke Zellinfiltration wie bei D o e h l e scher Aortitis. Endlich findet sich Arteriosklerose meist bei älteren Personen. 
Die D o e h l e sche Aortitis erstreckt sich meist nur auf die Aorta ascendens und den Arcus aortae, seltener auf die Aorta thoracica, sehr selten auf die Aorta abdominalis; es besteht nur geringe Neigung zu regressiver Veränderung in den dabei vorhandenen Intimaverdickungen. Die Intima hat ein strahlig-narbiges, höckeriges, runzeliges Aussehen. Der Hauptteil der Erkrankung ist Media und Adventitia; es sind eigenartige Entzündungsherde vorhanden.

Ganz besonders beachtenswert und diagnostisch wichtig ist die Anwesenheit von Aneurysmen an syphilis-verdächtigen Aorten. Der lange Kampf um die Ätiologie der Aneurysmen ist zugunsten der syphilitischen Ätiologie entschieden. Es sei gleich hier bemerkt, daß sämtliche (27) von mir untersuchten Fälle sich auch abgesehen von dem mikroskopischen Befunde als syphilitisch nachweisen ließen.

Man trifft auch tuberkulöse Veränderungen in der Aorta, wenn sie auch äußerst selten sind. Dabei können die histologischen Veränderungen genau so wie bei syphilitischer Aortitis aussehen. Deshalb ist es auch nötig, die beiden voneinander zu unterscheiden.

Tuberkulös erkrankt die Aorta am häufigsten durch Kontakt, wenn benachbarte Organe erkrankt sind, meist Drüsen usw. Seltener geschieht die Infektion. auf hämatogenem Wege, wobei entweder die Intima ergriffen wird oder Knoten sich in der Wand selbst bilden, dadurch, daß die Tuberkelbazillen in die Vasa vasorum eindringen. Es muß also entweder in der Nähe der Aorta ein tuberkulöser Herd oder eine allgemeine Miliartuberkulose bestehen. Kann man beides mit Sicherheit ausschließen, so hat man ein Recht, die Tuberkulose als ätiologisches Moment für diesen Fall abzulehnen. Natïrlich ist das Fehlen von Tuberkelbazillen in den Herden der Aortenwand sehr wichtig.

Immerhin ist es noch fraglich, ob diese eigenartige Veränderung der Aortenwand spezifisch syphilitisch ist oder auch durch andere Noxen, wie Infektion und Intoxikation usw. erzeugt werden kann, wenn auch in einem solchen Fall eine syphilitische Infektion an sich nachgewiesen ist.

In neuester Zeit hoffte man, mit Hilfe der L evaditi schen Methode die Spirochaeta pallida in den Aortenherden nachweisen zu können und damit die syphilitische Natur dieser so viel umstrittenen D o e h 1 e - H e 11 e r schen Aortitis sicherzustellen.

Bisher haben viele Forscher in der Aorta vergeblich nach Spirochäten gesucht, während Beitzke, A s.ch of f, Stras s m a n usw. in der Wand der syphilitischen kleinen Arterien (meist Hirnarterien) Syphiliserreger fanden.

Zuerst haben Reuter, Schmorl und Benda Syphiliserreger in einzelnen Fällen reiner oder mit Aneurysmabildung kombinierter syphilitischer Aortitis gefunden. Im Jahre 1909 gelang der Nachweis der Syphiliserreger in den Herden der Media W r i g h t und $\mathrm{R} \mathrm{i} \mathrm{ch}$ a $\mathrm{rd}$ s o $\mathrm{n}$.

Dagegen hat $\mathrm{F} \mathrm{ahr}$ bei 31 untersuchten Aneurysmen mit starken entzündlichen Herden in der Media keine Spirochaeta pallida gefunden. T h o r el untersuchte 4 Fälle, und zwar ebenfalls ergebnislos. A s ch off hatte bei gummöser Form ein negatives Resultat. Ben da be- 
schreibt in einem Falle von Arteriitis syphilitica Spirochäten im Gebiet der frischen Peri- und Mesarteriitis, die nicht die typisch geschlängelten Formen aufweisen, sondern einen starken körnigen Zerfall in kleine Fragmente zeigen, wie ihn neuerdings D o u tre lepont gerade bei den Produkten der tertiären Syphilis beobachtet hat; außerdem waren sehr zahlreiche stark gestreckte Spirochäten zu sehen. Th orel hält diese sogenannte Spirochäte Bendas für ein Kunstprodukt. Ebenso hegt Fränkel Zweifel in dem Reuterschen Falle. Ste in meier hat bei Untersuchung eines Falles von syphilitischem Aneurysma keine Spirochäten nachweisen können.

Im Jahre 1908 haben als erste E. Frä $\mathrm{nkel}$ und M u ch die syphilitische Natur durch die Wassermannsehe Reaktion am Leichenblut aufzuklären versucht. Seitdem wurde diese Reaktion von vielen Forschern bei zahlreichen Aortenerkrankungen für diesen Zweck gebraucht, ohne daß ihre Ergebnisse einwandfrei gewesen wären. Deswegen wurde sie bei meinen Untersuchungen nicht verwendet. Es folgt aus den angestellten Untersuchungen jedenfalls, daß auch der positive Ausfall der Was sermann sehen Reaktion am Leichenblut nicht mit absoluter Sicherheit für eine vorausgegangene syphilitische Infektion spricht, und daß darum auch die $W$ as sermain $\mathrm{sche}$ Reaktion allein weder in positivem noch in negativem Sinne imstande ist, eine Entscheidung dafür zu liefern, ob alle Fälle von granulierender oder narbiger Aortitis auf syphilitischer Basis entstehen. Aber selbst beim Lebenden gibt ja die Wassermannsche Reakti on keine absolut zuverlässigen Resultate, da sie bisweilen trotz manifester Syphilis negativ ausfallen kann.

Jes i o n e k und Meirow ski erhielten bei Syphilis II ebensoviel positive wie negative Resultate, in der Spätlatenz sogar mehr negative. L e d e $\mathbf{r}$ m a $n$ n erhielt bei offenbarer Syphilis III die meist von positiver Was s r m a n n $\mathrm{ch}$ er $\mathrm{Reakti}$ o begleitet zu sein pflegt, noch $4 \%$ negative Resultate.

Wenngleich also weder durch die bakteriologisehe noch durch die serologische Untersuchung ein sicherer Beweis für die syphilitische Natur der Aortenerkrankung erbracht werden konnte, so wird trotzdem in Berïcksichtigung aller Besonderheiten heute fast übereinstimmend eine syphilitische Ätiologie der in Frage stehenden Aortenerkrankung angenommen. Es spielen dabei die anatomischen Befunde eine Hauptrolle, obgleich über die Deutung besonders der mikroskopischen Bilder im einzelnen eine Einigkeit bisher nicht erzielt worden ist, wie denn überhaupt die mikroskopischen Verhältnisse noch nicht bis in die feinen Einzelheiten klargelegt worden sind.

Einer Erscheinung insbesondere, der meines Erachtens eine nicht unerhebliche Bedeutung zukommt, nämlich dem V ork o m men von Plasmazellen, ist bisher noch keine entsprechende Würdigung zuteil geworden.

Das verhältnismäßig große Material des Pathologischen Institutes der Berliner Universität an Aneurysmen gab den ersten Anlaß, die Aorten dieser Fälle in Rücksicht auf syphilitische Veränderungen zu untersuchen, weiterhin wurden aber auch Fälle ohne Aneurysmen, sowohl solche, bei denen Syphilisverdacht bestand, 
als auch unverdächtige mit Skleratheromatose in die Untersuchung einbezogen, so daß ich über 92 Fälle berichten kann, bei deren Verarbeitung ich einerseits auf das Vorhandensein der Spirochaeta pallida, andererseits auf das Vorkommen von Plasmazellen (und auch Mastzellen) resp. ihre eigenartige Lokalisation in der Wand, ihre Anordnung und ihre differentialdiagnostische Bedeutung geachtet habe.

Die Präparate, die ich untersucht habe, stammen nicht alle frisch von der Leiche. 21 Fälle (bis 1910) waren schon vor Beginn meiner Arbeit zum Teil in K a is e rling scher Flüssigkeit konserviert, zum Teil waren sie nach Fixierung in Or th sehem Gemisch in 70 proz. Alkohol aufgehoben. 49 Fälle (1911 bis 1912), welche ich nach dem Beginn meiner Arbeit bekam, sind frisch von der Leiche entnommen; ich habe meist sofort nach der Sektion die eine Hälfte des Materials teils in absolutem Alkohol für Plasmazellenfürbung, teils in gewöhnlichem Alkohol, teils in Müller - Formol, die andere Hälfte immer in 10 proz. Formalin für die Le va dit i sche Methode fixiert. Von jedem Präparat wurden mehrere Stücke von Aorta ascendens, Arcus aortae und Aorta descendens, eventuell von Aorta mit Klappen oder Arteria pulmonalis genommen. Ein Teil dieser Stückchen wurde in Paraffin eingebettet. Die Schnitte $(3-5 \mu$ dick) wurden mit Hämalaun, Hämatoxylineosin, va n Gi e s o n, roter und blauer Elastikafärbung, polychromem Methylenblau nach Unna, P a p penheim-Unnas Pyronin-Methylgrïnfärbung gefärbt. Außerdem wandte ich noch eventuell die P e $x l$ sche Eisenreaktion und die $R$ o e $\mathrm{h} I$ sche Methode zum Nachweis yon Kalk an. Von den Präparaten, welche in $\mathrm{O}$ t $\mathrm{t}$ schem Gemisch fixiert wurden, wurden Gefriermikrotomschnitte zur Sudanfärbung angefertigt. Die L e va diti sche Methode habe ich zu meiner Arbeit etwas modifiziert. Ich brauchte als Reduktionsmittel mehr Pyrogallussäure als der Vorschrift Le va ditis entspricht, nämlich $5 \mathrm{~g}$ auf $4 \mathrm{ccm}$ Formalin $(40 \%)$ und $100 \mathrm{ccm}$ dest. Wasser. Als Silberimprägnationsmittel gebrauchte ich 2 proz. wässerige Lösung von Argent. nitric. bei $38^{\circ} 6$ Tage. Nach meinen Erfahrungen gibt diese Methode gute Erfolge. In allen Fällen habe ich zur Kontrolle je ein Stück einer kongenital-syphilitischen Leber verwendet.

Die 92 Fälle habe ich der leichteren U̇bersicht wegen in folgende Gruppen getrennt:

A. Arteriosklerose.

(22 Fälle)

$\begin{array}{ll}\text { 1. }(418 / 11 .) & \text { 2. }(422 / 11 .) \\ \text { 3. }(440 / 11 .) & \text { 4. }(446 / 11 .) \\ \text { 5. }(455 / 11 .) & \text { 6. }(887 / 11 .) \\ \text { 7. }(890 / 11 .) & \text { 8. }(914 / 11 .) \\ \text { 9. }(916 / 11 .) & \text { 10. }(926 / 11 .) \\ \text { 11. }(950 / 11 .) & \text { 12. }(953 / 11 .) \\ \text { 13. }(960 / 11 .) & \text { 14. }(1328 / 11 .) \\ \text { 15. }(110 / 12 .) & \text { 16. }(114 / 12 .) \\ \text { 17. }(237 / 12 .) & \text { 18. }(276 / 12 .) \\ \text { 19. }(376 / 12 .) & \text { 20. }(377 / 12 .) \\ \text { 21. }(398 / 12 .) & 22 .(408 / 12 .)\end{array}$


B. Syphilis. befund:

I. Fälle mit anatomisch nachweisbarer Syphilis, abgesehen vom Aorten(19 Fälle)
23. ( 186/11.) 24. ( $350 / 11$.
25. ( $477 / 11$.$) 26. (629/11.)$
27. $(1164 / 11) \quad 28 ..(1171 / 11$.
29. $(1176 / 11) \quad 30 ..(1289 / 11$.
31. $(1416 / 11) \quad 32 ..(78 / 12$.
33. ( 81/12.) 34. ( 124/12.)
35. ( 206/12.) 36. ( 251/12.)
37. ( 303/12.) 38. ( 309/12.)
39. ( $425 / 12$.$) \quad 40. ( 637/12.)$
41. ( $676 / 12$.

II. Fälle, in denen, abgesehen von den vorgenannten, Syphilis anamnestisch und klinisch vorhanden:

\section{(25 Fälle)}

\begin{tabular}{|c|c|}
\hline 42. ( $\check{5} 60 / 08$.) & 43. ( $134 / 10)$. \\
\hline 44. ( $594 / 10)$. & 45. ( $791 / 10)$. \\
\hline 46. $(843 / 10)$. & 47. $(845 / 10)$. \\
\hline 48. ( $926 / 10)$. & 49. $(1125 / 10)$. \\
\hline ธ็0. (1180/10.) & 51. $(1414 / 10)$. \\
\hline 52. ( 303/11.) & 53. ( $348 / 11)$. \\
\hline 54. ( 396/11.) & 55. ( 427/11.) \\
\hline 56. (563/11.) & 57. ( $825 / 11)$. \\
\hline 58. (1141/11.) & 59. (1321/11.) \\
\hline 60. (1413/11.) & 61. ( $1 / 12)$. \\
\hline 62. ( 75/12.) & 63. ( 144/12.) \\
\hline 64. ( $336 / 12)$. & 65. ( $547 / 12)$. \\
\hline 66. ( 661/12.) & \\
\hline
\end{tabular}

III. Sogenannte metasyphilitische Fälle:

$$
\text { (3 Fälle) }
$$
67. $(1314 / 09$.
68. $(1459 / 09$.
69. ( 404/12.)

IV. Fälle ohne syphilitische Anamnese und ohne Befund an anderen Organen. Aorta syphilisverdächtig (zum Teil Aneurysma): 


\section{(23 Fälle)}

\begin{tabular}{|c|c|}
\hline 70. ( $534 / 03)$. & 71. (924/04.) \\
\hline 72. ( $194 / 07)$. & 73. $(766 / 10)$. \\
\hline 74. ( 797/10.) & 75. (1016/10.) \\
\hline 76. (1108/10.) & 77. $(1254 / 10)$. \\
\hline 78. $(1462 / 10)$. & 79. ( $264 / 11)$. \\
\hline 80. ( $284 / 11)$. & 81. ( 507/11.) \\
\hline 82. ( $520 / 11)$. & 83. ( $625 / 11)$. \\
\hline 84. ( 898/11.) & 85. (937/11.) \\
\hline 86. ( $53 / 12)$. & 87. ( 63/12.) \\
\hline 88. ( 99/12.) & 89. ( 157/12.) \\
\hline 90. ( $223 / 12)$. & 91. ( $231 / 12)$. \\
\hline 2. $(677 / 12)$. & \\
\hline
\end{tabular}

Auf eine Einzelbehandlung der Fälle der Gruppe A (Fälle 1-22) konnte verzichtet werden. Sie zeigten durchweg die bekannten und eindeutigen Befunde, wie sie für die Arteriosklerose charakteristisch sind: Eine makroskopisch sichtbare rundliche oder unregelmäßig beetartige Verdickung der Intima, entsprechend mikroskopiseh Wucherung der Intimazellen, Infiltrationen aus Lymphozyten und wenigen polymorphkernigen Leukozyten, zuweilen Neubildung elastischer Fasern und die regressiven Prozesse wie hyaline Degeneration, Verfettung und atheromatöse Veränderung. 8 mal fand sich Verkalkung, zuweilen große Kalkplatten. Die Media war im allgemeinen wenig, dann mehr in der nach der Intima zu gelegenen Hälfte verändert (Kalkablagerung, Verfettung, geringe Infiltration um die Vasa vasorum mit Rundzellen). Nur in den schwersten Fällen war die ganze Media von Kalk durehsetzt und das Bindegewebe in geringem Maße gewuchert. Die Adventitia erwies sich bei leichten Fällen fast durchweg intakt, nur einige der schwersten Fälle zeigten hier mäßig starke Infiltrate aus Lymphozyten und polymorphkernigen Leukozyten um die Vasa vasorum. In einem Falle fanden sich ganz vereinzelte Plasmazellen.

Es wird auf das mikroskopische Bild bei der allgemeinen Betrachtung noch einmal zurückgegriffen werden.

F all 23. K. W., Gastwirt, 52 Jahre.

Klinische Diagnose: Aneurysma der gesamten Aorta thoracica. Angina pectoris.

Er hat stets in guten Verhältnissen gelebt. Ehe 1899, steril. Alkohol: 30-40 Glas Bier und 6-10 Schnäpse täglich. Seit 3 Jahren trinkt er weniger. Nikotin: 16-20 Zigarren täglich. In 11/2 Jahren in Rußland (1883-1884) 40-50 Zigaretten täglich. Infektion: Gonorrhos 1878. Lues: 1886 hatte er eine wunde rote Stelle am Glied, die ungefähr 2-3 Wochen bestand und wieder von selbst verging. Keine Exantheme, keine Kur. 1882 Buboinzision. Am Glied hat er in dieser Zeit nichts Krankhaftes bemerkt. - Jetzige Krankheit seit September 1910.

Wassermannsche Reaktion +++ . Exitus 19. Februar 1911. 
S.-Nr. 186; 1911. Obduktion 20. Februar (B e itzk e).

Pathologisch-anatomische Diagnose: Diffuses Aneurysma der Aorta thoracalis bei schwerer Endaortitis (und Mesaortitis?). Dilatation und Hypertrophie des linken Ventrikels. Geringe Endaortitis mitralis, zahlreiche graurote Herzmuskelschwielen. Stauungslunge mit Bronchitis und mäßigem Ödem. Schwere Stenose des Anfangs der Pars cavernosa urethrae mit starker Dilatation und Epidermisation der Pars membranacea. Hypertrophie der Blase. Periorchitische Verwachsungen beiderseits. Mäßige fibröse interstitielle Orchitis links.

Aorta thoracica diffus erweitert. Der Umfang beträgt dicht über den Klappen $14 \mathrm{~cm}$, am Arkus ebensoviel, dicht über dem Zwerchfell $8 \mathrm{~cm}$; hier verengt sich das Aortenrohr plötzlich und mißt in Höhe der Arteria coeliaca nur noch $5 \frac{1}{2} \mathrm{~cm}$ im Umfang. Die Wand der ganzen erweiterten Strecke ist ziemlich starr, die Intima schwer miBgestaltet, voller unregelmä:Biger, flacher Erhebungen und kleiner Usuren mit zahlreichen eingestreuten schwefelgelben Kalkplättchen. Dabei ist die Wand ziemlich dünn, stellenweise nur $1 / 2-1 \mathrm{~mm}$, während sie unterhalb des Zwerchfelles etwa $1 \frac{1}{2} \mathrm{~mm}$ dick ist.

Präparate I entstammen einer unregelmäßig flachen Erhabenheit von der Übergangstelle des Brust- und Bauchteils der Aorta. Präparate II sind der Aorta thoracalis entnommen, einer Stelle von gleicher Beschaffenheit wie I.

\section{Mikroskopiseher Befund.}

Präparate I. Intima: ist überall etwas sklerotisch mit geringen Infiltraten aus Lymphozyten und Plasmazellen.

Media enthält reichlich kleine und große Gefäße mit perivaskulären Infiltrationen aus zahlreichen Lymphozyten und wenigen Plasmazellen. Die elastischen Fasern sind wenig verändert.

Adventitia: Sie ist am schwersten erkrankt. Die auffallendste Veränderung ist eine totale Obliteration zahlreicher Gefäße und außerordentlich ausgedehnte perivaskuläre Zellanhäufungen, die aus zahlreichen Lymphozyten und etwas weniger Plasmazellen zusammengesetzt sind; die letzteren finden sich meist in der Peripherie des Herdes. Die übrigen Gefäße sind stark erweitert, strotzend gefüllt. Die Umgebung der Gefüße und die Räume zwischen zahileichen aneinanderliegenden Gefälien sind mit Plasmazellen und Lymphozyten ausgefüllt; auch sieht man hier und da eine rosettenartige Anordnung der Plasmazellen. Die im Grenzgebiet zwischen Media und Adventitia infiltrierten Zellen sind meist Plasmazellen. Um die Nerven besteht ebenfalls eine Infiltration, und Plasmazellen gehen in das Perineurium über. Das Bindegewebe der Adventitia ist stark entwickelt und verbreitert. Mastzellen sehr viel, auch in dem Endoneurium vorhianden.

Präparate II ähnlich wie I.

F all 24. H. M., Klempner, 40 Jahre.

Klinische Diagnose: Lues III, Aorteninsuffizienz. Lungeninfarkt.

Obduktion 3. April. S.-Nr. 350; 1911 ( $\mathrm{L} \ddot{\mathrm{oh}} \mathrm{e}$ ).

Pathologisch-anatomische Diagnose: Retrahierende Endocarditis aortica fibrosa mit narbenartiger Schrumpfung der hinteren Aortenklappe (Gummi?). Aortitis syphilitica mit flächenhafter Gummibildung (?) im aufsteigenden Teil. Multiple steckmadelkopfgroße Infarkte und Schwielen der Herzmuskulatur. Dilatation und Hypertrophie beider Ventrikel. Multiple Lingeninfarkte, ausgehend von einer Thrombose der rechten Vena femoralis am Abgangspunkt der rechten saphena. Kompression der rechten saphena durch eine geschwollene verhärtete Inguinaldrüse. Alte, über erbsengroße Narbe im Sulcus coronarins. Parenchymatöse Degeneration der Nieren.

Präparate I sind dicht an den hinteren Aortenklappen einer narbig geschrumplten, zum Teil verdickten Stelle entnommen (mit der A. pulmonalis). Präparate II stammen von oben beschriebener Stelle der Pars ascendens. 
Mikroskopischer Befund.

Präparate I. Intima: Sie ist auf eine lange Strecke hin stark verdickt mit geringem Infiltrat aus Lymphozyten und Plasmazellen. Die tiefste Sehicht der Intima weist stellenweise eine schwielige Struktur mit Einlagerung von spindeligen Kernen auf.

Media: Im allgemeinen ist sie verschmälert. Die der oben beschriebenen Verdickung der Intima angrenzende Partie der Media bietet viele aneinanderliegende und kommunizierende, manchmal die ganze Mediabreite durchsetzende, narbige Herde dar. In deren Umkreis finden sich zahlreiche Gefäße, von denen einige verdickt sind und die ganze Mediabreite durchziehen. Hier und da, besonders in der Umgebung der Gefäße, sieht man Zellanhäufungen, an denen Plasmazellen wenig beteiligt sind. Die oben erwähnten Erkrankungsherde haben eine weitgehende Schädigung, steılenweise sogar totalen Defekt der elastischen Fasern hervorgerufen. An einer Stelle, und zwar in der obersten Schicht der Intima, wo die elastischen Fasern ganz verschwunden sind, sind die Muskelfasern erhalten.

Adventitia: In der Adventitia fallen die zahlreichen verdickten oder sogar ganz obliterierten Gefäße auf (anch zwei sehr große Gefäße). Zellanhäufungen und perivaskuläre Infiltrate sind in großer Zahl, zum Teil sogar makroskopisch sichtbar. Die großen Zellherde bestehen aus vielen Lymphozyten, am Rande finden sich Plasmazellen in mäßiger Menge; die kleinen Infiltrate jedoch bestehen nur aus Plasmazellen. Ein in seiner Peripherie mit Plasmazellen versehenes Lymphknötchen ist vorhanden. Die Nerven sind frei von zelligem Infiltrat. Mastzellen sind nachweisbar. In der Adventitia sind Bindegewebsfasern neugebildet. Die A. pulmonalis zeigt keine Veränderungen.

Präparate II ähnlich.

F all 25. C. H., Arbeiter, 45 Jahre.

Klinisehe Diagnose: Aortenaneurysma. Tabes.

Alkohol - etwa 4 Flaschen Bier. Nikotin: 3-4 Zigarren. Infektion: 1902 Tripper.

Wassermannsche Reaktion +. 4. Mai gestorben.

S.-Nr. 477; 1911. Obduktion 5. Mai ( K o g h ).

Pathologisch-anatomische Diagnose: Großes, sackförmiges Aneurysma des Arkus und der Pars ascendens der Aorta. Ruptur in dem Herzbeutel. Aortitis syphilitica. Hodenschwielen rechts. Tabes dorsalis. Geringe Hypertrophie des linken Ventrikels. Stauungsorgane, Stauungsmilz, Stauungsfettleber, Hydrothorax links. Geringer Aszites. Starke Abbiegung der Trachea nach rechts mit Tracheitis. Pleurale Verwachsungen und schiefrige Spitzeninduration Iinks. Kleines Adenom der Leber. Skoliose der Brustwirbelsäule nach links, Exostosen an den untersten Brustwirbeln.

Direkt oberhalb des Ostium aorticum beginnt eine außerordentlich starke Erweiterung der Aorta, die die ganze Pars ascendens und den Arkus betrifft. Der Tumor ist gut kindskopfgroB. Dicht über dem Ostium aort. ist die Wand des Sackes gelblich gefärbt und zeigt zahllose, runzlige Verdickungen und Erhabenheiten von gelbweißer Farbe. Dicht über dem Ostium pulmonale zeigt der Sack noch zwei kleinere kirsch- bis erbsengroße Ausstülpungen, deren Wandung von dunkelroten, sehr fest anhaftenden Massen bedeckt ist. Der größte Teil des ganzen Tumors zeigt eine ähnliche Färbung an seiner Innenfäche, die durch faserige ziemlich derbe rotbraune Aaflagerungen bedeckt ist. Ungefähr an der Übergangsstelle zwischen Arkus und Pars descendens aortae geht der Sack mit einem deutlichen Knick in die Pars ascendens aortae über. Die Breite der absteigenden Aorta beträgt an dieser Stelle $7 \mathrm{~cm}$. Dicht oberhalb des Ursprungs der Vena pulmonalis superior findet sich eine, größtenteils durch derbe Kruorgerinsel verlegte, die Wand völlig durchsetzende, fast $3 \mathrm{~cm}$ lange schlitzförmige Öffnung, durch die man in den Herzbeutel hineingelangt. Die Wand des von der Aorta gebildeten Sackes ist stellenweise $2 \mathrm{~cm}$ dick. Aorta descendens thoracalis et abdominalis ähnelt in ihrem Aussehen sehr dem obersten Teil der Pars ascendens. 
Präparate I stammen von einer sklerotisch, zum Teil narbig veränderten Stelle der Pars ascendens. Präparate II entstammen dem Aneurysmateil des Arkus und der Pars ascendens.

Mikroskopischer Befund.

Präparate I (Pars ascendens). Intima: Sie ist überall mäBig verdickt mit zarten Spalten, die Intimalamellen sind sehr deutlich zu sehen. An einer Stelle finden sich Rundzelleninfiltrationen in mäßiger Menge.

Media: Die Media zeigt sehr starke Veränderungen, so dab sie fast in ihrer ganzen Ausdehnung schwielig umgewandelt ist. Besonders der an die Intima grenzende Teil der Media zeigt ausgedehnte Schwielenbildung. An einigen Stellen sieht man noch gefäßreiches Granulationsgewebe, dort treten auch Infiltrationen aus Plasmazellen und wenigen Lymphozyten auf. Diese Herde haben die hochgradige Schädigung, sogar Zerstörung des elastischen Netzes hervorgerufen, so daß man nirgends mehr seine normale Struktur erkennen kann, vielmehr nur noch Trümmer sieht. Die Muskelfasern sind stellenweise noch erhalten. Man sieht hier und da viele kleine, ans Plasmazellen bestehende Zellherde und auch Hämosiderin.

Adventitia: In der Adventitia ist die Veränderung der Vasa vasorum weitaus am meisten auffallend. Viele große Gefäße weisen starke Spaltung und Auflockerung der elastischen Lamellen in der verdickten Wand auf; diese Veränderung hat starke Verengerung oder sogar totalen Verschluß des Lumens herbeigeführt. Diese großen obliterierten Gefäße haben verhältnismäßig schwache Infiltrationen, die aus Lymphozyten und wenigen in der Peripherie liegenden Plasmazellen zusammengesetzt sind. Dagegen sind die kleinen normalen und erkrankten Gefäße mit starken. Infiltrationen umsäumt. Während Mastzellen in der Media nicht vorhanden sind, trifft man sie in der Adventitia sehr viel. Das adventitielle Bindegewebe ist stark entwickelt.

Präparate II (Aneurysmateil). Intima ist stellenweise nicht zu sehen. Auf der Intima ist thrombotische Masse aufgelagert, die an einer Stelle organisiert ist.

Media ist noch viel stärker wie in den Präparaten I verändert. Die elastischen Fasern sind durch sehr ausgedehnte, derbe Schwielenbildung fast vollständig verschwunden. An einer Stelle findet sich Granulationsgewebe, hier treten viele erweiterte Gefäße mit Lymphozyten und Plasmazellen in mäßiger Menge auf. Der übrige Teil der Media enthält ganz kleine Zellherde in geringer Anzahl.

Adventitia ist mit vielen makroskopisch bereits erkenntlichen Zellanhäufungen durchsetzt. Diese großen Zellanhäufungen sind scharf begrenzt und bestehen aus Lymphozyten mit wenigen Plasmazellen; die letzteren gruppieren sich nicht nur in der Peripherie, sondern auch vereinzelt in den Herden. Lymphknötchen sind nachweisbar, die in ihrer Umgebung einige Plasmazellen haben. Die Veränderung der Vasa vasorum ist verhältnismäßig gering. Hier und da sieht man in der Adventitia Blutpigment. Mastzellen sind sehr wenig vorhanden. In der Adventitia sieht man auch starke Entwicklung der Bindegewebsfasern.

Fall 26. A. 0., Brauer, 45 Jahre.

Klinische Diagnose: Aortenaneurysma (perforiertes).

Syphilis: negiert (?). Tripper (?). Alkohol: 4 Liter, zuletzt 2 Liter Bier täglich. Schnaps: $2-3$ Kognak. Nikotin; -

Wassermannsche Reaktion +. 12. Juni 1911 gestorben.

S.-Nr. 629; 1911. Obduktion 13. Juni ( $\mathrm{K}$ o c h ).

Pathologisch-anatomische Diagnose: Großes Aneurysma des Arcus aortae mit Perforation im Bronchialaste der linken Lunge. Kleine Aneurysmen im oberen Teil der Pars ascendens. Aortitis syphilitica. Hypertrophie des linken Ventrikels mit geringer Verfettung. Großes Transsudat in der linken Pleurahöhle. Kompressionskollaps der linken Lunge. Lungenödem und alveoläres Emphysem rechts. Stauungsnieren. Stalungsleber; kleine Adenome der Leber. Rinden- 
fibrome in der rechten, Nebennierenkeim in der linken Niere. Hodenschwielen und periorehitisthe Verwachstungen $\mathrm{r}$. Chronische Gastritis mit Sanduhrmagenbildung.

Oberhalb des Ostium aorticum finden sich in der Aorta markstückgroße muldenartige Ausbuchtungen; die Aorta selbst ist in ihrem Bauchteil ziemlich glatt, im Brustteil und Pars ascendens zeigt sich eine große Menge Rumzeln und flacher beetartiger Erhabenheiten von graugelblicher Farbe. Auf einem Querschnitt sieht man hier die Media als gelben, vielfach unterbrochenen Streifen. Von ähnlicher Beschaffenheit wie die eben beschriebene Stelle sind auch die erwähnten Ausbuchtungen. $15 \mathrm{~cm}$ oberhalb der Klappen im Bereich des Arkus findet sieh eine kindskopfgroße, mit derben leistenartigen Rändern umgebene Höhle, die mit der unten beschriebenen Öffnung zusammenhängt. Die Höhle wird durch rotbraune, geschichtete, ziemlich derbe Massen gut zur Hälfte ausgefüllt.

Präparate I stammen von einex flachen beetartigen Erhabenheit von graugelblicher Farbe der Pars ascendens mit der A. pulmonalis. Präparate II wurden dem Aneurysmahalsteil der Pars ascendens entnommen.

\section{Mikroskopischer Befund.}

Präparate I (Pars ascendens mit der A. pulmonalis). Intima: Stellenweise zeigt sie Sklerose und beginmende atheromatöse Veränderung. An einer Stelle sieht man einen nekrotischen Herd, in seiner Ungebung sind zahlreiche polymorphe ovale und runde Kerne sichtbar.

Media: An einer Stelle ist sie verschmälert und enthält vereinzelte Gefäße. Sonst zeigts sie keine besondere Veränderung.

Adventitia weist eine hochgradige Verändexung auf. Während mehrfach zahlreiche verdiekte Gefäße sich finden, bemerkt man an einer Stelle, und zwar dicht unter der Media, eine großes ganz obliteriertes Gefäß mit einer aus Plasmazellen und Lymphozyten gruppenweise zusammengesetzten Infiltration. An anderer Stelle sieht man adventitielle Nerven, um sie herum starke, nur aus Plasmazellen bestehende Infiltrationen; die Plasmazellen treten nicht nur in dem Perineurium auf, sondern anch in dem Endoneurium. Die übrige Partie der Adventitia enthält sehr viele, zum Teil schon makroskopisch sichtbare Zellherde. Im allgemeinen sind diese so zusammengesetzt, daß die in der mediawärts gelegenen Adventitiahälfte befindlichen Zellherde zum größten Teil aus Plasmazellen, stellenweise sogar nur aus Plasmazellen bestehen; dagegen besteht in dem äußeren Teil der Adventitia die Infiltration hauptsächlich ans Lymphozyten, doch finden sich an der Peripherie der Zellherde einige Plasmazellen. In der Adventitia trifft man viele Plasmazellen in rosettenartiger Anordnung; auch sind reichlich Mastzellen nachweisbar. In der Adventitia sieht man starke Neubildung von Bindegewebe und elastischen Fasern. Die A. pulmonalis zeigt gar keine mikroskopische Veränderung.

Präparate II (Aneurysmahalsteil). Intima: Am Halsteil des Aneurysma ist sie stari rerdickt, und man sieht hier einige neugebildete elastische Lamellen. Am übrigen Aneurysmateile ist sie mäßig stark geschädigt und durchweg mit Thrombusmasse bedeckt.

Media: Da, wo am eigentlichen Aneurysmateile die elastischen Fasern total zerstört sind nur noch einige feine Trümmerchen sind sichtbar _-, haben sich teilweise derbe Schwielen gebildet; die Muskelfasern sind auch stark geschädigt. Infiltrate sind kaum vorhanden. Der Halsteil des Aneurysmas weist gleichfalls außerordentliche Schädigung, stellenweise sogar vollständige Zerstörung der elastischen Fasern auf. Hier sieht man zwei große, viele erweiterte Kapillaren enthaltende Herde, die sich größtenteils aus Granulationsgewebe, zum Teil aus Schwielen, zusammensetzen. In diesen Herden finden sich nur noch einzelne, grane, kurze Trümmerchen oder Reste der elastischen Fasern. Infiltration ist kaum exkennbar. An anderen Stellen bemerkt man geschlängelte, knäuelartige, dicke Gebilde, die sich mit roter Elastika intensiv rot, mit PolychromMethylenblau nicht färben. 
Adventitia: enthält mehrere makroskopisch schon sichtbare Zellherde, die sich aus Lymphozyten und Plasmazellen, diese entweder gruppenweise oder kreisförmig um die Lymphozyten herum, zusammensetzen. An anderen Präparaten besteht einer von diesen Herden nur aus Plasmazellen. In großen Zellherden finden sich auch verdickte und obliterierte Gefäße. Sonst sind Vasa vasorum stark entwickelt. $\mathrm{Um}$ die adventitiellen Nerven bestehen ebenfalls starke Infiltrate; Plasmazellen finden sich im Peri- und Endoneurium. Mastzellen trifft man sehr viel. Adventitielle Bindegewebs- und elastische Fasern sind auch neugebildet.

F all 27. P. M., Schuhmachersirau, 37 Jahre.

Khinische Diagnose: Hernia incarcerata (Littré). Peritonitis.

Pat. befindet sich wegen eines Ausschlages (papulöses Syphilis) auf der Station. Mit Ausnahme des Gesichts und der Hände bzw. der Fiaßß ist der Körper mit linsengroßen Papeln bedeckt. Laparotomie wegen Ileus.

Wassermannsche Reaktion fehlt. Am 28. Oktober 1911 Exitus letalis.

S.-Nr. 1164; 1911. Obduktion 30. Oktober ( C e e l e n ).

Pathologisch-anatomische Diagnose: Diffuse, fibrinöse eitrige Peritonitis nach クleusoperationswunde aus der Grenze von Jejunum und Ileum (Resektion des invaginierten Darmstïcks). Parenchymatöse Trübung von Leber, Nieren und Herz. Lungenödem beiderseits. Tracheobronchitis. Endometritis haemorrhagica. HaselnuBgroßer Gallenstein, Fettresorption der Gallenblasenschleimhaut. Chronische Gastritis. Papulöses Syphilid am ganzen Körper. Dilatation beider Herzventrikel.

Am ganzen Körper sieht man verschiedene große, über die Hautoberflärhe leicht erhabene, blaßrote und rotgraue Flecken, die bis Linsengröße erreichen (papulöses Syphilid). An dem Anfangsteil der Pars ascendens sieht man einige Erhabenheiten, Aorta descendens o. V. A. iliaca comm. zeigt eigentümliche spiralige Falten.

PräparateI sind einer grauweißlichen, leicht verdickten Stelle der Pars ascendens, Präparate II einer leichten Erhabenheit des Arkus entnommen.

\section{Mikroskopischer Befund.}

Präparate I (Pars ascendens). Intima zeigt keine Veränderung. In der adventitiawärts gelegenen Mediapartie bemerkt man vereinzelte Plasmazellen und Lymphozytenanhäufungen. Man sieht auch ein stark verdicktes GefäB. Adventitia ebenso. Mastzellen sind sehr selten exkennbar.

Präparate II (Arcus aortae) ebenso.

F a 11 28. M. S., Musikerswitwe, 55 Jahre.

Klinische Diagnose: Leptomeningitis spinalis et basilaris (syphilitica). Urämie.

Von vier Geburten zwei Frühgeburten.

Wassermannsche Reaktion fehIt. Am 30. Oktober 1911 Exitus.

S.-Nr. 1171; 1911. Obduktion 31. Oktober $(K o \mathrm{ch})$.

Pathologisch-anatomische Diagnose: Knötchenförmige Leptomeningitis spinalis et basilaris (syphilitica?), Piaödem, Hydrocephalus int.; Ependymitis granularis; Skleratheromatose (Syphil.) der Aorta; kleines sackförmiges Aneurysma im obersten Bauchteil mit starker Arrosion eines Wirbelkörpers. Mäßjge Verdickungen der Trikuspidal- und Aortenklappen. Geringe parenchymatöse Trübung beider Nieren. Zyste in der linken Niere; Cystitis und Pyelitis eystica beiderseits. Starke pleuritische Verwachsungen und sehnige Verdickung der Pleura pulm. rechts. MäBige Tracheobronchitis. Amygdalitis lacunaris. Anthrakose der Hilus- und Bronchialdrüsen. Kalkherd und flache Schnürfurche des rechten Leberlappens; geringe Gastritis, pelveo-peritonitische Verwachsungen; strangförmige Verwachsungen des Netzes. Gicht in beiden Nieren.

Aorta zeigt besonders im Brustteil starke grauweiße, derbe, runzlige Verdickangen, daneben finden sich zahlreiche gelbliche geschwürig aussehende Stellen und derbe kalkharte Platten, durch 
die an vielen Stellen die Abgänge der Aa. intercost. verschlossen bzw. verengt werden. Im Bauchteil nehmen die Veränderungen immer mehr ab. Dicht unterhalb des Zwerchfells findet sich eine kirschgroße Ausbuchtung der Aorta, die durch einen engen, kaum linsengxoßen Hals mit dem Gefäßlumen in Verbindung steht und von rotbraunen, derben Massen ausgefüllt ist. Dieser Sack ist in den Körper des gegenüberliegenden Wirbels eingebettet.

Die Präparate I sind einer Stelle der Pars ascendens entnommen, die zum Teil eine grauweiße, derbe Verdickung, zum Teil nur gelbliche Verfärbung zeigt. Präparate II stammen von einer ähnlichen Stelle der Pars descendens.

\section{Mikroskopischer Befund.}

Präparate I (Pars ascendens). Intima ist stellenwẹise etwas verdickt und zeigt fettige Degeneration. An einer Stelle, wo die Intima sklerotisch verändert ist, sieht man eine ziemlich umfangreiche zirkumskripte Infiltration aus zahlreichen Plasmazellen. An einer anderen Stelle der Intima finden sich einige kleine Kalkablagerungen.

Die Media ist in ihrem ganzen Verlaufe schwer geschädigt, streckenweise vollständig zerstört, so daB die Muskelschicht bei va n Gi e s o n - Färbung stellenweise unterbrochene, sehr schmale, gelblich gefärbte Streifen und Inseln darstellt. Die elastischen Fasern sind auch stark geschädigt, bisweilen sogar unterbrochen wie die Muskelfasern. Die erkrankten Herde der Media sind von derben Schwielen und gefäBreichen Zellherden durchsetzt. Die Mehrzahl dieser Zellherde besteht zum größten Teil aus Plasmazellen, die teils in zu Strängen angeordneten, annähernd parallelen Zügen vereinigt, teils unregelmäßig gruppiert sind.

Adventitia: Die adventitiellen Bindegewebsfasern sind mäßig vermehrt. Hier und da finden sich verdickte oder sogar ganz obliterierte Vasa vasorum, von denen einige von zahlreichen Lymphozyten umsäumt sind. In der Adventitia sind die Plasmazellen viel weniger reichlich als die Lymphozyten, doch sind sie an einigen Stellen angehäuft und auch rosettenartig angeordnet. Mastzellen sind in mäßiger Menge vorhanden.

Präparate II (Pars descendens) ebenso.

F a 11 29. J. R., Friseur, 43 Jahre.

Klinische Diagnose: Aorteninsuffizienz, Syphilis der Aorta, Schluckpneumonie links, tuberkulöse Pleuritis (links).

Jetzige Krankheit seit 1908. Alkohol: 5-6 Glas Bier täglich. Nikotin: 10-12 Zigaretten pro die. Infektion: Gonorrhoe 2 mal. Lues: 1899 (Geschwür an der Eichel) drei Schmierkuren.

Wassermannsche Reaktion fehlt. Tod am 2. November 1911.

S.-Nr. 1176; 1911. Obduktion 4. November ( C e ele n).

Pathologisch-anatomische Diagnose: Schwere syphilitische Aortitis des Arcus aortae und des oberen Brustteils. Sackförmiges Aneurysma in der Pars ascendens aortae. Beginnende Perforation in den linken Hau,tbronchus. Blutaspiration in beiden Lungen. Ausgedehnte eitrige Aspirationspneumonie der ganzen linken Lunge. Fibrinöse Pleuritis links. Kleine Bronchiektasien im linken Unterlappen. Myodegeneratio cordis, Fettdurchwachsung der Herzmuskulatur. Verdickung der Schließunossränder der Aortenklappen; starke Dilatation beider Herzventrikel, besonders des linken. Parenchymatöse Trübung von Herz und Nieren. Große weiche Milz. Verknöcherung beider Lig. stylohyoidea. Nebennierenkeim und Markfibrom in der rechte Niere. Hodenschwielen beiderseits. Periorchitische Verwachsungen. Alte Ulkusnarbe am Penis. Piaödem. Die Abgangsstelle der linken Koronararterie, die etwas höher als normal liegt, ist verengt infolge einer ausgedehnten narbenartigen sehnigweiß glänzenden Veränderung der Aorta, die in multiplen, dicht beisammenliegenden Herden die ganze Pars ascendens betroffen hat. Auf einem Querschnitt durch die Aortenwand sieht man stellenweise die Media anßerordentlich verdünnt.

Nach Aufschneiden des Arkus von der Pars ascendens aortae sieht man an der Grenze von Arkus und Pars descendens etwa $5 \mathrm{~cm}$ oberhalb des ersten Paares der Interkostalarterien an der 
Hinterwand der Aorta eine für den Daumen gut durchgängige und auch etwa daumengroße Ausstülpung der Aorta, die nach rückwärts auf die hintere Seite des linken großen Bronchus sich erstreckt und von Intima ausgekleidet ist. Thre Wand ist im ganzen nur halb so dick als die der übrigen Aorta. Der Bronchus ist durch dieses sackförmige Gebilde komprimiert, seine hintere Wand durch dasselbe arrodiert. Der ganze Arkus und die Pars descendens aortae bis zur Abgangsstelle des zweiten Interkostalarterienpaares ist durch grauweiße, derbe, teils strahlige, teils prominierende Platten in ausgedehnter Weise verändert. Dazwischen finden sich in der Intima liegende, hellgelbe und weiße Flecken. Die A or ta abdominalis und die lliacae sind im Gegensatz zu den oberen Teilen elastisch, dünn und nur von vereinzelten weißlichen Fleckchen durchsetzt.

Präparate I sind einer sehnig verdickten Stelle dicht oberhalb der Klappen entnommen (mit der A. pulmonalis). Präparate II sind einer weißlich glänzenden Stelle der Pars ascendens entnommen.

Mikroskopiseher Befund.

Präparate I. Intima: Sie zeigt auf eine lange Strecke hin eine hügelartige starke Verdickung; in ihrem stärksten Teil erreicht sie fast doppelte Mediabreite. Die verdickte Intima weist zahlreiche zarte Spalten anf und verschiedentliche Infiltrationen, die sich an einer Stelle aus vielen strangförmig angeordneten Plasmazellen zusammensetzen. Elastische Fasern sind viel neugebildet.

Media: Die Muskelfasern sind in dem ganzen Verlaufe der Media durchweg zerstört, von elastischen Fasern sind nur noch Trümmer erkennbar. In diesen Herden sind ausgedehnte Schwielen, zum Teil auch frisches Granulationsgewebe ausgebildet. Die Grannlationsherde haben viele Gefäße in't starken Zellanhäufungen, bestehend aus reichlichen, in Gruppen angeordneten Plasmazellen und ebenfalls gruppierten Lymphozyten in mäßiger Menge. Diese Zellanhäufungen durchziehen an einer Stelle die ganze Mediabreite. Einige Gefäße in diesem großen Herde sind so stark erweitert, dab sie bereits makroskopisch sichtbar sind. Sonst bemerkt man einzelne kleine Zellherde von gleicher Zusammensetzung.

Adventitia: Sie ist mit einigen, mit bloßem Auge erkenntlichen Infiltraten durchsetzt. Diese großen. Infiltrate bestehen aus vielen Lymphozyten; in der Peripherie sind gruppenweise oder zerstreut Plasmazellen mehr oder weniger reichlich vorhanden. In den übrigen kleinen Zellherden kann man viele Plasmazellen, sogar in rosettenartiger Anordnung sehen. Die adventitiellen Nerven sind mit gleicher Infiltration umsäumt. Hier und da bemerkt man zahlreiche verdickte; sogar obliterierte Gefäße, meist frei von Infiltrationen. Die Adventitia enthält stellenweise Blutpigment und viele Mastzellen. Die A. pulmonalis zeigt keine mikroskopische Veränderung.

Präparate II (Pars ascendens). Intima: Die Verdickung der Intima ist gleichmäBig, nicht so stark wie in den Präparaten I. In der tiefsten Schicht der Intima ist Lipoid abgelagert. An einer Stelle sieht man einen beginnenden atheromatösen Herd mit kleiner Blutung. Sonstiger Befund in der Intima ist gleich dem in den Präparaten I. In einem großen, gefäßreichen Zellherd der Media findet sich viel Hämosiderin. Sonst zeigen Media, besonders in dem intimawärts liegenden Teil, und Adventitia die gleiche mikroskopische Veränderung wie in den Präparaten I, nur in geringerem Grade.

F a ll 30. H. G., Handelsmann, 53 Jahre.

Klinische Diagnose: Myopathia cordis. Aorteninsuffizienz, Nephritis, Aszites, Hydrothorax, Anasarka.

Seit 1885 ist er verheiratet, Frau gesund, keine Kinder, ein Abort. Mit etwa 25 Jahren zog er sich einen linksseitigen Bubo und harten Schanker zu. Er machte eine 20 tägige Schmierkur durch und hat späterhin keine syphilitischen Erscheinungen bemerkt. Pat. war früher starker Potator. Nikotin: früher 6 Zigarren täglich; seit 1 Jahr nicht mehr. Jetzige Krankheit begann im Dezember 1910.

Wassermannsche Reaktion ++ . Exitus am 27. November 1911.

S.-Nr. 1289; 1911: Obduktion 29. November ( $\mathrm{S} \mathrm{c} \mathrm{h} \mathrm{u} \mathrm{m} \mathrm{).}$ 
Pathologisch-anatomische Diagnose: Chronische retrahierende Endocarditis aortica und mitralis. Arteriosklerose (Mesaostitis syphilitica?) der Aorta mit diffuser Erweiterung des Arkus und der Arteria anonyma. Sklerose der Koronararterien mit vollständiger Obliteration der rechten A. coronaria. Hypertrophie und Dilatation des linken Ventrikels. Kleine Herzschwielen. Thrombus im rechten Herzohr. Aszites, Hydrothorax beiderseits. Stauungsinduration von Lunge, Leber, Milz, Stauungskatarrh der Luftwege und des Magendarmkanals. Stauungsnieren mit parenchymatöser Trübung. Mehrere Zysten der linken Niere. Kleine Hodenschwielen. Vielfache peritonitische Verwachsungen. Schnupitabaksprostata.

Die aufsteigende Aorta ist unregelmäßig erweitert. Die Innenfäche ist grau und uneben, von allerlei Furchen und Iinien durchsetzt, andererseits mit weißlich gelben Platten besetzt. Auf dem Querschnitt erseheint nicht nur die Intima verdickt, sondern auch die Media enthält gelblichweiße, scharf umgrenzte Flecken. Beim Aufschneiden der Brustaorta zeigen sich dieselben Veränderungen wie in der Aorta ascendens, wenn auch im allgemeinen nicht so stark ausgesprochen; dagegen erscheint besonders schwer betroffen die Abgangsstelle der A. anonyma, die kegelförmig erweitert ist. Die Basis dieses Kegels hat etwa Zweimarkstückgröße.

Die Präparate dieses Falles entstammen einer grauen, narbigen Stelle der Pars ascendens.

\section{Mikroskopischex Befund.}

Intima: Utberall ist sie mäßig stark verdickt und zeigt allerwärts spindelzelliges, kernhaltiges, derbes Bindegewebe. Eine Stelle enthält verschieden starke Rundzelleninfiltrationen. In der tiefsten Schicht der Intima finden sich an einer Stelle viele kleine neugebildete Gefäße, die mit wenigen Plasmazellen und einzelnen Lymphozyten umkränzt sind, ferner infiltrieren die Plasmazellen die obere Schicht der Intima. Die elastischen Fasern sind š́ellenweise lamellenartig neugebildet; keine Erweichungsherde.

Media: Jedes Gesichtsfeld zeigt auffällige Zerstörungsherde der Mediaschicht; bei v a n Gie s on - Färbung sieht man hier deutlich die gelb gefärbte, schmale, fleckweise ganz unterbrochene Muskelschicht. Bei Elastikafärbung (rot und blau) kann man deutlich folgende Veränderungen der elastischen Fasern erkennen. Während die elastische Schicht an einer Stelle ihre normale Breite hat, wird sie alsbald schmäler, löst sich sodann in einzelne Faserzüge auf, um dann wieder für eine kurze Strecke die Dicke eines halben normalen Durchmessers anzunehmen. Plötzlich sind die elastischen Faserringe für eine kurze Strecke völlig unterbrochen, alsdann folgen Reste derselben, und bei starker Vergrößerung sieht man hier, daß einzelne Fasern ganz fein geteilt und gespalten und teilweise zu kleineren Klumpen zusammengeballt sind. Schließlich gehen die elastischen Fasern zu einer fast normalen Breite über. Auch der normalbreite Mediateil enthält hier und da kleine zirkumskripte Herde von Resten elastischer Fasern. In diesen Herden sind viele alte derbe, kernarme Narben entwickelt, zum Teil auch Granulationsgewebe und Infiltrationen. Mit den grolien Defekten verglichen sind die Infiltrationen ziemlich schwach; auch finden sich an vielen Stellen, bald diffus, bald scharf begrenzt, Plasmazellenanhäufungen, Lymphozyten ziemlich wenig. Die narbige Partie enthält wenige Plasmazellen und Lymphozyten. Hin und wieder finden sich in verschiedenen Mediateilen, besonders in den erkrankten Herden, erweiterte Gefäße gruppenweise vor, die meisten mit mehr oder minder ausgesprochenem Plasmazellenmantel. Lymphozyten sind sehr wenig vorhanden. In der Media sieht man keine typisehen Mastzellen.

Adventitia: leidet auch an mäBigen Infiltrationen aus Plasmazellen und Lymphozyten; die Infiltrationen sind stets begleitet von strotzend gefüllten Blutgefäßen. Auch kann man solche Infiltrationen in adventitiellen Lymphräumen deutlich finden. Einige Gefäße zeigen Intimaverdickung. Das Fettgewebe, und zwar das Zwischengewebe, enthält auch viele, netzartig angeordnete Plasmazellen; hier findet man auch, makroskopisch schon sichtbar, ein größeres Lymphknötchen, in dem sich kolossale Mengen Plasmazellen gruppenweise, besonders in der Peripherie, aufhalten. In der Nähe dieses Lymphknötchens finden sich zwei relativ große Blutgefäße, die 
auch einige Plasmazellen enthalten. Innerhalb sowie außerhalb des Lymphknötchens sieht man viel Blutpigment; Mastzellen sind in der Adventitia, besonders in der Umgebung der Gefäße, reichlich vorhanden.

F a 1131. A. K., Glaser, 68 Jahre.

Klinische Diagnose: Aortenaneurysma. Magenkrebs.

Alkohol: 2--3 Glas Bier. Nikotin: für 10 Pf. Kautabak. Infektion: Gonorrhoe 1866 und 1870.

Wassermannsche Reaktion fehit. Exitus am 31. Dezember 1911.

S.-Nr. 1416; 1911. Obduktion 2. Januar 1912 ( $\mathrm{S} \mathrm{c} \mathrm{h} \mathrm{u} \mathrm{m}$ ).

Pathologisch-anatomische Diagnose: Aortitis syphilitica mit mehrfacher Aneurysmenbildung und Arrosion der Wirbelsäule. Schwiele im rechten Hoden. Hydrothorax links mit Kompression der Lunge. Kalkherde in der rechten Lungenspitze. Sehr schlaffes, braunes Herz, geringe Koronarsklerose. Schrumpfherde in beiden Niexen. Ventilartige Hypertrophie des mittleren Prostatalappens, Balkenblase.

Bei Eröffnung der Brust- und Bauchhöhle findet sich über und unter dem Zwerchfell je ein reichlich faustgroßer Tumor dicht vor der Wirbelsäule, der obere liegt mehr links, der untere etwas rechts von der Mittellinie, die Konsistenz ist prall elastisch. Nach Entfernung des Herzens gelangt man durch den weiten Arcus aortae mit dem Finger bis in den oberen Tumor, aus dem Arkus entleert sich bei Druck auf die Tumoren reichliches, schwarzrotes Blut, wobei die Konsistenz der Tumoren so schlaff wird, daß man die anliegende Fläche der Wirbelkörper durchtasten kann, diese ist ganz uneben und zerklüftet. Es wird fast die ganze Wirbelsäule mit der Aorta, dem Ösophagus und Magen herausgenommen; es zeigt sich nun deutlich, daß die erwähnten Tumoren durch Erweiterungen der etwas S-förmig gekrümmten Aorta gebildet werden; an der links unten gelegenen Partie des unteren Sackes fühlt man knochenharte Platten. Der ganze linke M. iliopsoas ist von schwarzroten, blutigen Massen durchsetzt, die sich unter dem Peritonäum ausgebreitet und zwischen den Blättern des Mesokolons bis an das Kolon vorgedrängt haben. Im rechten Hoden grauweiße streifige Flecken.

Präparate I sind einer gran-weißlichen, narbigen Stelle der Pars ascendens entnommen. Präparate II entstammen dem Aneurysmahalsteil.

$$
\text { Mikroskopischer Befund. }
$$

Präparate I (Pars ascendens). Intima: Sie ist stellenweise sklerotisch leicht verdickt mit stellenweise auftretender Rundzelleninfiltration. An einer Stelle, wo die elastischen Fasern der Media ganz unterbrochen sind, zeigt die Intima eine starke Einziehung. Sonst ist keine atheromatöse Veränderung nachweisbar.

Media: Sie ist durchweg geschädigt, streckenweise sogar völlig zerstört. Bei Elastikafärbung erkennt man nur noch Trümmer von elastischen Fasern. Besonders zeigt die oben genannte Stelle, wo die elastischen Fasern verschwunden und die Schwielenbildung aufgetreten ist, eine beginnende Aneurysmabildung. In dem ganzen Verlauf dieses Mediateiles ist Infiltration kaum sichtbar, während ausgedehnte Schwielenbildung überall vorhanden ist.

In der Adventitia lassen sich Gruppen von Gefäßen, einige verdickt oder sogar ganz verschlossen, nachweisen. Während die perivaskulären Infiltrationen meist aus Lymphozyten und Plasmazellen zusammengesetzt sind, bestehen die in den interstitiellen Lymphräumen befindlichen Zellanhäufungen zumeist aus Plasmazellen. Es finden sich auch rosettenartig angeordnete Plasmazellen. Mastzellen sind in geringerer Zahl vorhanden.

Präparate II (Aneurysmahalsteil). Die Intima am eigentlichen Aneurysmateile ist stark geschädigt und hat in ihrem Verlaufe thrombotische Massen aufgelagert, die hauptsächlich aus Erythrozyten bestehen. Die Intima am Aneurysmahalsteile ist verdickt, ohne atheromatöse Veränderang. 
Media am eigentlichen Aneurysmateile sowohl wie am Halsteile ist erheblich verschmälert, sogar streckenweise durch ausgedehnte Schwielen unterbrochen. Bei Elastikafärbung sieht man die Schädigung der elastischen Fasern, gibt es doch keine Stelle, an welcher sie nicht unterbrochen oder zerstört sind. Die Muskelfasern sind teilweise auch da noch erhalten, wo die elastischen Fasern zerstört sind. Hier und da bemerkt man Blutpigment. Infiltration ist kaum erkennbar.

Adventitia: enthält geringe Infiltration aus Lymphozyten und Plasmazellen. Verdickte Gefäße sind wenig nachweisbar. Mastzellen sind in mäßiger Menge vorhanden.

F a 11 32. E. R., Hotelier, 43 Jahre.

Klinische Diagnose: Bösartige Rippenfellgeschwulst.

1890 Schanker (harter?). Potus mäßig stark. Pat. ist mittelstarker Raucher.

S.-Nx. 78; 1912. Obduktion 19. Januar ( Marti in).

Pathologisch-anatomische Diagnose: Aortitis syphilitica mit Aneurysmenbildung im Aortenbogen (Pars descendens). Syphilitische Narbe am Sulcus coronar. penis, syphilitische Narbe der linken Lunge. Chronische Pneumonie links mit Alveolarverfettung, putride Bronchitis links. Pleuritis exsudativa haemorrhagica. Arrosion des linken Hauptbronchus durch das Aneurysma. Ödem, alveoläres Emphysem rechts, schlaffes Herz. Kalkkörperchen in beiden Nieren. Divertikel des Ösophagus. Periorchitis fibrosa obliterans. Hypertrophie des rechten Ventrikels, Bronchiektasie.

Der linke Hauptbronchus zeigt an der der Aorta zugekehrten Seite eine starke Hervorwölbung seiner Wand mit Zerstörung derselben, so daß eine in den Bronchus eingeführte Schere mit Leichtigkeit durch diese Wand in die hier fest angeheftete Aorta hineinkommt. Im Ösophagus, ungefähr an der Bifurkation, eine etwa haselnuBgroße Ausbuchtung. Der Anfangsteil der Aorta ist von Schwielen durchsetzt, zum Teil mit strahligen Furchen versehen, von graner Farbe, auf dem Durchschnitt erscheint die Intima unterbrochen. Weiterhin ist das Lumen der Aorta stark vergröBert und besonders sackförmig an der Pars descendens, überall den oben beschriebenen Befund der Intima zeigend, an zwei Stellen in diesem Sack fest verwachsenes Blutgerinnsel.

Bauchaorta enthält nur fleckweise gelbliche Buckel der Intima.

Prïparate I und II stammen von einer mit Schwielen durchsetzten, zum Teil mit strahligen Furchen versehenen Stelle der Pars ascendens; dieser Schnitt ist $3 \mathrm{~cm}$ lang.

\section{Mikroskopischer Befund.}

Präparate I (Pars ascendens). Intima: Überall etwas verdickt; man sieht nirgends atheromatöse Herde, aber an vielen Stellen der Intima flache und tiefere Falten. An zwei Stellen der Intima trifft man Infiltrationen aus Lymphozyten, sogar Plasmazellen.

Media: Diese Präparate zeigen in ganzer Ausdehnung hochgradige Zerfallserscheinungen der Media. Bei der van Gi e s o n - Färbung fällt die stark verschmälerte, stellenweise unterbrochene, gelb gefärbte Muskelschicht auf, ebenso die die Mediaschicht netzartig durchziehenden breiten oder schmalen rot gefärbten narbigen Streifen. Bei der Elastikafärbung sieht man überall das Fehlen der elastischen Fasern und stellenweise die Reste derselben als kurze einzelne Stiuckchen oder als kleine Inseln. An den Stellen, wo die Elastika fehlt, sieht man narbiges Gewebe, teilweise frisches Granulationsgewebe mit vielen Gefäßen, stellenweise aber Infiltrationen, die zumeist aus Plasmazellen, teilweise sogar nur aus solchen bestehen. Dann sieht man die Plasmazellen in rosettenartiger Anordnung. Mastzellen sind nicht zu sehen.

Adventitia: In der Adventitia fällt der Reichtum an Blutgefäßen auf, die mit ziemlich großen Infiltrationen umgeben sind. Während sich diese Infiltrationen meist ans vielen Lymphozyten mit randständigen Plasmazellen zusammensetzen, bestehen einige Gruppen nur aus Plasmazellen. Mehrere Gefäße sind stark verdickt. In der Adventitia finden sich einige Nerven, in deren Perineurium viele Plasmazellen liegen. Mastzellen trifft man sehr viel an, anch in den Infiltrationen. Die adventitiellen Bindegewebsfasern sind stark entwickelt. 
Präparate II (Pars ascendens) zeigen dieselben mikroskopischen Veränderungen.

$\mathrm{F}$ a II 33. E. W., Reisender, 32 Jahre.

Klinische Diagnose: Herzschwäche, wahrscheinlich Lungenentzündung.

S.-Nr. $81 ; 1912$. Obduktion 20. Januar ( C e el e n ).

Pathologisch-anatomische Diagnose: Schwere Aortitis syphilitica mit starken sklerotischen und mesaortitischen Veränderungen im Pars ascendens, Arkus und Pars descendens; nur geringe Herde in Brust und Bauchteil der Aorta. Starke Stenosierung der Abgangsstelle der linken Koronararterie. Multiple Schwielen und Infarzierung der Musknlatur des linken Herzventrikels, rekurrierende Endocarditis aortica verrucosa mit Verwachsungen der Klappen. Starke Hypertrophie und Dilatation des linken Ventrikels. Lungenödem beiderseits. Hydrothorax links. Schwellung des lymphatischen Rachenringes. Enteritis nodularis im unteren Ileum, kleine Hämorrhagien in der Dünndarmschleimhaut. $\mathrm{M} \mathrm{e} \mathrm{c} \mathrm{k}$ e l'sches Divertikel. Leistenbruch rechts. Atrophie des rechten Hodens, Hypertrophie des linken. Versprengter Nebennierenkeim in der rechten Niere. Pleuritische Verwachsungen beiderseits, Schankernarbe am Penis. Defekt des linken Armes. Amputationsneurome am Stumpf des linken Armes.

Schließungsränder der Aortenklappen verdickt und mit ganz feinen kleinen gallertig aussehenden Wärzchen bedeckt; namentlich die vordere rechte Klappe ist stark geschrumpft und mit der einen Hälfte ihres Schließungsrandes an die Aortenwand angelötet, der unterste Teil der Pars ascendens der Aorta von dicken Platten durchsetzt, so daß die Wand an einzelnen Stellen eine Dicke von $1 / 2 \mathrm{~cm}$ hat; der übrige Teil der Aorta ascendens, des Arkus und der Aorta descendens sind ebenfalls von plattenartigen Verdickungen durchsetzt, die zum Teil strahlen- und narbenartige Einziehungen haben. Die Abgangsstelle der linken Koronararterie ist bis auf eine kleine öffnung durch die Veränderung der Aorta verschlossen, beide Koronararterien sind in ihrem Ver . lanf zartwandig und frei von jeder Veränderung.

Die Aorta thoracalis und abdominalis ist ziemlich elastisch und zeigt nur einzelne umschriebene Verhärtungen.

Präparate I stammen von einer strahlen- und narbenartigen Stelle der Pars ascendens mit verdickter Klappe. Präparate II wurden einer plattenartigen Verdickung der Pars descendens entnommen.

Mikroskopischer Befund.

Präparate I (Pars ascendens mit der Klappe). Intima ungleichmäßig stark verdickt. Diese Verdickungsstelle selbst zeigt noch mehrere ganz kleine Erhabenheiten. Im allgeneinen weist die Intima derbes Aussehen auf, man sieht überall spindelige, ovale und unregelmäßßige Kerne. In dem am stärksten verdickten Intimateile finden sich solche Kerne viel mehr als in der übrigen Intima, und hier treten zellige Infiltrationen aus Lymphozyten auf. Ebenso bemerkt man hier und zwar in der tiefsten Schicht der Intima eine groBe Kalkplatte; in der Umgebung dieser Kalkplatte und an anderen Stellen ist fettige Degeneration vorhanden; bei Sudan III färbt sich die ganze Partie hellrot. Elastische Fasern sind mäßig stark neugebildet mit typischer Lamellenbildung.

Media: Mikroskopisch bemerkt man stark erkrankte Herde großer Ausdehnung. Diese Herde sind meistens scharf begrenzt und verschieden geformt (rhombisch, trichter- und sternförmig) und stellen Defekte von gànz verschiedener Größe dar. Einer dieser Herde erreicht die Mitte der Media, ein anderer reicht schief fast über die ganze Media. Die Herde liegen im übrigen meistens intimawärts. In den Defekten fehlen elastische Fasem völlig. Die Reste der elastisçhen Fasern sind an ihrem nach dem Defekt augekehrten Ende hakenförmig gekrümmt, scharf durchschnitten oder in kleinen Inseln erhalten. Die Herde selbst bestehen größtenteils aus entzündlichen Infiltrationen und frischem Granulationsgewebe nebst kernarmen Narben; besonders dieses Granulationsgewebe und die Narben greifen auf die Intima über; daher zeigen die Herde, wo man sie in beiden Schichten sieht, deutlich eine durch narbige Schrumpfung bedingte, unregelmäßig 
gestaltete Einziehung des Intimaniveaus. Die entzündlichen Infiltrationen bestehen fast alle aus Plasmazellen, bei Pyronin-Methylgrünfärbung (Unna-Pappenheim) färben sich die in Frage kommenden Partien ganz hellrot und bei Polychrom-Methylenblaufärbung ganz hellblau. Die in einigen Herden neugebildeten Gefäße sind vollständig von Plasmazellen umgeben. Sonst sieht man in der Media viele Vasa vasorum, welche stark dilatiert und zum Teil verdickt sind und perivaskuläre Infiltration zeigen. Diese Infiltrationen enthalten ebenfalls viele Plasmazellen und nur wenige Lymphozyten, die ersteren führen kontinuierlich in einer geraden Linie bis zur Adventitia. Eine der Adventitia naheliegende Stelle ist bei 70facher Vergrößerung durch das ganze Gesichtsfeld von einem Plasmazellenstrang durchzogen. Der der oben erwähnten Kalkablagerung in der Intima entsprechende Mediateil weist eine eigentümliche Stelle au?, bestehend aus nekrotischem Granulationsgewebe und außerdem Bindegewebe, umgeben von vielen Leukozyten und einer kleinen Kalkablagerung. Auch intimawärts erkennt man hier und da kleine Kalkablagerungen. In dem dem normalen Intimateile entsprechenden Mediateile treten stellenweise kleine Herde mit Fehlen der elastischen Fasern und Infiltration aus Plasmazellen und Lymphozyten auf. Mastzellen sind nur spärlich in einem in der tiefsten Schicht der Media liegenden kleinen Infiltrat vorhanden, sonst finden sie sich nicht.

Adventitia: In der Adventitia befinden sich viele Vasa vasorum, die meistens von zelliger Infiltration (viele Plasmazellen und wenige Lymphozyten) umgeben sind. Auch sonst sieht man hier und da Infiltrationen fleckweise aus Plasmazellen und Lymphozyten zusammengesetzt. Besonders auffallend sind einige wie Lymphknötchen aussehende Infiltrationen mit randständigen. Plasmazellengruppen. Manchmal sind die Plasmazellen rosettenartig um die Kapillaren herum angeordnet. Die Nerven in der Adventitia sind frei von Plasmazellen. Mastzellen sind auch sehr viel vorhanden, teilweise trifft man sie in den Plasmazellenanhäufungen an. In der Adventitia sind die Bindegewebsfasern stark entwickelt. Die Klappe ist fibrös verdickt und zeigt keine Zellanhäufungen.

Präparate II (Pars descendens). Intima: hügelförmigg, stark verdickt. An der tiefsten Schicht der Intima ist eine ganz geringe Fettablagerung. Im allgemeinen enthält der verdickte Intimateil spindelige Kerne, während die Übergangsteile der Verdickung ovale, runde und spindelige Kerne in frischem Granulationsgewebe und auch Lymphozyten und Plasmazellen enthalten, zum Teil zerstreut, zum Teil kettenartig und strangförmig: In der Mitte sowohl wie an den Übergangsstellen haben sich viele neue elastische Fasern lamellenartig gebildet, jedoch sind die in der Mitte liegenden, neugebildeten elastischen Fasern durch Infiltrationen (fast alles Plasmazellen) wieder zerstört.

Media: zeigt ganz charakteristische syphilitische Veränderung, die stärker als in den Präparaten I (Pars ascendens) ist.

Diese Präparate II zeigen in allen ihren Teilen starke Zerstörungen der Muskelschicht und der elastischen Fasern; besonders der der verdickten Intima angrenzende Mediateil ist von dieser Zerstörung betroffen. Hier finden sich trichterförmige, korkzieherartige, ganz unregelmäßige Defekte. Die Art der Zerstörung der elastischen Fasem ist genau dieselbe wie die oben bei Präparat I (Pars ascendens) beschriebene. Die Media- und Adventitiagrenze ist durch die starke Zerstörung unkenntlich. Die Defekte bestehen aus Narben und Granulationsgewebe, größtenteils aber aus zelligen Infiltrationen; diese letzteren sind zusammengesetzt aus Plasmazellen und wenigen Lymphozyten. Einige Herde bestehen nur aus Plasmazellen; bei Methylgrün-Pyronin färben sie sich ganz und gar hellrot. Die Infiltrationen setzen sich ununterbrochen von der Media zur Intima fort. Die Gefäße sind meist frei von Infiltrationèn. In dem der Adventitia naheliegenden Mediateile befinden sich viele kleinere Plasmazelleaherde, von denen einige mit den oben erwähnten größeren Herden durch einen schmalen Plasmazellenstrang verbunden sind. Auf der Grenzlinie der Media und Adventitia sieht man einige dickwandige Gefäßß3e, die mit hochgradigen Infiltrationen, meist aus Plasmazellen, umgeben sind. Ganz spärlich sind Mastzellen vertreten. 
Adventitia: Überall sind dilatierte, vollständig mit Blut gefüllte Vasa vasorum reichlich zu sehen. Einige Vasa vasorum sind endarteriitisch erkrankt mit scharf begrenzter perivaskulärer Infiltration. Nur aus Lymphozyten zusammengesetzte Infiltrationen sind äußerst selten vorhanden, meist finden sich in ihrer Umgebung mehr oder weniger Plasmazellen. In der Adventitia sieht man zwei Lymphknötchen von netzartig geordneten Plasmazellen umgeben. Mastzellen sind gleichmäßig vorhanden, ihre Beschaffenheit genau wie in den Präparaten I.

F a 11 34. H. W., Werkmeister, 53 Jahre.

Klinische Diagnose: Aortenaneurysma.

Alkohol: 6 Glas Bier, ab und zu Schnaps. Nikotin: mäßig. Infektion: als Soldat Tripper, 1882 Syphilis, keine Schmier- oder Spritzkur.

S.-Nr. 124; 1912. Obduktion 30. Januar ( $\mathrm{K} \mathrm{oc} \mathrm{h}$ ).

Pathologisch-anatomische Diagnose: Schwere Aortitis syphilitica mit großem sackartigen Aneurysma der Pars ascendens und des Arkus. Aorteninsuffizienz mit Retraktion und Verdickung der Klappen. Kompression und Arrosion des rechten Hauptbronchus, sehr starke eitrige Tracheobronchitis, besonders rechts. Bronchiektasenbildung, Kollaps und beginnende Pneumonie rechts: sero-fibrinöse Pleuritis m. gr. Exsudat rechts. Alte pleuritische Verwachsungen, verkalkte und indurierte Herde in beiden Spitzen. Lungenödem und alveoläres Emphysem links. Pleuritis callosa der parietalen linken Pleura. Säbelscheidentrachea. Adhäsive Perikarditis. Stauungssorgane, Narbe am Penis. Struma suprarenalis links, versprengter Nebennierenkeim rechts. Renkuläre Zeichnung beiderseits mit Sehrumptherden und Zysten rechts und links. Taenia saginata (Bandwurmglieder im Appendix), kleiner Schleimhautpolyp im oberen Colon ascendens.

Es wölbt sich rechts oberhalb des Herzbeutels ein rundlicher, kindskopfgroßer, schwappender Sack nach rechts und vorn vor, der sowohl mit den Rippen wie mit dem Manubrium sterni ziemlich fest verwachsen zu sein scheint. Oberhalb des Aortenostium gelangt man in den schon vorher beschriebenen kindskopfgroßen Sack, der aus der stark erweiterten Pars ascendens und dem größten Teil des Arkus der Aorta besteht. Die Aortenwand zeigt hier an der Innenfläche eine gelblich weiße Farbe und ist mit zahlloșen runzeligen und narbenartigen Vertiefungen versehen. Ein Teil ihrer Wand zeigt außerdem einige Zentimeter dicke, braunrote, fest aufsitzende derbe Massen. Kurz vor der Carotis communis sinistr. setzt sich der Sack mit scharfem, halsartigen Knick von dem folgenden, im übrigen normal werdenden Teil der Aorta ab. In dem nun folgenden BrustteiI der Aorta zeigt diese bis drei Finger breit oberhalb des Zwerchifells ein der Wand des Aneurysma ähnliches Aussehen, und finden sich hier noch sehr zahlreiche zackig nach dem Innern vorragende kalkharte Massen, wobei die oberste Schicht der Intima mehrfache Substanzverluste aufweist. Bauchaorta zeigt dieselben geringen Veränderungen wie die Brustaorta.

Präparate I entstammen der sackförmigen Aneurysmawand der Pars ascendens; Präparate II stammen von einer verdickten Stelle der Pars ascendens mit verdickter Klappe: Prüparate III wurden einer narbigen Stelle der Pars ascendens entnommen.

\section{Mikroskopischer Befund.}

Präparate I (Aneurysmasackwand). Intima zeigt stellenweise nicht normale Struktur. In ihrem ganzen Verlaufe sieht man Thrombusmassen, die hauptsächlich aus Fibrin bestehen.

Media ist überall stark verschmälert. Während die elastischen Fasern in dem ganzen Verlaufe dex Media völlig verschwunden sind, tritt überall schwielenbildung auf. Die Muskelfasern sind noch stellenweise erhalten. Diese ganze veränderte Media enthält viele Gefäße.

Adventitia: An einer Stelle ist Bindegewebe sehr stark entwickelt. Überall fallen die stark verdickten GefäBe auf; die um diese GefäBe bestehenden Infiltrate sind meist gering, manchmal fehlen sie auch völlig. Totale Obliteration des Lumens zeigen einige große und viele kleine Gefäße, von denen wieder viele mit kleinen Infiltraten umgeben sind. Hier und da bemerkt man Blutpigment. An der Peripherie der Adventitia findet man eine kleine Lymphdrüse, in der besonders 
in den Lymphräumen und im Kapselraum Plasmazellen reichlich auftreten; diese finden sich auch in der Umgebung der Drüse. Blutpigment ist in der Drüse nachweisbar. Mastzellen sind sehr viel vorhanden.

Präparate II (Pars ascendens mit der Klappe). Während die Aortenwand starke Veränderungen zeigt, ist die Klappe nur fibrös verdickt und zeigt keine Zellanhäufungen.

Präparate III (Pars ascendens). Intima ist auf eine lange Strecke hin mäßig stark sklerosiert, zeigt einige kleine Kalkablagerungen und geringe Infiltration.

Media: Die unter dem sklerosierten Intimateile liegende Media ist am schwersten erkrankt, stellenweise bis zur völligen Zerstörung. In diesem ausgedehnten erkrankten Teile der Media fallen viele große, auch mit bloßem Auge schon als Flecken erkennbare, meist unregelmäßige, manchmal bäumchenartige Zellherde auf, welche die ganze Mediabreite durchziehen. Thre Bestandteile sind meist Plasmazellen und nur wenige Lymphozyten. Außer diesen Zellen findet man in den Herden ganz frisches, gefäßreiches Granulationsgewebe mit wenig Blutpigment. An anderer Stelle bemerkt man noch mehrere ausgedehnte, kernarme, derbe Schwielen, in deren unmittelbarer Umgebung Zellherde, in der Hauptsache aus Plasmazellen bestehend, gelagert sind. In den obengenannten Erkrankungsherden sind die elastischen Fasern vollständig vernichtet. Die übrige Media zeigt dieselben Veränderungen, nur in geringerem Maßstabe.

Adventitia enthält einige makroskopisch sichtbare Zellherde, von denen einer Plasmazellen und Lymphozyten gemischt enthält, während die anderen als Zentrum nur Lymphozyten, an der Peripherie nur Plasmazellen enthalten. Diese Herde besitzen etwas Blutpigment und Gefäße. Kleine perivaskuläre Infiltrate und in den interstitiellen Lymphräumen befindliche Zellstränge sind meist Plasmazellen, die sich auch in rosettenartiger Anordnung finden. Die Nerven sind umsäumt von starken Infiltraten, auch finden sich Plasmazellen in dem Perineurium und Endoneurium. Man sieht hier und da stark gefüllte Vasa vasorum, einige davon verdickt. Mastzellen sind sehr viel nachweisbar. In der Adventitia sind die Bindegewebsfasern stark entwickelt.

F a 11 35. A. M., Oberstenermannsmaat, 33 Jahre.

Klinische Diagnose: Dementia paralytica mit epileptischen Anfällen.

1901 syphilitisch infiziert. Schmierkuren.

Wassermannsche Reaktion fehlt. Am 17. Februar Exitus.

S.-Nr. 206; 1912. Obduktion 18. Februar ( $\mathrm{L}$ ö h e ).

Pathologisch-anatomische Diagnose: Leptomeningitis chronica, Tonsillarabszeß links mit Phlegmone der linken Pars laryngea pharyngis und des Kehlkopfeingangs, alte Narbe am Sulcus coronarius penis. Mesaortitis syphilitica (?). Bronchitis. Blutungen in das Parenchym der Lunge. Pleurale Adhäsionen links; parenchymatöse Trübung der Nieren. Spulwurm.

Aorta: In der Aorta, die im allgemeinen leicht gelbliche Farbe hat, finden sich eine größere Anzahl von umschriebenen grauen beetartigen Herden. Die Pia mater hat eine grauweiße Farbe, erscheint stark getrübt und ist undurchsichtig. Die Gefäße der Basis klaffen etwas, ihre Wand ist scheinbar nicht verdickt. Mehrere durch das Gehirn gelegte Frontalschnitte zeigen normals Verhältnisse.

Präparate I sind einer mit grau-weißlichen, beetartigen Herden durchsetzten Stelle der Pars ascendeas, Präparate II einer ebensolchen der Pars descendens entnommea.

\section{Mikroskopischer Befund.}

Präparate I (Pars ascendens). Intima: Auf eine lange Strecke hin ist sie stark höckeigg verơickt, ohne regressive Veränderung. In dem verdickten Teil der Intima sieht man hier und da Rundzelleninfiltration in mäBiger Menge.

Media: Der dem oben beschriebenen verdickten Teil der Intima angrenzende Mediateil ist überall in seiner Breite verringert, sogar stellenweise durch Schwielenbildung stark zerstört. Die elastischen Fasern in diesem der stark verdickten Intima angrenzenden Teil sind intensiv gefärbt, 
während die übrige Media schwach gefärbt ist. An zwei Stellen sind die elastischen Fasern völlig unterbróchen. Im allgemeinen enthält die Media wenig Zellherde.

Adventitia: In der Adventitia fallen viele lang gestreckte Zellherde auf, die aus vielen Lymphozyten und sehr wenigen Plasmazellen bestehen. Man sieht viele stark dilatierte, strotzend gefülte Gefäße, auch einige obliterierte. Um die Nerven keine Infiltration. Mastzellen sind sehr viel nachweisbar.

Präparate II (Pars descendens) ebenso.

F a 11 36. E. G., Tischler, 54 Jahre.

Klinische Diagnose: Todesursache unbekannt. Nach Angabe der Angehörigen bestand starker Diabetes.

S.-Nr. 251; 1912. Obduktion 29. Februar ( G e ele n).

Pathologisch-anatomische Diagnose: Syphilis, multiple Aneurysmenbildung der Pars ascendens, des Arkus, der Pars descendens und des Brustteiles der Aorta. Perforation der Aortenwand in der linken Pleurahöhle. 31 Blut daselbst. Schankernarbe am Penis, Hodenschwielen links. Hypertrophie des linken. Herzventrikels, verruköse Endocarditis aortica; Säbelscheidentrachea, geringer Kollaps der linken Lunge, multiple Schrumpfherde in beiden Nieren. Tracheobronchitis, Prostatahypertrophie, geringe Balkenblase. Cholestearinstein in der Gallenblase, Zysten in der Leber.

Die Aorta ascendens ist diffus etwa apfelgroß erweitert, die Innenfläche ist rauh, und zwar finden sich zahlreiche dicht zusammenstehende prominierende verkalkte Platten, zwischen denen Stellen liegen, die in der Tiefe erweicht und an der Oberfäche zerkliutet sind. Auf einem Querschnitt durch die Aortenwand hat man den Eindruck, als ob außer diesen Intimaverdickungen anch die Media verändert wäre, es finden sich nämlich Stellen, wo dieselbe nur als ganz schmale, dünne Schicht zu sehen ist. Am Beginn des Arcus aortae bildet die Aortenwand ein dickes halsartiges Septum, das die erwähnte Erweiterung der Pars ascendens von dem kindskopfgroß erweiterten Arkus abtrennt. In diesem Teil ist die Aortenwand stark verdünnt, die Innsenseite des Sackes ist stark zerklüftet, an fünf Stellen stülpen sich kleinere, halbkugelige Erweiterungen aus, die Haselnuß- bis Kartoffelgröße haben, und deren größte an der Vorderseite der Aorta sich in das Interstitium zwischen oberem und unterem linken Lungenlappen hineinstreckt. Der oberste Teil der Pars descendens ist in diesen kindskopfgroßen Sack mit einbezogen, während der untere Teil durch eine quergestellte Leiste, die von der Aortenwand gebildet wird, abgegrenzt wird. An der oberen Seite der zwisehen den Lungenlappen hineinragenden Ausstülpung findet sich ein linsengroBes Loch in der Aortenwand, in dessen Umgebung die Adventitia von Blutungen durchsetzt ist, und durch das auch die große Blutung in die linke Pleurahöhle exfolgt ist. Der Brustteil der Aorta ist bis zor Abgangsstelle der Arteria mesenterica superior in toto diffus sehr stark erweitert. Breite am aufgeschnittenen Präparat bis $12 \mathrm{~cm}$. Die Innenfläche hat ähnliches Aussehen wie die oben beschriebenen Teile, nur sieht man hier zwischen den vorspringenden Klappen narbenartige kalkige Vertiefungen; auch hier wölben sich an der allgemeinen Erweiterung kleine halbkugelige Säcke vor, im ganzen sechs, dessen größter Aprikosengröße hat und nach dem Unterlappen der linken Iunge vordrängt. Namentlich diese Ausstülpung ist durch einen scharfen Hals von dem diffusen Aneurysma abgesetzt. Von der Abgangstelle der Art. mesenterica superior an ist die Innenseite der Aorta glatt, aufgeschnitten $4,5 \mathrm{~cm}$ breit und ziemlich elastisch.

Präparate I entstammen einer graugelblichen, etwas verdickten Stelle der Pars ascendens. Präparate II wurden dem Aneurysmateil entnommen.

\section{Mikroskopischer Befund.}

Präparate I (Pars ascendens). Intima ist mäßig stark sklerotisch verändert; die tiefste Sehicht der Verdickung zeigt überall fettige Degeneration und weist auch eine Stelle mit beginnender Atheromatose auf. In der Umgebung tritt kleinzellige Infiltration auf. 


\section{4}

Media: Der unter der fast normalen Intima liegende Mediateil ist von einem großen Granulationsherde durchsetzt, in dem Plasmazellen in geringer Zahl vorhanden sind. In dem der Verdickung der Intima entsprechenden Abschnitt der Media treten einige bandartige Schwielen und viele GefäBe auf, hier ist Infiltration kaum sichtbar.

Adventitia: zeigt ganz geringe mikroskopische Veränderungen. Mastzellen sind in mäßjger Nenge vorhanden.

Präparate II (Aneurysmateil). Intima: Sie ist stellenweise verdickt und teilweise sind ihe thrombotische Massen aufgelagert. An einer Stelle, dicht neben der thrombotischen Masse, ist ein, viele mäßig erweiterte Kapillaren enthaltendes Granulationsgewebe aufgetreten. Sonst weist die Intima hier und da Rundzellinfiltration auf.

Media: In diesen Präparaten lassen sich im ganzen Mediaverlaufe hochgradige Zerfallerscheinungen feststellen. Während die Media bei van Gies on-Färbung eine erheblich verschmälerte, streckenweise unterbrochene, gelb gefärbte Muskelschicht aufweist, fallen bei der Elastikafärbung die starke Verschmälerung und die vielen Defekte der elastischen Fasern auf; diesseits und jenseits dieses soeben beschriebenen Mediateils sind die elastischen Fasern auf eine lange Strecke hin sogar vollständig verschwunden. An ihre Stelle sind ausgedehnte Schwielen und Granulationsgewebe getreten, so daß man den Findruck hat, als wären Media und Adventitia direkt miteinander verbunden. An anderen Defekten der elastischen Fasern sieht man auch Schwielen, bisweilen Granulationsgewebe und Schwärme von Lymphozyten und Plasmazellen. Ein Zellherd aus Lymphozyten und Plasmazellen reicht bis in die Intima, andererseits bis in einen gleichen Zellherd in der Adventitia hinein.

Adventitia: Während Infiltration in der Media verhältnismäBig selten ist, tritt sie in der Adventitia sehr stark auf. Die großen Zellanhäufungen sind meist lang gestreckt, so daß sie makroskopisch schon als lange Streifen sichtbar sind. Diese Zellanhäufungen bestehen meist aus Lymphozyten, in ihrer Peripherie oder seitlich sind viele Plasmazellen angehäuft. Kleinere Infiltrationen sind reich an Plasmazellen. Verdickte Vasa vasorum sind wenig sichtbar. Mastzellen sind gruppenweise viel vorhanden.

F a 11 37. B. G., Reisender, 62 Jahre.

Klinische Diagnose: Dementia postluetica, wahrscheinlich vaskuläre Lues. Herzschwäche.

Potus bis etwa 1899: 5-6 Glas Bier, später weniger. Angeblich 1873 mit Lnes infiziert (Geschwür am Penis), später noch zweimal Geschwür am Penis gehabt. 1902: Sehmierkur, wenig Ausschlag am Körper, 1907: Spritzkur.

Wassermannsche Reaktion + . Exitus am 12. März 1912.

S.-Nr. 303; 1912. Obduktion 13. März (C e elen).

Pathologisch-anatomische Diagnose: Syphilis. Schwere Mesaortitis syphilitica, stellenweise mit nekrotiseher Erweichung der Media. Diffuses Aneurysma der Aorta ascendens und des Arcus aortae. Gummöse (?) Verdickung an der Teillungsstelle der linken Carotis ext. und int. Aneurysmatische Erweiterung an der Anonyma und der rechten Subklavia. Alte Schankernarben am Penis. Leberzirrhose mit partieller Verfettung. Schwere parenchymatöse Degeneration mit oberfächlicher Granulierang beider Nieren. Multiple Zysten, kleineKalkkörperchen und größere Schrumpfherde, kleine Gichtherde in beiden Nieren. Allgemeine Arteriosklerose. Schlafies, trübes Herz mit Dilatation des rechten Ventrikels. IKleine Schwielen. Frische Endocarditis verrucosa aortica. Verdickung der Schließungsränder an der Mitralis und der zugehörigen Sehnenfüden. Geringer, allgemeiner Höhlenhydrops. Hydrops anasarca. Derbe, pleuritische Verwachsungen beiderseits. Geringer Kollaps des linken Unterlappens. In käsiger Eindickung und Verkalkung begriffener walnußgroßer Eiterherd zwischen Zwerchfell und linker Lungenbasis. Schwielige Umwandlung der Zwerchfellkuppe. Alte Thorakozentesenarbe links. Starke perisplenitische Verwachsungen. Stauungstracheobronchitis. Stauungsgastroenteritis. Chronische Stauungsmilz. Ödem der ary-epiglottischen Falten. Schiefrige Pigmentierung der gesehwollenen Lymphknötchen 
in Dünndarm. Chronische Leptomeningitis, besonders der Gehirnbasis. Chronische fibröse Pachymeningitis mit Knochenplättchen. Pia- und Gehimödem. Hydrocephalus internus. Fingertiefe Impressionen an der Unterseite der linken Kleinhimhemisphäre, herrührend von umschriebenem bulösem Piäddem. Induration des Pankreas. Multiple Epidexmisdefekte am Kopf und der linker Brnstseite (keine Gelenkgicht).

Präparate I und II sind der makroskopisch sichtbaren nekrotischen Erweichungsstelle der Yedia entnommen.

Mikroskopischer Befund.

Präparate I (Pars ascendens). Intima: Sie zeigt ïberall gleichmäßige leichte Verdickung; stellenweise mit Rundzelleninfiltration.

Media: Die intimawärts gelegene Mediahälste weist allenthalben viele stark ausgedehnte, scharf begrenzte, ganz dicht aneinander liegende, schon makroskopisch auffallende gummöse Herde auf, die nur kurze Stücke gesunder Media zwischen sich lassen. Diese gummösen Herde sind mit vielen Zellinfiltrationen aus reichlichen Plasmazellen umgeben. In den gummösen Herden sowie in deren Umgebung sieht man lipoide Degeneration. An einer Stelle ist eine umfangreiche Schwiele ausgebildet, daneben findet sich gefäßhaltiges Granulationsgewebe mit vielen Plasmazellen und Lymphozyten. Die elastischen Fasern sind stellenweise ganz zerstört. Während ein gummöser Herd noch Trümmer elastischer Fasern enthält, sieht man in den anderen gummösen Herden keine elastischen Fasern. Der adventitiawärts gelegene Mediateil ist mit zahlreiehen Gleinen Zeltherden durchsetzt.

Adventitia: Sie zeigt auch starke typische syphilitische Veränderungen. Die weitaus an! meisten auffallende Veränderung ist das Auftreten von Zellherden. Man kann sie schon mit bloßem Ange als etwa 20 umschriebene und diffuse Fleckchen deutlich sehen. Diese Zeliherde sind meist aus zahlreichen Lymphozyten zusammengesetzt, in der Peripherie sind auch zahlreiche Plasmazellen angehäuft, die manchmal miteinander verbunden sind. Kleinere Zellherde und die interstitiellen Zellinfiltrationen bestehen meist aus vielen Plasmazellen. Hier und da sieht man letzitere in rosettenartiger Anordnung. Viele Vasa vasorum sind verdickt, sogar obliteriert, und finden sich entweder innerhalb der oben erwähnten Zellherde oder außerhalb derselben. An dem Grenzgebiet der Adventitia und Media liegt ein großes ganz obliteriertes Gefäß, das mit schichtweise angeordneter Plasmazellenanhäufung umgeben ist. In der Jmgebung der adventitiellen Lymphknötchen liegen auch Plasmazellen. Mastzellen sind sehr viel nachweisbar. Die adventitiellen Bindegewebsfasern sind mäßig entwickelt.

Präparate II (Pars ascendens). In der Intima sieht man spärliche Plasmazellen. In der Adventitia finden sich mehr obliterierte Gefäße als in den Präparaten I. Der sonstige mikroskopische Befund ist fast gleich wie bei den Präparaten I.

Fall 38. F. K., Maurer, 55 Jahre.

Klinische Diagnose: Laes hepatis. Abdominaltumor. Pneumonie.

Nikotin: täglich 2 Zigarren. Potus: 2-3 Glas Bier. Vor 30 Jahren Tripper und harter Schanker, hat mehrere Schmierkuren gemacht, die letzte vor 8 Jahren, weil er sich verheiraten wollte. Zeichen einer tertiären Lues hat er nicht gehabt. Jetzige Erkrankung datiert seit etwa. 10 Wochen.

Wassermannsche Reaktion fehlt. Am 13. März 1912 Exitus letalis.

S.-Nr. 309; 1912. Obduktion 14. März ( O e elen).

Pathologisch-anatomisehe Diagnose: Syphilis. Hepar lobatum, Thrombose einiger Pfortaderäste im Bereich des rechten Leberlappens; großes subkapsuläres Hämatom der linken Niere, multiple Venenthrombose und Infarkte in beiden Nieren, Aortitis syphilitica, Hodenschwielen, Skleratheromatose der Aorta, hämorrhagische Infarkte in der linken Lunge. Bronchopneumonische Herde, besonders rechts, Hydrothorax beiderseits, besonders rechts. Verfettung der Hexzmuskulatur, 
Dilatation und geringe Hypertrophie beider Ventrikel, unschriebene fibrinöse Perikarditis unt Pleuritis. Finteritis nodularis, Hodengurnmata beiderseits, kleine hypertrophische Knoten in lex Prostata, schwere chronische Oesophagitis granularis, fibröse Verdickungen der Milzkapsel, chronische Staungsmilz, Stauungsleber, schwere, zum Teil hämorrhagische Gastritis.

Präparate I entstammen einer flachen, grauen, von feinen Runzeln umgebenen Vexdickumosstelle der Pars ascendens. Präparate II stammen von einer graugelblichen, unebenen, zum Teil verkalkten. Stelle der Pars descendens.

\section{Mikroskopischer Befund.}

Prüparate I (Pars ascendens). Intima: Sie ist teils leicht, teils mäBig stark verdickt. Zwischen diesen zwei Teilen liegt ein leicht verdickter Teil mit vielen flachen und tieferen FaIten. In dem tiefsten Abschnitt des oben erwähnten mäßig verdickten Teils der Intima sieht man atheromatöse Veränderung mit Fettablagerung. In der Umgebung dieses atheromatösen Herdes tritt Rundzelleninfiltration auf.

Media: In dem dem atheromatösen Herde angrenzenden Mediaabschnitt bemerkt man zahlreiche kleine Kalkablagerungen. Der gleiche, adventitiawärts gelegene Teil ist mit vielen kleinen Schwielen durchsetzt und zeigt viele Gefähe mit Infiltration. Während der Mlediateil. der unter dem faltenreichen Intimaabschnitt liegt, keine krankhafte Veränderung aufweist, zeigt die dem leicht verdichten Intimateil entsprechende Nedia erhebliche Veränderung. Hier sind ansgedehnte, narbige Gewebe, zum Teil Granulationsgewebe ansgebildet; dadurch ist die Medlia hier stark verschmälert und sind die elastischen Fasern zum größten Teil zerstört oder ganz verschwounden.

Adventitia: An dem Teil der Adventitia, der dem viele kleine und ansgedehnte Schwielenbildungen enthaltenden Mediaabschnitt entspricht, fällt der Reichtum von stark erweiterten, strotzend gefüllten Kapillaren und stark verdickten GefäBen auf. Infiltrationen treten zerstreut auf, bald aus Scharen von Lymphozyten und Plasmazellen, bald nur aus Plasmazellen bestehend. Letztere sieht man auch in rosettenartiger Anordnung. Mastzellen enthält die Adventitia sehr viel.

Präparate II (Pars descendens). Intima ist allenthalben mäBig stark verdickt mit vielen starken und flachen Vertiefungen. An einer Stelle ist Kalk abgelagert. Die tiefste Intimaschicht zeigt stellenweise lipoide Degeneration.

Media: Der adventitiawärts gelegene Mediaabschnitt ist mit vielen verschieden grolen Schwielenbildungen durchsetzt; die unter den tiefen Falten liegenden Schwielen sind klein. In der Media ist Infiltration kaum erkennbar, während an einer Stelle Kalk abgelagert ist.

Adventitia: Adventitielle Bindegewebssubstanzen und elastische Fasern sind mäßig entwickelt. Die Veränderung der Gefäße und das Auftreten der Infiltration sind verhältnismäßig gering. Mastzellen sind in mäßiger Menge vorhanden.

F a II 39. L, W., Witwe, 60 Jahre.

Klinische Diagnose: Apoplexie, Bronchopneumonie.

Wassermannsche Reaktion fehlt. Ein Tag nach der Aufnahme Exitus (8. April 1912).

S.-Nr. 425; 1912. Obdulstion 9. April ( $\mathrm{Heitz} \mathrm{mann}$ ).

Pathologisch-anatomische Diagnose: Syphilis, syphilitische Aortitis mit Aneurysmenbildungen in Areus und Thoraxteil. Knötchenförmige syphilitische Leptomeningitis basalis; Gummi der Dura, Falx cerebri an der Crista galli; Verwachsung mit der Pia und der Gehimrinde. Hepar lobatum, beginnende Schrompfnieren; Schwellung der Lymphknötchen der Milz; eitrige Bronchopneumonie beiderseits. Ödem beider Lungen. Chronische Cholezystitis mit Gallensteinen.

Die Präparate I entstammen einer teilweise gerunzelten, grauen, narbigen Stelle der Pars ascendens; Präparate II sind einex zart gefalteten, dicht bei einer beetartigen Verdickung Jiegenden Stelle entnommen. Präparate III entstammen dem Aneurysmahalsteil im Thoraxteil. 
Mikroskopischer Befund.

Präparate I (Pars ascendens). Intima ist stellenweise sklerotisch verändert. An einer Stelle sinkt sie stark ein, daneben zeigen sich noch einige flachere Finsenkungen. An einigen Stellen tritt kleinzellige Infiltration auf.

Am stärksten ist die Media verändert, so daß die Muskel- sowie elastischen Fasern überall stark geschädigt, streckenweise sogar zerstört sind. In diesen Herden sind ausgedehnte Schwielen, zum Teil vermehrte Gefäße mit Plasmazellen und wenigen Lymphozyten in der Umgebung ausgebildet. In der Media finden sich keine großen Zellherde.

Adventitia: Sie ist von vielen Zellherden, von denen einige schon mit bloßem Auge erkenntlich sind, durchsetzt. Während die großen Zellanhäufungen zum sroßen Teil aus Lymphozyten zusammengesetzt und nur an ihrer Peripherie vereinzelt mit Plasmazellen umgeben sind, bestehen die kleinen Zellanhäufnngen nur aus Plasmazellen. In dem Interstitium des Fettgewebes finden sich große Mengen von Plasmazellen. Man sieht ein adventitielles Lymphknötchen, an dessen Peripherie Plasmazellen angehänft sind. Um die Nerven besteht keine Infiltration. Viele Vasa vasorum sind verdiekt, zum Teil obliteriert. Mastzellen sind viel vorhanden. Die A. pulmonalis, die ich mit der Aorta zusammen geschnitten habe, zeigt keine Veränderung.

Präparate II (Pars descendens). Intima ist mäßig verdickt und weist in ihrem ganzen Verlaufe zahlreiche flache und tiefere Finsenkungen, entsprechend den makroskopisch sichtbaren feinen Falten der Intima, auf. Sonst zeigt die Intima nirgends degenerative Erscheinungen.

Media: In der intimawärts gelegenen Mediahälfte sind die elastischen Fasern etwas schwächer gefärbt als die adventitiawärts liegenden; hier sieht man keine Zerstörung der elastischen Fasern, sondern nur an einer Stelle ein langgestrecktes GefäB mit perivaskulärer Infiltration. In dem adventitiawärts gelegenen Mediateil, besonders im Grenzgebiet der Media und Adventitia fallen die vielen stark erweiterten und strotzend gefüllten. Blutgefäbe auf, die mit ganz geringfügigen Zellinfiltrationen umgeben sind. Die elastischen Fasern sind geschlängelt und an einer Stelle durch Granulationsgewebe ein wenig gesehädigt. Sonst findet man keine Schwielen.

Adventitia: Sie ist hier und da von größeren Schwärmen von Lymphozyten und Plasmazellen, von denen einige schon makroskopiseh sichtbar sind, durchsetzt. In dem Interstitium des Fettgewebes bemerkt man auch reichlich Plasmazellen. Die Vasa vasorum sind stark dilatiert und gefüllt. Auch endarteriitiseh veränderte Gefäße sind vorhanden. Mastzellen sind mäßig viel nachweisbar.

Präparate III (Aneurysmahals). In der Intima des Halsteiles treten kleinzellige Infiltrationen anf. Auf der ganzen Intima des Aneurysmateils lagert thrombotische Masse. Obwohl die elastischen Fasern stellenweise staxk zerstört sind, finden sich keine Zellherde.

F all 40. A. L., Bierfahrer, 52 Jahre.

Klinische Diagnose: Herzklappenfehler und chronische Herzmuskelentzündung.

Reichlicher AlkoholgenuB. Nikotin: 4 Zigarren. Infektion: Vor 30 Jahren Tripper, kein Schanker.

Wassermannsche Reaktion +. Exitus am 30. Mai 1912.

S.-Nr. 637; 1912. Obduktion 31. Mai ( L ö h e).

Sektionsdiagnose: Syphilitisches Aneurysma der Aorta ascendens, Arcus und Aorta thoracalis, Endocarditis chronica calculosa valvulae aortae et mitralis. Skleratheromathose der Aorta. Arteriosklerose der Aa. coronariae. Hypertrophie und Dilatation des Herzens. Trübung des Herzmuskels. Hypernephrom links. Stauungsniere mit Gichteinlagerung. Gelenkgicht. Stauung und Trübung der Leber. Stauungsmilz. Staungskatarrh des Darmes. Polyp im Dickdarm. Lungenödem und Emphysem. Pleuritis adhaesiva circumscripta dextra. Narbe im Sulcus coronarius des Penis. Plaques an den Zungenrändern. Höhlenwassersucht. Allgemeine Adipositas.

Die Präparate I und II sind einer Stelle der Aneurysmawand der Pars ascendens entnommen, die zum. Teil kleinhöckerige Erhabenheiten, zum Teil strahlige, narbige Einziehungen zeigt. 
Mikroskopiseher Befund.

Präparate 1. Intima: Überall ist sie ziemlich stark verdickt und sieht derb aus. An einer Stelle findet sich ein großes, strotzend gefülltes, neugebildetes GefäB; in dessen Umgebung sieht man eine kleine Menge von Plasmazellen und Lymphozyten.

Media: In ihrem ganzen Verlauf weist sie eine gleichmäßige Zerstörung der elastischen Fasem auf, während die Muskelfasern stellenweise ganz intakt geblieben sind, im ïbrigen aber schwielige Bindegewebsentwicklung mit Resten zugrunde gegangener elastischer Fasern sich findet. An einer Stelle ist das schwielige Bindegewebe sehr stark entwickelt, so daß hier gar keine elastischen Fasern vorhanden sind. Viele stark gefüllte, ganz wenig mit Rundzellen umgebene Blutgefälse sind sichtbar.

Adventitia: Die am meisten ins Auge springenden Veränderungen sind einige schon makroskopisch als Pünktchen erkenmbare, große entzündliche Infiltrationen der Adventitia. Namentlich finden sich diese Zellherde an der Stelle, wo der dem oben erwähnten, ganz schwielig veränderten Mediateil entsprechende Teil der Adventitia liegt, die hier starke Bindegewebsneubildung zeigt. Diese Zellherde enthalten stark verdickte Gefäße und bestehen aus Gruppen von Plasmazellen and Lymphozyten, bisweilen nur aus Plasmazellen. Finmal findet sich un ein stark verdicktes Gefäß herum zunächst ein Ring von Lymphozyten, dann eine mehrfache Schicht von Plasmazellen. In dem übrigen Teile der Adventitia finden sich Zellinfiltrate von Plasmazellen und Lymphozyten mit herdförmiger Gruppierung um die Vasa vasorum und auch die LymphgefäBe, oder strangtörmig in den interstitiellen Rärumen. Mastzellen sind in der Adventitia sehr wenig vorhanden.

Präparate II weisen dieselben mikroskopischen Veränderungen auf.

F a 11 41. A. R., Korbmacher, 38 Jahre.

Klinische Diagnose: Herzklappenfehler.

Alkohol: angehlich kein Alkohol. Nikotin: früher 2-3 Zigarren täglich. Infektion: negatutur.

Wassermannsehe Reaktion ++++ . Tod 9. Juni 1912.

S.-Nr. 676; 1912. Obdaktion 10. Juni ( K o c h).

Sektionsdiagnose: Endocarditis chronica fibrosa aortica verrucosa recurrens mitralis. Starke Retraktion und Verwachsung der Aortenklappen. Starke Dilatation und Hypertrophie beider Ventrikel bei Verfettung und Schwielenbildung in der Muskulatur. Herdweise Aortitis syphilitica im obersten Teil der Aorta, Intimaverfettung im übrigen Teil. Geringe Koronarsklerose. Völlige Obliteration der Perikard- und beider Pleurahöhlen. Pleuritis serofibrinosa rechts mit Verwachsung an der Spitze. Aszites. Starkes Anasarka. Stauungshnnge. Tracheobronchitis. Gastritis. Enteritis. Muskatnußleber. Stauungsniere mit Schrumpfherden und Zystchen und kleinem Kalkinfarkt. Pneumonisehe Herde rechts unterı. Starkes bullöses Emphysem in beiden Lungenspitzen. Stanung:mily. Am Präputium und der Glans zwei narbige Stellen.

Dicht oberhalb des etwas erweiterten Sinus Valsalvae finden sich an der Aorta beetartige, gut $2 \mathrm{~mm}$ hobe Erhabenheiten, deren Rand rötlich und wulstig aussieht, und deren Zentrum ein weißgraues, perlartiges Aussehen besitzt. Diese Erhabenheiten bilden oberhalb der Klappen eineu völligen Ring, während in der Pars ascendens und im Arcus mehr isolierte, meist zehnpfennigstückgroße Herde sich finden. Der übrige Teil der Aorta zeigt in seinem ganzen Verlauf feine gelbe Streifchen und Stippchen, die sich von der stark imbibierten Gefä,bwand deutlich abheben; die Koronararterien sind weit und zeigen nur an einzelnen Stellen kleine, gelbliche Verdicknngen. Pulmonalarterien zeigen ganz vereinzelt gelbliche Flecken an der Intima.

Die Präparate I sind einer Stelle dicht oberhalb des Sinus Valsalvae entnommen, die eine beetartige, gut $2 \mathrm{~mm}$ hohe Errhabenheit mit vielen längsverlaufenden Falten zeigt. Die Präparate II sind einer Stelle der Pars ascendens entnommen, die auch eine kleinere, granweibliche, narbige Wrhabenheit aufweist. 
Mikroskopischer Befund.

Präparate I (dicht oberhalb des Sinus Valsalvae). Intima: Sie zeigt auf eine lange Strecke hin höckerige Beschaffenheit und unter Faltenbildung zunehmende fibröse Verdickung. Diese verdickte Intima zeigt gar keine degenerative Veränderung und enthält nur vereinzelt Plasmazellen.

Media: Während der der normalen Intima entsprechende Teil der Media an einigen Stellen nur kleine Infiltrate zeigt, enthält der unter dem oben erwähnten verdickten Intimateil liegende Mediaabschnitt erhebliche, typisch syphilitische Herde. In deren Bereich finden sich zum Teil spindelförmige und ovale Zellen mit Gefäßen neben verdickten Gefäßen, zum Teil große Gruppen von Plasmazellen und Lymphozyten, und andererseits schwielige Bindegewebsneubildung mit Resten zugrunde gegangener elastischer Fasern. Der eine von diesen Herden nimmt fast die ganze Breite der Media ein.

Adventitia: In der Adventitia fallen zahlreiche, schon mit bloßem Auge als Flecken erkennbare Zellschwärme auf, die hauptsächlich aus Lymphozyten und wenigen Plasmazellen zusammengesetzt sind. Die letzteren sind meist gruppenförmig angeordnet. Hier und da finden sich verschieden große, verdickte und sogar obliterierte Vasa vasorum. Die übrigen Gefäße sind stark dilatiert und strotzend gefüllt. Das adventitielle Bindegewebe sowie die elastischen Fasern sind vermehrt. Mastzellen sind reichlich nachweisbar.

Präparate II (Pars ascendens) wie I.

Fall 42. A. H., Schneiderin, 38 Jahre.

Klinische Diagnose: Aorteninsuffizienz, Enteroptose.

Partus : 1 .

Wassermannsche Reaktion + . Exitus 24. Mai 1908.

S.-Nr. 560; 1908. Obduktion 26. Mai (R he ind orf).

Pathologisch-anatomische Diagnose: Chronische retrahierende Endocarditis aortica. Geringe Endocarditis mitralis. Starke Hypertrophie und Dilatation beider Ventrikel mit Verfettung. Stauungsorgane. Schwere hämorrhagisch-fibrinöse, nekrotisierende, ulzeröse Enteritis. Lungeninfarkte rechts (Thromben in der V. femoralis). Kleine Käseherde in der linken Lungenspitze. Starke Skleratheromatose des Arkus, der Pars ascendens der Aorta, lipoide Degeneration der Intima in der absteigenden Aorta.

Aorta ist ziemlich weit mit zahllosen, teils grauweißlichen, teils im Zentrum gelben Prominenzen; dicht oberhalb der Klappen je eine pfennigstück- und markstückgroße beetartig erhabene Partie mit einerseits grawweißlichen, andererseits mehr im Zentrum liegenden gelblichen Stellen, die hier von kalkartiger Konsistenz sind. Auf dem Durchschnitt zeigt sich die Intima stark verdickt, die Media ganz schmal. Der Eingang in die rechte Koronararterie ist durch diesen großen Fleck etwas eingeengt. Im übrigen ist die Aorta zart, elastisch mit zahllosen, feinsten gelblichen Flecken der Intima.

Präparate I sind einer verdickten Stelle dicht oberhalb der Klappen entnommen. Präparate II sind der Mitte der Pars ascendens entnommen.

Mikroskopischer Befund.

Präparate I (Pars ascendens). Intima: zeigt an zwei Stellen sklerotische Verdickungen mit spindeligen oder ovalen Kernen und Rundzelleninfiltration.

Media: Es finden sich in vielen Stellen bald scharf begrenzte Zellamhäufungen — hier fehlen die elastischen Fasern zum Teil völlig, und ihre Enden sind zum Teil zur Seite gebogen oder wie scharf abgeschnitten, - bald etwas diffuse Zellanhäufungen in mäBig großer Ausdehnnung. Diese Zellherde sind meist mit Plasmazellen und Lymphozyten übersät, in einigen finden sich auch viele Plasmazellen. Am adventitiawärts gelegenen Rande der Media sind einige hintereinander gelegene 
obliterierte Gefäße, mit geringen Plasmazellenanbäufungen vorhanden. Hier sind die elastischen Fasern dadurch bündelartig voneinander getrennt.

Adventitia: Sie ist am schwersten erkrankt. Die am meisten ins Auge springenden Veränderungen sind die stark erkrankten Gefäß乃e mit hochgradiger Infiltration aus Lymphozyten und einigen Plasmazellen. In den Gefäßen ist es zu einer starken Auflockerung ihrer elastischen Lamellen, einer Verdickung der Gefäßwand gekommen, die in vielen bis znr völligen Obliteration des Lumens geführt hat. Manchmal sieht man eine Gruppe von solehen Gefäßen, um die ausgedehnte Zellanhäufungen liegen. Um die Nerven besteht auch starke Infiltration, und einige Plasmazellen gehen in das Perineurium über. Man trifft anch Mastzellen an. Die adventitiellen Bindegewebs- und elastisehen Fasern sind stark entwickelt.

Präparate II zeigen dieselben mikroskopischen Veränderungen.

F a 11 43. M. G., Landhausbesitzersfrau, 58 Jahre.

Klinische Diagnose: Aneurysma aortae.

Partus: 1 Kind.

Wassermannsehe Reaktion + . Exitus letalis 4. Februar 1910.

S.-Nr. 134; 1910. Obduktion 4. Februar (B eitzke).

Pathologisch-anatomische Diagnose: Aortitis fibrosa mit Aneurysma der Aorta ascendens, des Arkus. Chronische Endocarditis aortica, in geringem Grade auch mitralis, Hypertrophie beider Tentrikel. Stauungsorgane. Mäßiger Höhlenhydrops und Hydrops anasarca. Thromben in der rechten Vena femoralis; hämorrhagische Infarkte der Lungen. Multiple Lungenemboli, kleiner brauner Erweichungsherd im linken Nucleus lentiformis. Mäßiges Himödem. Gallensteine. Kleines Nebennierenadenom rechts. Perimetritische Verwachsungen.

Die Abgangsstelle der rechten Koronararterie ist nicht zu finden, auch läßt sie sich nicht von der aufgeschnittenen Arterie aus sondieren. Aorta ascendens in mäBigem Grade ausgebuchtet, enthält nur flüssiges Blut. Die Erweiterung setzt sich auch auf die Anonyma fort, die an ihrer Abgangsstelle $5 \mathrm{~cm}$, an ihrer Teilnngsstelle $4 \frac{1}{2} \mathrm{~cm}$ im Umfang mißt. Die linke Karotis und Subklavia sind an ihrem Ursprung eher etwas verengert wie erweitert. . Die Aorta mißt am Arkus 71/2, dicht hinter dem Abgang der linken seitlichen großen Gefäß $8 \mathrm{~cm}$, dicht über dem Zwerchfell beträgt der Umfang $7 \mathrm{~cm}$. Die Innenfläche der ganzen Aorta thoracica zeigt ein buntes Bild. Schwefelgelbe, teils rauhe, teils glatte, leicht erhabene Stellen von sehr verschiedener Größe und äußerst unregelmäßiger Gestalt und Begrenzung wechseln mit weißgranen bis rötlichgrauen, glatten, etwas tiefer gelegenen, narbenartig aussehenden Partien; in den gelben Teilen finden sieh häuffig bis linsengroBe Usuren and Geschwürehen, in den granen sieht man ziemlich zahlreiche feinste Gruben und Fältchen, letztere besonders auch an der Grenze der gelben und der grauen Abschnitte. Die Veränderung setzt sich auf die Aorta und Anonyma, nicht aber auf die Karotiden und Subklavia fort. Die Vorspränge der Interkostalarterien sind an der Innenfläche der Aorta überhaupt nicht zu sehen.

Bauchaorta ähnlich wie Brustaorta, nur lange nicht so stark verändert und bedeutend enger.

Präparate I und II sind den Aorten ascendens und descendens (II) entnommen, beide von narbigen, unregelmäßig gestalteten Partien.

\section{Mikroskopischer Befund.}

Präparate I (Pars ascendens). Intima: gleichmäßig verdickt, an einer Stelle finden sich zwei kleine Kalkablagerungen mit Infiltration aus Lymphozyten, sonst keine Degenerationserseheinungen.

Media: An vielen Stellen, besonders in dem intimawärts gelegenen Abschnitt, sieht man viele große Zellanhäufungen, sowie kleine und ausgedehntere Sehwielen, dicht daneben Granulationsgewebe. In diesen Herden sind die elastischen Fasern stark geschädigt, an einigen Stellen fehlen sie streckenweise vollständig; dafür finden sich Gefäße mit Infiltration aus Plasmazellen. 
An anderen Stellen finden sich ähnliche Herde, doch sind die Infiltrate viel geringer. Dicht unterhalb der oben beschriebenen zwei kleinen Kalkherde bemerkt man ziemlich große Infiltrate ans Plasmazellen. Die Grenze zwischen Media und Intima ist durch die Narben ganz undeutlich. Mastzellen sind nicht zu sehen.

Adventitia: Die Veränderung in der Adventitia ist geringer als in der Media. Kollagene, bindegewebige Substanz ist in der Adventitia stark entwickelt und sehr breit. Infiltrate treten sehr wenig hervor, doch sieht man unter dem narbigen Herde in der Media einige sehr lange, makroskopisch schon sichtbare Infiltrate, die fast nur aus Lymphozyten bestehen. Einige Plasmazellen sind dazwischen gelegen. Vasa vasorum sind mäßig viel vorhanden. Die Nerven sind frei won Infiltraten. Mastzellen sind stellenweise nachweisbar.

Präparate II (Pars descendens) zeigen die gleichen Veränderungen.

F a 11 44. E. R., Steinsetzersfrau, 42 Jahre.

Klinische Diagnose: Ohronische parenchymatöse Nephritis. Insufficientia cordis (praecipue Aorteninsuffizienz), Tabes dorsalis. Lues III asymptomatica.

Lues (Ausschlag) mit 20 Jahren (Spritzkur vor 20 Jahren).

Wassermannsche Reaktion +. Exitus am 21. Mai 1910.

S.-Nr. 594; 1910. Obduktion 23. Mai ( K o c h).

Pathologisch-anatomische Diagnose: Schwere Myodegeneratio cordis mit Verfettung und Schwielenbildung. Starke Insuffizienz des Ostium aortae bei Retraktion dex hinteren und völligem Fehlen der vorderen linken Klappe und Kugelthrombus an der Spitze des linken Ventrikels. tortitis syphilitica. Staungslungen, Stauungsmilz, Stauungssnieren, Stauungsleber, Stauungskatarrh von Magen und Darm. Hydroperikard, Hydrothorax, Aszites. Leichtes Ödem. Tracheobronchitis, Anthrakose der Hilus- und Bronchialdrüsen. Pleurale Verwachsungen der Lungen. Kleine submuköse Fibromyome des Magens. Alte Infarktnarben in beiden Nieren. Renkuläre Lappung, geringe Staumgsnephritis und leichte Verfettung. Urocystitis cystica. Pelveo-peritonitische Verwachsungen. Alte Hämatosalpinx beiderseits. Endometritis haemorrhagica. Yerschluß der A. coron. sin. und geringe Sklerose beider Koronararterien. Tabes dorsalis.

Am Ostium aorticum sieht man nur noch die beiden hinteren Klappen. Die Klappen sind leicht verdickt, graugelblich und derb. Ihre Ränder liegen der Wand fest an. Von der vorderen linken Klappe sieht man nur noch Erweiterungen. in Form einiger gelblich-weißer Stränge und Falten. Von einer Tasche ist nichts mehr zu sehen.

Die Aorta ist ziemlich weit. Im aufsteigenden Teil, in Bogen und absteigenden Teil erseheint die Wand stark verdickt, und die Intima zeigt an ihrer Oberfäche zahllose gelbliche hanfkorn- bis linsengroße Erhabenheiten und Runzeln. Diese Veränderung wird in der unteren Brustaorta geringer, ist aber auch im oberen Teil der Bauchaorta noch zu konstatieren. In der unteren Bauchaorta finden sich vorzugsweise nur noch feine, gelbweiße, in Streifen angeordnete Fleckchen und Rippehen.

Präparate I sind einer leicht erhabenen Stelle der Pars ascendens entnommen. Präparate II sind einer stark verdickten Stelle der Pars descendens mit den Klappen entnommen.

$$
\text { Mikroskopischer Befund. }
$$

Präparate I (Pars ascendens). Intima: Ist auf eine lange Strecke hin mäBig stark verdickt und nicht derb aussehend. An der Übergangsstelle zur Intimaverdickung sieht man eine starke Vertiefung.

Media: Der dem am stärksten verdickten Teile der Intima angrenzende Mediateil läßt zahlreiche, verschieden große, unregelmäßig gestaltete Schwielenbildungen erkennen, wo die elastischen Fasern allenthalben zerstört sind. Hier gibt os keine Infiltrationen, während der übrige Teil der Media, der an die Adventitia angrenzt, längs den elastischen Fasern viele langgestreckte Zellinfiltrationen aufweist. Hier findet man viele Gefäße, auch verdickte. Die Infiltrationen bestehen 
zum großen Teil aus Plasmazellen. In dem betreffenden Teil sind die elastischen Fasen durch die Iniltrationen in einzelne Bündel getrennt. Der unter der oben erwähnten starken Vertinfung liegende Mediaabschnitt zeigt keine Veränderung.

Adventitia: Sie ist mit einigen makroskopisch bereits kenntlichen, großen, lymphknötchenartigen Zellanhäufungen durchsetzt, die meist aus Lymphozyten bestehen, in der Peripherie viele Plasmazellen. In anderen, kleineren Zellherden und perivaskulären Infiltraten kann man ebenfalls: sehr viele Plasmazellen konstatieren. Hier und da bemerkt man die Plasmazellen in rosettenartiger Anordnung. Die Vasa vasorum sind stark entwickelt, einige stark verdickt, sogar obliteriert. Yastzellen sind viel in der Adventitia nachweisbar.

Präparate II (Pars ascendens mit den Klappen). Intima: ist am schwersten erkrankt. Sie überschreitet ihre normale Breite um etwa das Dreifache; diese starke, in der Nähe der Ansatzstelle der Klappe im Sinus begimende Verdickung steigt ganz plötzlich rapide an, und enthält viele neugebildete elastische Lamellen. In der verdickten Intima finden sich einige große, schon makroskopisch deutlich erkennbare Zellschwärme, meist aus Plasmazellen und nur sehr wenigen Lymphozyten bestehend. In den gröBten Zellherden erscheinen die Plasmazellen zu Ketten aneinandergereiht, die zahlreiche Kapillaren umgeben. Auch sind einige Mastzellen vertreten. In dem Grenzgebiet zwischen Media und Intima sind ausgedehnte Schwielen ausgebildet. Es gibt zwei große, mit bloßem Auge erkennbare, scharf begrenzte nekrotische Herde, in denen viele ovale, spindelige und polymorphe Kerne vorhanden sind.

Media: Sie ist in ihree ganzen Ausdehnung verschmälert. Auf eine lange Strecke hin sieht man zahlreiche Schwielenbildungen. mittleren Grades, die elastischen Fasern sind vollständig zerstört. An einer anderen Stelle finden sich viele kleine Zellherde mit vielen Plasmazellen. Mastzellen trifft man in der Media an.

Adventitia: An einer Stelle sind adventitielle Bindegewebsfasern mäßig stark entwickelt: hier bemerkt man Seharen von Plasmazellen mit wenigen Lymphozyten, die Plasmazellen auch in rosettenartiger Anordnung. Vereinzelt finden sich verdickte Gefäße, auch obliterierte, die letzteren mit Plasmazellen umgeben. Mastzellen sind zahlreich vorhanden. Die Klappe ist stark fibrös verdickt und sieht derb aus, sie zeigt sonst keine Veränderung. Die Muskulatur des Herzens zeigt auch keine besondere Vexänderungen.

Fal1 45. Frau H., Posamentiersfrau, 52 Jahre.

Klinische Diagnose: Lues cerebri. Syphilis anamnestisch nicht sicher.

Wassermannsche Realition + .

S.-Nr. 791; 1910. Obduktion 8. Juil (Beitzke ).

Pathologisch-anatomische Diagnose: Starke Atrophie des Gehirns, chronische Leptomeningitis adhaesiva, Ependymitis granularis. Dekubitus am Kreuzbein, Oberschenkel und an den Fersen. Aortitis fibrosa. Allgemeine Adipositas, Fettherz, Fettleber mit Schnürfurche und Gallensteinen. Kleines Uterusmyom, Parovarialzyste, Hydrosalpinx, perimetritische Verwachsungen rechts. Narbe in der rechten Lungenspitze. Embolie eines rechtsseitigen Lungenarterienastes. Ziemlich große, kräftige weibliche Leiche von gutem Ernährungszustande.

Aorta ascendens leicht ausgebuchtet, mißt dicht über den Klappen fast $8 \mathrm{~cm}$ im Umfang. Farbe blaßgelblich-rosa. An der Innenffäche zahlreiche linsen- bis pfennigstückgroße, flache Verdickungen sowie sehr viele kleine dicht gedrängte Falten und Runzeln, die nicht parallel zur Gefäßrichtung verlaufen und die Verdickungen öfter durchschneiden.

Aorta descendens und Arcus ähnlich wie Aorta ascendens; sie nehmen an den kleinen Falten nach unten zu an Zahl ab. Die Verdickungen der Intima werden grob erhabon, teilweise von weifer: Farbe.

Präparate I sind einer flachen, faltigen Erbabenheit der Aorta thoracalis entnommen. Präparate II sind einer faltenreichen, stark erhabenen Partie der Aorta abdominalis entnommen. 
Mikroskopisoher Befund.

Präparate I (Aorta thoracalis). Intima: ungleichmäßig, etwas sklerotisch verdickt. Eine Stelle der verdickten Intima zeigt in ihrer tiefsten Schicht einen atheromatösen Herd, in dem viele Cholestearinkristalle vorhanden sind. An einer Seite dieses atheromatösen Herdes befindet sich eine Infiltration, die aus Rundzellen und spindeligen oder ovalen kernhaltigen Zellen besteht.

Media: ist nicht so stark verändert, doch sieht man hier und da kleine Herde, in deren Bezirk sich Rundzellen mit relativ wenigen Plasmazellen befinden; hier sind auch die elastischen Fasern zerstört.

Adventitia: In der Adventitia finden sich viele Gefäße mit Zellanhäufungen umgeben; die letzteren bestehen in der Hauptsache aus Lymphozyten mit wenigen Plasmazellen am Rande. Mastzellen sieht man nirgends.

Präparate II (Aorta abdominalis). Diese Präparate zeigen viel stärkere Veränderungeu als die Präparate I. Die Intima zeigt viele kleine Vertiefungen. Sie zeigt skleratheromatöse Veränderungen mit zwei Kalkplatten; die atheromatösen Herde sind klein, enthalten Fettkristalle und liegen in der tiefsten Schicht der verdickten Intima. An einer Stelle in der Nähe eines atheromatösen Herdes bemexkt man einige Gefäße mit Rundzelleninfiltrationen. Die übrigen Partien der Intima zeigen viele kleine flache Falten. Lamellenartige elastische Fasern sind stellenweise vorhanden.

Media: Während die den oben beschriebenen atheromatösen Herden der Intima entsprechende Partie der Media nicht so stark zerstört ist, zeigt der übrige, und zwar der intimawärts liegende Teil der Media an manchen Stellen starke Veränderungen. An einzelnen Stellen sieht man teilweise Auffaserung oder starke Zerbröckelung, ja sogar einen Defekt der elastischen Fasern. In diesem Defekt hat sich Granulationsgewebe und eine Infiltration entwickelt; die letztere reicht bis in die Intima und besteht aus Plasmazellen und wenigen Lymphozyten. An anderer Stelle bemerkt man mehrere Gefäße mit perivaskulärer Infiltration.

Adventitia: In der Adventitia fällt der Reichtum an Blutgefäßen auf, die meist mit Infiltrationén aus Lymphozyten und wenigen Plasmazellen umgeben sind. Die adventitiellen Nerven sind frei von Infiltration. Mastzellen sind sehr wenig zu sehen.

F all 46. M. Z., Kaufmann, 43 Jahre.

Klinische Diagnose: Sepsis.

Anamnese: Früher starker Raucher und Trinker. 1890 Infektion mit Syphilis. 1. Juli: Wassermannsche Reaktion ++ . 20. Juli 1910: Exitus letalis.

S.-Nr. 843; 1910. Obduktion 21. Juli ( B e it zke).

Pathologisch-anatomische Diagnose: Tabes dorsalis; Operationsnarbe am Rücken; operativer Defekt der drei untersten Wirbeldornfortsătze; mehrfacher Bruch der rechten Beckenhälfte mit ziemlich starker Kallusbildung. Hydrops und Blutungen in der Glutaealmuskulatur. Hypertrophie der Harnblase; Cystitis granularis, chronische Gastritis. Arteriosklerose; allgemeiner Ikterus. Bronchitis. Mehrere kavernöse Angiome in der Leber. Milzschwellung.

Aorta ascendens: ist an der Innenfläche mit mehreren zehnpfennigstückgroßen, flachen höckerigen Erhabenheiten besetzt, zwischen denen sich zahlreiche, feine, meist längsgestellite Runzeln finden. Mehrere dieser Verdickungen tragen an ihrer Oberfläche hirsekorn- bis linsengroße Ulzerationen. Außerdem findet sich fingerbreit über der hinteren Aortenklappe eine markstückgroße, knochenharte Platte.

Arcus aortae und Aorta descendens von ähnlicher Beschaffenheit wie Aorta ascendens, nur sind die Geschwüre auf den Arkus beschränkt, weiter abwärts nehmen auch die plattenförmigen Vexdickungen und die Runzeln an Zahl und Größe ab.

Präparate I und II sind den Aorten ascendens, respektive descendens entnommen und zwar größeren, flachen, höckerigen, durch zahlreiche, feine Punzeln unterbrochenen Verdickungspartien. 
Mikroskopischer befund.

Präparate I (Pars ascendens). Intima: zeigt skleratheromatöse Veränderung mit Kalkablagerungen. In der Nähe dieser Kalkablagerungen finden sich mehrere neugebildete GefäBe mit Lymphozyten in mäßiger Menge und wenigen Plasmazellen. In dem sklerotischen Teil sieht man lamellenartige elastische Fasern.

Media: Überall fallen stark vermehrte Gefäße mit geringen Infiltrationen auf. Eine Schädigung der elastischen Fasern ist nicht dentlich nachweisbar.

Adventitia: Man sieht einige stark verdickte Gefäße, von denen eines außer einer Verdickung anch Auflockerung der elastischen Lamellen der Wandung zeigt; diese Veränderung hat zu einer starken Verengerung des Lumens geführt. Perivaskuläre Infiltrate lassen sich an vielen Stellen nachweisen, sie bestehen meist ans getrenten Gruppen von Lymphozyten und Plasmazellen. Uim die Nerven besteht keine Infiltration. Mastzellen sind sehr viel nachweisbar.

Präparate II (Pars descendens). Intima: An zwei Stellen ist sie erheblich verdickt, so daßs zwischen diesen Verdickungen eine starke Vertiefung gebildet wird. Die Kalkablagerung ist sehr gering; sonst ebenso wie in den Präparaten I.

Media: Die ganze Međia ist verschmälert, besonders der unterhalb der oben beschriebenen Vertiefung liegende Teil. Die Zellherde und die Schädigungen der elastischen Fasern in dem intimawärts liegenden Mediateil sind stärker als in den Präparaten I.

Die Adventitia weist geringere Veränderung als in den Präparaten I auf.

F' a 11 47. A. F., Musiker, 49 Jahre.

Klinische Diagnose: Tabes. Dementia paralytica.

Laes: 1884 Schanker, Schmierkur.

Wassermannsche Reaktion fehlt. Exitus am 20. Juli 1910.

D.-Nr. 845; 1910. Obduktion 21. Juli ( S chum).

Pathologisch-anatomische Diagnose: Pachymeningitis haemorrhagica interna." Graue Degeneration der Hinterstränge. Chronische Leptomeningitis spinalis. Bronchitis beiderseits. Endocarditis chronica fibrosa. Mesaortitis syphilitica. Schlaffe Milz. Hydrocele beiderseits. Prostatakonkremente und kleine Zysten.

An einzelnen Stellen der Koronararterien sieht man leicht gelbliche Streifen und vereinzelte gelbliche Verfärbungen. Im Anfangsteil der Aorta sind sie vereinzelt. An den Klappen der Aorta sieht man weißlichgrane, schwielige Erhabenheiten, zwischen denen eingesprengt sich einzelne gelblichweiße Streifen und stockförmige Figuren befinden. Bauchaorta wie Brustaorta.

Präparate I und II sind einer weißlichen, diffusen, narbigen Partie der Pars ascendens entnommen.

Mikraskopiseher Befund.

Präparate I (Pars ascendens). Intima: An einer Stelle ist sie intensiv sklerotisch verdickt, dort sieht man viele feine elastische Fasern. Eine Partie weist einige mit Plasmazellen amgebene neugebildete Gefüße auf, die von der Media hineindringen.

Media: Der unter der stark verdickten Intima liegende Teil der Media ist hochgradig, an manchen Stellen sogar vollständig zerstört. In diesen Herden ist von elastischen Fasern nichts mehr, an ihrer Stelle ein gefäBreiches, frisches Granulations- oder Narbengewebe vorhanden, das bis an die Intima heranreicht, so daß an den betreffenden. Stellen die Grenze zwischen Media und Intima ganz undeutlich ist. Die oben erwähnten Herde weisen Zellanhäufungen mit vielen Plasmazellen auf. Der übrige Teil d̉er Media zeigt hier und da kleine perivaskuläre Zellanhäufungen von denen eine auch Mastzellen enthält.

Adventitia: Viele Vasa, vasorum sind endarteriitisch verändert, sogar einige große Gefäbe sind gänzlich obliteriert. Zellinfiltrationen finden sich sehr viel, sie bestehen ans Plasmazellen 
und Lymphozyten. Um Nerven besteht keine Infiltration. Mastzellen sind sehr viel vorhanden, vereinzelte anch in den oben beschriebenen Zellanhäufungen.

Präparate II (Pars ascendens) zeigen dieselben Veründerungen.

F a.ll 48. A. C., Schlächter, 45 Jahre.

Klinisehe Diagnose: Chronischer Herzklappenfehler (Aorten- und Mitralinsuffizienz).

Anamnese: Vor 15 Jahren Lues.

Wassermannsche Reaktion + (15 Tage vor dem Tode). Exitus am 6. August 1910.

S.-Nr. 926; 1910. Obduktion 8. August ( $\mathrm{K} 0 \mathrm{ch})$.

Pathologisch-anatomische Diagnose: Schwere Aortitis. Großes sackförmiges Aneurysma der Pars ascendens aortae mit gänseeigroßem, mit Thrombenmassen erfülltem von ihm ausgehenden Seitenaneurysma. VerschluB der Arteria coronaria dextra. Endocarditis chron. fibrosa aortica et mitralis. Cor bovinum (Hypertrophie und Dilatation des linken Ventrikels). Großer Infarkt im Septum ventriculorum, zahlreiche gröBere und kleinere Schwielen beiderseits. Schwere Skleratheromatose der Artt. coronariae besonders links. Sehnenflecke am Epikard. — Stauungsiungen, -leber, -nieren, -darm. Hydrothorax, Hydroperikard, Aszites. Staungsgastritis. Pleuritische Adhäsionen, rechts stärker, links nur an der Spitze. Alte Spitzeninduration beiderseits. -- Lungenödem, alveoläres Randemphysem. Tracheobronchitis. Verkallste Hilusdrüsen. Taenia saginata. Nebenmilz.

Dicht oberhalb der Klappen zeigt die Aorta eine fast mannsfaustgroße sackförmige Ausbuchtung, von der nach hinten und rechts gelegen, durch einen engen Hals mit ihr in Verbindung stehend, sich eine zweite gänseeigroße Aussackung abzweigt. Diese kleine Aussackung ist fast völlig mit einer braunweißen, zum größten Teil aber graurötlichen derben, der Wand fest anhaftenden Masse erfültt. Die Wand der Aorta, besonders der Pars ascendens und der Arcus, zejgt außerordentlich zahlreiche derbe graugelbliche Verdickungen zwischen denen sich an vielen Stellen bröcklige, steinharte Stellen finden. An mehreren Stellen sieht man auch kieine hanfkorngroße Substanzverluste. Auf dem Querschnitt der Aorta findet man neben einer starken Veränderung der Intima zahlreiche gelblichweiße bis grauweiße Flecken in der Media, auch die Adventitia soheint verdickt.

Präparate I sind $2 \mathrm{~cm}$ oberhalb der Klappen einer sackförmigen Ausbuchtung mit Arteria pulmonalis entnommen.

Präparate II entstammen einer diffusen Verdickung mit Runzeln der Pars descendens.

Mikroskopiseher Befund.

Präparate I (Pars ascendens). Intima: Sie zeigt mäßig starke Verdiekung. An einer Stelle sieht man einige neugebildete Kapillaren mit geringer Infiltration, an anderen Stellen finden sich auch Infiltrationen aus Lymphozyten. In der Intima trifft man keine neugebildeten elastischen Lamellen.

Media: Sie ist in ihrem ganzen Verlaufe schwer erkrankt, stellenweise voliständig zerstortt. Bei va n Gi e s o n - Färbung zeigt die Muskelschicht stark unterbrochene, sehr schmale, gelblich gefärbte Streifen. Die elastischen Fasern sind auch erheblich geschädigt und an vielen Stellen unterbrochen; der noch erbaltene Teil der elastischen Fasern ist streifig verschmälert. Die erkrankten Herde der Media sind meist von derben Schwielen durchsetzt; eine Schwiele ist so hochgradig entwickelt, daß sie schon makroskopisch als großer Knoten sichtbar ist; sie durchsetzt nicht nur die ganze Media, sondem auch noch einen Teil der Adventitia. Die Ungebung dieses Knotens weist zellige Infiltration auf, stellenweise mit zahlreichen stark gefüllten GefäBen. Fin stark verdicktes Gefäß ist sogar mit Blutungsherden ungeben. In dem übrigen Teil der Media treten stellenweise Infiltrationen in mäßiger Menge auf, sie bestehen aus Lymphozyten und wenigen Plasmazellen. Einige Blutungsherde sind anch hier erkennbar.

Adventitia: Die in erster Linie ins Auge springende Veränderung der Adventitia besteht 
im Auftreten von scharf begrenzten Infiltraten, die schon makroskopisch sichtbar sind und sich zusammensetzen aus zahlreichen Lymphozyten und wenigen an dex Peripherie befindlichen Plasmazellen. In diesen großen Zellanhäufungen oder in der Nähe derselben finden sich viele verdickte und ganz obliterierte Gefäße. Um die obliterierten GefäßBe besteht nur ein geringes Infiltrat. Die Umgebung des oben beschriebenen schwieligen Knotens ist mit zahlreichen, strotzend gefüllten Gefäßen, sogar Blutungsherden, durchsetzt. Hier bemerkt man viele Plasmazellenanhäufungen, teilweise in rosettenartiger Anordnung. In der Nähe der A. pulmonalis, die ich mit der Aorta zusammen geschnitten habe, finden sich zwei Lymphknötehen, in deren Peripherie viele Plasmazellen nachweisbar sind. Hier und dort sieht man einige Nerven, in deren Perineurium Lymphozyten und Plasmazellen liegen. Mastzellen sind in der Adventitia viel vorhanden, auch in dem Endoneurium. Die adventitiellen Bindegewebs- und elastischen Fasern sind mäBig stark entwiekelt. Die A. pulmonalis zeigt gar keine Veränderung.

Präparate II (Pars descendens). Intima: An einer Stelle weist sie eine ausgedehnte Ver* dickung auf; man sieht auch mäßig große nekrotische Herde, in denen noch zahlreiche ovale oder spindelige Kerne sichtbar sind; teilweise ist Kalk in Form ganz kleiner Krümelchen abgelagert. Hier und da bemerkt mản Infiltrate, die aus Lymphozyten bestehen. An anderer Stelle sieht man. einige tiefe Einsenkungen.

Media: Die unter der oben enwähnten stark verdickten Intima liegende Media zeigt viele große Defekte der elastischen Fasern, so daß sie an der am stärksten veränderten Stelle nur als ganz schmales Band vorhanden sind. Hier finden sich Bchwielen und Zellanhäufungen hauptsächlich aus Plasmazellen mit wenigen Lymphozyten, doch besteht das Infiltrat an einer Stelle nur aus Lymphozyten. In dem Mediaherde bemerkt man auch ein stark verdicktes Gefäb. Mastzellen sind spärlich vorhanden. Der den Vertiefungen der Intima entsprechende Teil der Media zeigt keine besondere Veränderung.

Adventitia: Die Veränderung in der Adventitia ist gleich der in den Präparaten I.

Fal1 49. B. R., Geschäftsfübrersfran, 45 Jahre.

Klinische Diagnose: Chronische Nephritis, Herzschwäche. Dekompensationsstaumgen der Organe, Anasarka.

Aborte: zwei, jedesmal nach 2 Monaten. Infektion: Pat. ist mit 20 Jabren von ihrem ersten Mann infiziert. Sie hat damals zwei Quecksilberkuren durchgemacht.

Wassermannsche Reaktion fehlt. Exitus am 28. September 1910.

S.-Nr. 1125; 1910. Obduktion 29. September ( Ceelen).

Pathologisch-anatomische Diagnose: Beginnende Schrumpfnieren beiderseits. Scchwere Aortitis besonders der Pars ascendens und des Arkus mit Übergreifen auf die Aortenklappen. Hypertrophie und Dilatation beider Yentrikel. Kirschkerngroßer wandständiger Thrombus in linken Vorhof. Thrombose des linken Herzohrs. Schwielenbildung in der Herzmuskulatur. Alte Infarkte in Milz und beiden Nieren. Stauungsorgane. Chronische Gastritis. Multiple alte submuköse Blutungen in der Magenschleimhaut. Muskatnußleber, Gallensteine. Geringe Kolloidstruma. Haselnubgroßer Kropflnoten im linken Lappen. Geringer Aszites. Hydrops anasarca. Peri- nod parametritische Verwachsungen. Mikroskopische Untersuchung der Nieren: Vereinzelte hyaline Glomeruli; Nekrose der Fpithelien der Tubuli contorti und anfsteigenden Schenkel der $\mathrm{H}$ e n le schen Schleifen.

Präparate I sind $3 \mathrm{~cm}$ oberhalb der Klappen einer narbigen, zum Teil verdickten Stelle mit der A. pulmonalis entnommen. Präparate II sind einer gelblichen, diffusen Verdickungsstelle der Aorta descendens entnommen.

\section{Mikroskopischer Befund.}

Präparate I (Pars ascendens mit der A. puImonalis). Intima: zeigt drei skleratheromatöse Herde, zwei sind stärker als der dritte. Nur an einer Stelle beteiligt sich auch die betreffende Media 
ganz schwach an diesen degenerativen Veränderungen. Es finden sich ziemlich viel neugebildete, lamellenartige elastische Fasern an zahlreichen Stellen vor. In einem atheromatösen Herde sieht man auch einige Reste von elastischen Fasern. Die verdickte Intima zeigt hier und da, besonders zwischen den skleratheromatösen Herden viele zerstreute oder strangförmig angeordnete Plasmazelleninfiltrationen.

Media: An zwei Stellen der Media sind große Defekte, wo die elastischen Fasern streckenweise ganz zerstört und Plasmazellen in kolossaler Menge vorhanden sind; deswegen färben sich diese Stellen bei Methylgrün-Pyronin ganz hellrot. Die übrigen Partien der Media haben auch an verschiedenenen Stellen kleine Erkrankungsherde, welche meist infiltrative Form zeigen. Mastzellen trifft man sehr wenig an.

Adventitia: Überall sieht man zahlreiche Gefäße, die teils stark erweitert, teils verdickt und sogar ganz obliteriert sind; sie sind vereinzelt von kleinen oder größeren. Zellanhäufungen umgeben. Einige Infiltrationen sind so groß, daß sie makroskopisch schon deutlich sichtbar sind. Die großen Zellanhäufungen bestehen hauptsäehlich aus Lymphozyten, am Rande findet man auch kleine Gruppen von Plasmazellen; dagegen bestehen die kleinen Infiltrationen meist nur aus Plasmazellen. Mastzellen sind überall zahlreich vorhanden, besonders in der Umgebung der Infiltrationen. Die A. pulmonalis zeigt gar keine mikroskopische Veränderung.

Präparate II (Pars descendens). Intima: zeigt mäßig starke Ausbuchtungen von derbem Anssehen. Überall bemerkt man neugebildete lamellenartige elastische Fasern, welche an einer Stelle teilweise zerstört und geschlängelt sind; diese Stelle weist viele Lymphozyten und nur wenige Plasmazellen auf, welche teils zerstreut, teils reihenweise auftreten. Auch der übrige Teil der Intima zeigt keine Erweichungsherde.

Media: Der den oben beschriebenen Ausbuchtungen entsprechende Mediateil hat einen trichterförmigen Erkrankungsherd, der in ganzer Mediabreite eine fast vollständige Zerstörung: und Verklumpung der elastischen Fasern hervorgerufen hat. In dem Bereich dieser Erkrankung: sind frisches Granulationsgewebe, viele neugebildete Gefäße und Infiltrationen hauptsächlich aus Plasmazellen mit nur wenigen Lymphozyten vorhanden. In einem anderen Schnitt ist dieser Herd nicht mehr trichterförmig, sondern hat er AmboBform mit nach der Intima zu gerichteter breiter Basis und ist so groß, daß er bei 100 facher Vergrößerung mit seinem gröbten Durchmesser fast ein ganzes Gesichtsfeld einnimmt. Ein anderes Gesichtsfeld zeigt stark geschlängelte und aufgefaserte Elastika, zwischen deren einzelnen Fasern sich ein- und zweireihig reichlich Plasmazellen befinden, die auch zerstreut auftreten. Nahebei bemerkt man auch einige Lyymphozytenanhäufungen. Der übrige Mediateil zeigt zahlreiche relativ kleine Infiltrationen aus Plasmazellen und Lymphozyten. Mastzellen nicht vorhanden.

Adventitia: In der Adventitia fallen die Erweiterung der Gefäße und die zahlreichen periraskulären Infiltrationen auf. Einige Infiltrationen sind so groß, daß sie schon makroskopisch sichtbar sind; sie bestehen hauptsächlich aus Lymphozyten und wenigen Plasmazellen; diese sind anch in der Umgebung, gruppenweise zerstreut, vorhanden. Die übrigen, kleineren Infiltrationen bestehen meistens aus zahlreichen Plasmazellen. Mastzellen sind überall reichlich vorhanden und finden sich auch in den Infiltrationen vor. In der Adventitia sind die Bindegewebs- und elastischen Fasern mäßig stark entwickelt.

Fall 50. Frau M., Schneidersfrau, 53 Jahre.

Klinische Diagnose: Insuffizienz. Aorta lata (luetica), Tabes dorsalis.

Partus: 5. Abortus: 5. Infection: vor 16 Jahren Lues.

Wassermannsche Reaktion fehlt. Exitus letalis am 10. Oktober 1910.

S.-Nr. 1180; 1910. Obduktion 12. Oktober (C e e I e n ).

Pathologisch-anatomische Diagnose: Schwere Mesaortitis der ganzen Aorta. Gänseeigroße aneurysmatische Ausdehnung der Pars ascendens, Erweiterung der Pars descendens. Endocarditis aortica fibrosa. Hypertrophie und Dilatation beider Ventrikel. Tabes dorsalis. Absteigende 
Degeneration des linken Pyramidenstranges. Erweichungsherd am rechten Nucleus lentiformis. Sklerose der Gehimarterien. Oystitis, aszendierende Pyelonephritis links. Doppelseitige Arteriitis. Hühnereigrober Echinokokkus am unteren Rand des rechten Leberiappens. Glatter Zungengrumd. Tracheobronchitis. Pleuritische Verwachsung rechts. Chronische Gastritis mit Exkoriationen. Geringer Aszites. Hydrops pericardii. Anasarka. Schwerer Dekubitus.

Mikroskopisch: Im Gehim und in den Hintersträngen Kömchenzellen. In dem leberechinokokkus massenhafte Haken, Cholestearin, Leucin.

Präparate I sind der Pars ascendens, dicht oberhalb der Klappen, an einer unebenen, narbigen Partie entnommen. Präparate II sind einer teils narbigen, teils transparenten Partie der Pars descendens entnommen.

Mikroskopiseher Befund.

Präparate I (Pars ascendens). Intima: Überall ist es in der Intima zu erheblicher Verdickung gekommen, die stellenweise die Mediabreite erreicht. In der Intima treten vereinzelt Infiltrationen aus Lymphozyten und Plasmazellen auf, die sich teilweise mit der Infiltration in der Media verbinden. Elastische Fasern sind lamellenartig neugebildet.

Media: Sie zeigt starke Zerstörung der elastischen Fasern, besonders der intimawärts liegende Teil. Die Deferte ergreifen fast die ganze Mediabreite und zeigen die Reste der elastischen Fasern als kurze Trümmer. An Rande dieser Herde erscheinen die Enden der elastischen Fasern seharf durchschnitten und dicht gedrängt. Diese Bezirke sind mit stark ausgedehnten Zellanhäufungen aus Plasmazellen und einigen Jymphozyten durchsetzt, an einigen Stellen ergreifen sie nicht nur die Media, sondern gehen auch in die Intima über. Stellenweise bemerkt man Granulationsgewebe. An einer Stelle indet sich ein nekrotischer Herd mit Kalkablagerung. Hier sieht man keine Plasmazellen.

Adventitia: In ihr fallen zahlreiche Gefäße mit Plasmazellen und Lymphozyten auf. Einige Gefäße sind verdickt oder sogar obliteriert. Die Plasmazellen sind gruppenweise oder zerstreut, bisweilen rosettenartig um die Kapillaren angeordnet. Mastzellen finden sich sehr viel.

Präparate II (Pars descendens). Intima: An einigen Stellen ist es zum Auftreten von Kapillaren in der stark verdickten Intima gekommen, einige davon sind erweitert. Im übrigen weist die Intima nur stellenweise eine derb aussehende, schwielige Struktur auf.

Media: Am schwersten ist die Media, besonders der intimawärts gelegene Mediateil, dieser bis zur vollständigen Zerstörung, exkrankt. An vielen Stellen sieht man einen die ganze Mediabreite sehief oder quer ergreifenden, schon makroskopisch sichtbaren Zellherd, in dem sich zahlreich Lymphozyten und Plasmazellen, meist gruppenweise, finden, während die elastischen Fasern ganz verschwunden sind. Die sonstige, perivaskuläre Infiltration, oder die in den lymphräumen zwischen den Muskelfasern infiltrierten Zellen sind meist Plasmazellen.

Adventitia: Sie zeigt die gleiche Veränderung wie die der Präparate $I$.

F a 11 51. K. O., Buchhalter, 57 Jahre.

Klinische Diagnose: Syphilitische Aortitis und Aorteninsuffizienz mit Dekompensations. störungen. Stauungsnephritis.

Nikotin: etwa 2 Zigarren täglich. Alkohol: etwa 4 Glas Bier pro die. Infektion: Tripper zweimal. Lues ror 33 Jahren, 1 Schmierkur.

Wassermannsche Reaktion ++ . Exitus letalis am 15. Dezember 1910.

S.-Nr. 1414; 1910. Obduktion 16. Dezember (C e e len).

Pathologisch-anatomische Diagnose: Endocarditis fibrosa aortica, schwere Aortitis und Perikarditis, perikarditische Verwachsungen über dem linken Ventrikel, Hypertrophie und Dilatation beider Ventrikel, fast völliger Verschluß der Abgangsstelle der linken Koronararterie. Schwielenbildung der Herzmuskulatur, parietaler Thrombus in rechten Vorhof; Lungenembolie, hämorrhagische Lungeninfarkte, Tracheobronehitis, Stauungsorgane, Zysten und versprengte 
Nebennierenkeime in beiden Nieren, plennigstückgroBer Nebennierenteil in der linken Niere, hypertrophische Knoten in der Prostata, geringe Balkenblase, Hydrocele beiderseits, Corpus liberum in den Füllen des linken Hodens, Tonsillarabszeß rechts, Varix im Ösophagus, chronische Gastritis; Magengeschwüre in der Nähe des Pylorus, Muskatnußleber, allgemeiner Höhlenhydrops, Hydrops anasarea, zahlreiche feste peritoneale Verwachsungen zwischen Darmschlingen and abdominalen Organen.

Die Aorta ascendens ist auffallend verdickt, Innenfläche uneben, von zahlreichen, teils prominierenden, teils mehr eingesunkenen narbenartigen Herden durchsetzt. Mit der Umgebung: ist die Aorta ascendens, so vor allem mit der Pulmonalis fast unlöslich verwachsen. Aorta bis zur Abgangsstelle der A. renalis von oben beschriebener Beschaffenheit.

Präparate I sind einer mäßig prominierenden Stelle des Arcus aortae entnommen. Präparate II sind einer transparenten Stelle mit den Abgangsstellen zweier Aa. costales entnommen.

\section{Mikroskopiseher Befund.}

Präparate I. (Arcus aortae). Intima: An einer Stelle ist sie stark sklerotisch verdickt, so daß sie die Mediabreite erreicht. Der übrige Teil ist mäßig verdickt, und hier zeigt sie Infiltrationen aus Plasmazellen. In der oben erwähnten stark verdickten Intima und Media findet sich ein nekrotischer Herd, in dessen Innerem zahlreiche rundliche, ovale oder spindelige Kerne sichtbar sind. Ein anderes Präparat zeigt in dem verdickten Teil der Intima einige Gefäße.

Media: Der dem stark verdickten Intimateil entsprechende Mediateil hat einen großen Defekt der elastischen Fasern, der mit wenigen, zu Gruppen angeordneten Lymphozyten, und einer großen Anzahl von Plasmazellen gefüllt ist und einige Gefäßie enthält. Die übrige Media ist sehr wenig verändert. Mastzellen lassen sich mur in der Umgebung des oben beschriebenen Herdes, hier aber sehr zahlreich nachweisen.

Adventitia: Während die Zellanhäufungen verhältnismäBig gering sind, enthält die Adventitia stark verdickte, sogar obliterierte Gefäße; die letzteren sind größtenteils frei von Infiltrationen, doch sieht man in der Peripherie Plasmazellen. Mastzellen sind sehr viel nachzuweisen.

Präparate II (Aorta thoracalis). Intima: zeigt überall geringe Verdickung; während sich an einer Stelle viele einzelne Plasmazellen und Lymphozyten finden, bemerkt man an einer anderen einen nekrotischen Herd von gleicher Beschaffenheit, wie der in den Präparaten I beschriebene, der noch einen groBen Teil der Media ergreift.

Media: Die Nachbarschaft des oben beschriebenen nekrotischen Herdes weist einen großen Zellherd auf, dex zum Teil nur aus Plasmazellen besteht, sonst hauptsächlich aus Iymphozyten zusammengesetzt ist, die mit Plasmazellen untermischt sind; hier sieht man auch einige Gefäße. Der übrige Teil der Media enthält viele Gefäße mit gexinger Infiltration. Einige Mastzellen. Die Aa. intercostales sind ohne wesentliche Veränderung.

Adventitia: Im Gegensatz zu den Präparaten I finden sich große Veränderungen in der Adventitia, namentlich in der dem oben beschriebenen nekrotischen Herde entsprechenden Partie. Man bemerkt hier viele große lymphknötchenartige Zellanhäufungen, die schon makroskopisch sichtbar sind und ans Lymphozyten mit wenigen Plasmazellen zusammengesetzt sind; hier kann man auch einige rosettenartig angeordnete Plasmazellen erkennen. Auch sind viele verdickte und obliterierte Gefäße vorhanden, und viele Mastzellen.

F all 52. S. J., Packer, 57 Jahre.

Klinische Diagnose: Aorteninsuffizienz. Lungenembolie. Lues (alte).

Infektion: vor 25 Jahren Lues. Alkohol: mäßig. Nikotin: mäßig.

Wassermannsche Reaktion +++ . Exitus am 15. März 1911.

S.-Nr. 303; 1911. Obduktion. 23. März (Staatsprüifung).

Pathologisch-anatomische Diagnose: Chronische Endocarditis aortica mit Verwachsung, Schrumpfung und Verdickung der Segel (vom linken geht eine gelbliche, strangartige Schwiele 
anf die Ventrikelseite des groben Mitralsegels und anf die Kammerwand über); schwere Skleratheromatose des Anfangsteils der Aorta mit starker Beteiligung der Wand der Klappentaschen; Arcus und übriger thorakaler Abschnitt viel weniger verändert. Hypertrophie and Dilatation beider Herzkammern. Allgemeine Stauungserscheinungen. Staungsgastritis und -enteritis.

Präparate I stammen von einer granweißlichen, unebenen Verdickungsstelle des Anfangst teiles der Aorta. Präparate II entstammen der Aorta mit Klappen.

Mikroskopiseher Befund.

Präparate I (Pars ascendens). Intima: Sie zeigt in ihrer ganzen Ausdehnung mäBig stark sklerotische Veränderung. Hier und dort finden sich Infiltrationen, die meist aus Iymphozyten bestehen, nur in der tiefsten Schicht sieht man reichliche Infiltration von strangartig angeordneten Plasmazellen. Im Grenzgebiet zwischen Intima und Media sind viele ausgedehnte Schwielen zu sehen, auch ist die Grenze zwischen Intima und Media ganz undentlich. In dieser Gegend bemerkt man ejnen gefüßreichen Granulationsherd mit vielen Plasmazellen.

Media: Die Veränderung der Media ist lokalisiert in der intimawärts gelegenen Mediahälfte. An einer Stelle fällt ein großer, makroskopisch bereits sichtbarer gefäßreicher Zellherd auf und reichliches zum Teil frisches Granulationsgewebe. In diesem Herd finden sich Schwärme von Lymphozyten, umgeben von außerordentlich vielen Plasmazellen, die zum Teil rosettenartig angeordnet sind. Von hier setzen sich die Plasmazellen in die Intima fort. Die elastischen Fasern sind in dem Herde total zerstört, ihre Enden sind verdiekt und umgebogen. Die übrige Media ist mit einigen fast nur aus Plasmazellen bestehenden Zellanhäufungen und Schwielen durchsetzt.

Adventitia: In der Adventitia sind die Bindegewebsfasern mäbig stark vermehrt. Hier und da finden sich mehrere, große, mit bloßem Auge schon erkenntliche Schwärme von Lymphozyten; während verdickte Gefäße zahlreich vorhanden sind, sieht man nur wenige obliteriert. Um die Nerven besteht keine Infiltration. Mastzellen sind viel erkennbar.

Präparate II (Aorta mit Klappen). Die Intima der Aorta und die Klappen sind mäBig stark verdickt, besonders unterhalb der Aortenklappen sieht man ausgedehnte Schwielenbildung. Infiltration kaum erkennbar. In dem Sinus, und zwar auf der Imnenfiuche des Ansatzteils der Klappe, ist thrombotische Masse abgelagert.

Fall 53. E. N., Schlosser, 34 Jahre.

Klinische Diagnose: Endokarditis auf luetischer Basis. Stauungsorgane.

Wassermannsehe Reaktion +. Exitus letalis am 2. April 1911.

S.-Nr. 348; 1911. Obduktion 3. April (Staatspriufung).

Pathologisch-anatomische Diagnose: Chronische und schrumpfende Aortenendokarditis. (Aortitis gummosa?). Multipler Verschluß der hinteren Koronararterien durch Endo- und Mesaortitis. Hypertrophie und starke Dilatation beider, besonders des linken Ventrikels. Vielfache ältere und frische myokarditische Schwielen. Staungslungen, -leber, -nieren, -milz. Hydronephrose der linken. Niere durch Abknickung des Harnleiters unterhalb des Nierenbeckens. Gastroenteritis eyanotica. Thrombus im rechten Herzohr, mehrere hämorrhagische Infarkte im rechten Unterlappen. Pleuraadhäsionen. Hydrothorax dexter, geringer Aszites. Sehnenfleck auf der vorderen Seite des linken Ventrikels.

Präparate I sind einer wulstig verdickten Stelle am Anfangsteil der Aorta thoracalis entnommen. Präparate II einer angrenzenden Stelle entnommen.

\section{Mikroskopischer Befund.}

Präparate I (Anfangsteil der Aorta thoracalis). Intima: weist eine große zirkumskripte, allmählich immer stärker werdende Verdiekung auf; diese enthält einige Gefäße mit Infiltration aus Lymphozyten und wenigen Plasmazellen; an anderer Stelle eine kleine Kalkablagerung. Einige neugebildete elastische Lamellen sind zn sehen. 
Media: Der unter der verdickten Intima liegende Mediateil zeigt erhebliche Exkrankungsherde, wo man starke Zertrümmerung der elastischen Fasern, ausgedehnte Schwielen, neugebildete Gefäbe und Zellanhänfungen aus Lymphozyten und wenigen Plasmazellen sieht. Auch in dem übrigen Teil der Media finden sich viele Zellherde; an einer Stelle bemerkt man ein stark verdicktes GefäßB, um das herum eine ausgedehnte Infiltration aus etwa der gleichen Menge von Lymphozyten und Plasmazellen besteht.

Adventitia: Die ganze Adventitia ist mit stark erweiterten und strotzend gefüllten Kapillaren und einem größßeren verdickten Gefäß durehsetzt. Dieses ist nur wenig sichtbar. Die perivasknläre Infiltration, in der mehr Lymphozyten als Plasmazellen sichtbar sind, ist nur gering. Mastzellen sind viel vorhanden.

Präparate II (angrenzend an das für die Präparate I verwendete Stück). Die mikroskopische Veränderung ist fast gleich dex in den vorigen Präparaten.

F a 11 54. H. L., Milchhändler, 47 Jahre.

Klinische Diagnose: Dementia paralytica. Gehinnerweichung.

Mit 23 Jahren Sehanker. Schmierkur. Potus: Kognak und Bier.

Wassermannsche Reaktion fehlt. Exitus letalis am 14. April 1911.

S.-Nr. 396; 1911. Obduktion 18. April (Ceelen).

Pathologisch-anatomische Diagnose: Chronische Leptomeningitis. Ependymitis granularis. Schwere Aortitis (syphilitica?), besonders der aufsteigenden Aorta und des Arkus. Gummiartige Verdickungen dex Aorta oberhalb der hinteren Aortenklappe. Hypertrophie und Dilatation beider Ventrikel, besonders des linken. Bronchitis beiderseits. Bronchopneumonische Herde rechts. Geringe Stauungsorgane. Prostatakonkremente. Thrombose der prostatischen Venen. Geringe Granulierung beider Nieren.

Präparate I stammen von einer dicht oberhalb der Klappen gelegenen, wulstig verdickten Stelle (mit der A. pulmonalis). Präparate II sind einer grauweißlich verdickten Stelle einer der arderen Klappen entnommen.

\section{Mikroskopischer Befund.}

Präparate I (dicht oberhalb der Klappen mit der A. pulmonalis). Intima: Sie ist auf eine lange Strecke hin treppenweise immer stärker fibrös verdickt, und zwar sind die einzelnen Stufen der Treppe sehr lang. Plötzlich geht sie wieder zu normaler Breite über. Der nicht so stark verdickte Teil der Intima zeigt in seiner innersten Schicht Granulationsgewebe mit Rundzelleninfiltration. Während der stark verdickte Teil der Intima größtenteils aus kernarmen Geweben besteht, enthält er hier und da besonders in der tiefen Schicht zahlreiche, ziemlich weite neugebildete Kapillaren, von denen viele von geringer oder stärkerer Infiltration aus Lymphozyten und Plasmazellen umgeben sind. Am Grenzgebiet zwischen Media und dem stark verdickten Intimateil ist eine derbe Schwiele ausgebildet.

Media: Thre Breite ist verschieden. Da, wo die Intima nur wenig verdickt ist, ist die Media normal breit. Je dicker die Intima wird, desto schmäler wird die Media. Diese Versehmälerung ist eine ganz allmähliche, so daß an den Stellen, wo die Intimaverdickung am stärksten, die Media an dünnsten ist. Sie hat hier nur $1 / 3$ der normalen Dicke. Da, wo die Intima plötzlich wieder normal wird, bleibt die Media sehr dünn. An dem der oben beschriebenen, nicht so stark verdickten Partie der Intima angrenzenden Mediateil, finden sich zwei etwas umfangreichere scharf begrenzte, gefäßhaltige Zellherde. Diese haben große Defelkte der elastischen Fasern hervorgerufen. Während der eine von diesen Zellherden gleịchmäßjig aus Plasmazellen und Lymphozyteu besteht, finden sich in dem anderen fast nur Plasmazellen. In dem unter dem stark verdickten Intimateil liegenden Abschnitt der Media fallen zahlreich entwickelte, erweiterte, mit vielen Plasmazellen und wenigen Lymphozyten umgebene Gefäße auf. Nan sieht auch hier ebenso wie in der Intima eine Schwiele, sowie Zerstörung der elastischen Fasern. 
Adventitia: Sie enthält viele verdickte, sogar obliterierte Gefäße, von denen eines weitaus am meisten auffallend ist; es ist sehr groß und zeigt einen totalen Verschlup des Lumens. Dieser ist bedingt durch eine mit starker Spaltung und Auflockerung der elastischen Fasern einhergehende Verdickung der Wand. Dieses Gefäß hat spärliche zellige Infiltration. In der Adventitia. der Aorta finden sich sonst hier und da Zellanhäufungen, von denen die großen meist aus Plasmazellen, die an der Peripherie liegen, bestehen. Nerven sind mit Plasmazellen und Lymphozyten stark umsäumt. Mastzellen sind in der Adventitia reichlich vorhanden.

Die A. pulmonalis zeigt keine mikroskopische Veränderung.

Präparate II (dicht oberhalb der anderen Klappen). Die mikroskopischen Veränderungen sind gleich denen in den Präparaten $I$.

Fall 5. E. E. L., Kaufmann, 49 Jahre.

Klinische Diagnose: Dekompensationsdelirien bei Aorteninsuffizienz, Nephritiø.

Potus: wöchentlich 4-5 Glas Bier, 1 Schnaps. Nikotin: 2-3 Zigarren täglich.

Wassermannsche Reaktion ++ . Tod 22. April 1911.

S.-Nr. 427; 1911. Obduktion 24. April (Staatsprijung).

Pathologisch-anatomische Diagnose: Schwere (syphilitische) Aortensklerose mit Beteiligung der Aortenklappen (Insuffizienz), geringe Veränderung der Bauchaorta. Dilatation (mit Abplattung der Muskelballen) und Hypertrophie der linken Kammer, geringe Dilatation der rechten Kammer. Exsudat und part. adhäs. Pleuritis, Tracheobronchitis, Hyperämie und Ödem der Lungen, Randemphysem, Pharyngitis, Stauungsmilz, -nieren, -leber, Gastroenteritis haemorthagica.

Präparate 1 sind einer fleckigen, teilweise gerunzelten Stelle der Pars ascendens entnommen, Präparate II einer gleichen Stelle der Pars descendens.

\section{Mikroskopischer Befund.}

Präparate I (Pars ascendens). Intima zeigt starke Vexdickung wit einigen flachen and tieferen Einsenkungen, entsprechend den makroskopisch sichtbaren Falten. An zwei Stellen dex Intima sieht man atheromatöse Herde, in denen viele Cholestearinkristalle vorbanden sind.

Media: Sie ist in ihrem ganzen Verlaufe schwer erkrankt, streeivenweise vollständig zerstört. Bei van Gies on - Fürbung zeigt die Muskelschicht stark unterbrochene, schmale, gelblich gefärbte Streifen. Bei „,roter und blauer Elastikafärbung" sieht man auch eine erhebliche Schädigung bzw. Zerstörung der elastisehen Fasern. Diese erkrankten Teile der Media sind meist von derben Sehwielen durchsetzt. Der den oben beschriebenen Vertiefnngen der Intima entsprechende Teil der Media weist umfangreiche Granulationsherde auf, in welchen man keine elastischen Fasern sieht. In dem übrigen Mediateil bemerkt man hier und da kleine Zellherde aus Lymphozyten und Plasmazellen.

Adventitia: In der Adventitia fallen die zablreichen stark verdickten oder sogar ganz obliterierten Vasa vasorum auf. Perivaskuläre Infiltrationen, die aus Lymphozyten und Plasmazellen zusammengesetzt sind, sind in geringerex Zahl vorhanden. Die adventitiellen Bindegewebsfasern sind mäßig stark entwickelt. Mastzellen sind viel vorhanden.

Präparate II (Pars descendens). Die Veränderungen in den Präparaten II sind in allen Schichten stâxker wie in den Präpasaten I. Aber die adventitiellen Bindegewebsfasern sind nicht so stark entwickelt.

F all 56. F. B., Sehlächter, 35 Jahre.

Kinische Diagnose: Lungentuberkulose, Aorteninsuffizienz.

Pat. hat sich mehrmals mit Tripper infiziert $(1900,1902)$ und im Jahre 1903 Schanker a.m Gliede gehabt. Er ist nicht mit Schmier- oder Irjektionskur behandelt worden.

Wassermannsche Reaktion +. Exitus am 27. Mai 1911. 
S.-Nr. 563; 1911. Obduktion 29. Mai (Martin).

Pathologisch-anatomische Diagnose: Tuberkulose. Aknte miliare Bauchfelltuberkulose. Pleuritis exsudativa tuberculosa rechts. Chronische Miliartuberkulose mit Kavernenbildung links. Pleirritis adhaesiva fibrinosa links. Miliartuberkel in Trachea und Larynx. Tuberkulöse Geschwüre am Kehldeckel. Tuberkulöse Hilusdrüsen, tuberkulöse Geschwüre des Darmes. Braune Leber, schlaffe Milz. Aorteninsuffizienz, Dilatation und Hypertrophie des linken Ventrikels, Mesaortitis syphilitica, multiple Aneurysmen der Aorta. Hydrops der Gallenblase durch SteinverschluB. Hydrops anasarka und Höhlenhydrops. Bronchitis, Tracheitis.

Xeben der Abgangsstelle der rechten Koronararterie ist die Aortenwand stark verdickt strahlig, darüber befinden sich zwei etwa haselnuBgrobe Ausbuchtungen der Wand mit unregelmäßig gestalteten strahligen Einziehungen in derselben. Auf einem Durchschnitt durch eine derartige dritte Ausbuchtung der Wand zeigt sich der Sitz der Erkrankung in der Media. Die Aorta weist im Brustteil eine ausgedehnte Schwellung an der Intima auf, am Bauchteil befindet sich eine Ausbuchtung etwa von Taubeneigröße mit einem undeutlich erkennbaren Rand. Die Wand ist hier ziemlich verdickt, an der Stelle der weitesten Ausbuchtung.

Präparate I entstammen einer stark schwielig, uneben verdickten Stelle der Pars ascendens mit der A. pulmonalis. Präparate II sind einer schwielig flachen Stelle der Aorta thoracalis entnomimen.

\section{Mikroskopischer Befund.}

Präparate I (Pars ascendens mit A. pulmonalis). Intima: Sie zeigt fast in ihrem ganzen Verlaufe unregelmäßige Verdickung; an einer Stelle ist sie erheblich verdickt, so daß sie ihre normale Breite bis etwa um das zweifache überschreitet. Hier ist eine stark ausgedehnte Schwiele an dem Grenzgebiet zwischen Intima und Media ausgebildet. Durch den starken Druck, den diese große Schwiele auf die Media ausübt, ist diese hier adventitiawärts stark eingebuchtet. Anch an anderen Stellen des tiefsten Teils der Intima sieht man Sehwielenbildungen. Anderwärts treten Infiltrationen auf, von denen sich eine nur aus sehr vielen Plasmazellen zusammensetzt.

Media: Sie ist am stärksten geschädigt, sogar streckenweise durch ausgedehnte, zum Teil bandartige lange Schwielenbildung zerstört, so daß der unter dem verdickten Intimateil liegende Mediaschnitt keine normale Stelle zeigt. Diese sehwieligen Herde haben große Defekte der ejastischen und Muskelfasern hervorgerufen. Besonders an der Stelle, wo die Media eine starke Einbuchtung adventitiawärts zeigt, sind keine Muskelfasern mehr vorhanden, während die elastischen Fasern nur noch als ganz kleine Trümmer in schmaler, geschlängelter Linie bleiben. Diese Herde enthalten viele Gefäße, einige dayon sind schon makroskopisch sichtbar erweitert, mit Zellinfiltration aus Plasmazellen in mäßiger Menge und sehr wenigen Lymphozyten.

Adventitia: Die weitaus am meisten auffallende Veränderung der Adventitia besteht im Auftreten von verdickten und obliterierten Gefäßen. Man sieht einige Schwärme von Lymphozyten, von denen zwei makroskopisch schon sichtbar sind, mit spärlichen Plasmazellen vergesellschaftet. Andere kleine Infiltrate bestehen zum Teil nur aus Pasmazellen. Hier und da sind Blutpigmente zu sehen. Mastzellen spärlich nachweisbar. Die A. pullmonalis zeigt keine mikroskopische Veränderung.

Präparate II (Aorta thoracalis). Diese Präparate weisen geringere mikroskopische Veränderungen auf wie die Präparate I. Intima ist stellenweise leicht verdickt. In der tiefen. Schicht der Intima sieht man teilweise lipoide Degeneration und geringe Kalkablagerung.

Media: Sie enthält einige kleine Schwielenbildungen, in denen keine elastischen Fasern nachweisbar sind; sonst viele Gefäße. Infiltration ist sehr spärlich.

Adventitia: Die Veränderung der Gefäße ist wie in den Präparaten $I$, während die Infil. tration nicht so stark ist. Lymphknötchen finden sich in der Adventitia, in ihrer Peripherie vereinzelt Plasmazellen. Man sieht einige Nervenschnitte, vón denen einer mäßig stark infiltriert ist. Mastzellen sind viel vorhanden. 
Fall 57. V. P., Weber, 47 Jahre.

Klinische Diagnose: Osteosarkom.

Lues 1891; eine Spritzkur.

Wassermannsche Reaktion negativ. Am 29. Juli Exitus letalis.

S.-Nr. 825; 1911. Obduktion 31. Juli (Ce elen).

Pathologisch-anatomische Diagnose: Operiertes Mysochondrosarkom der 5. und 6. Rippe. Schwere eitrige Bronchitis beiderseits. Bronchopneumonische Herde rechts. Etwa $100 \mathrm{ccm}$ blatig getrübter Flüssigkeit in der hinteren Pleurahöhle. Zirkumskripte fibrinöse Pleuritis von Handtellergröße auf der Vorderseite und den lateralen Partien an der Grenze des linken Ober- und Unterlappens. Kollaps der linken Lunge. Aortitis syphilitica.

Präparate I und II entstammen einer grau-weißlichen diffusen Verdickungsstelle dicht oberhalb der Klappen.

\section{Mikroskopiseher Befund.}

Präparate I (Pars ascendens). Intima: Stellenweise zeigt sie ganz leichte Verdickung, doch sieht man lamellenartige neugebildete elastische Fasern. Die Intima weist hier und da mäßig starke Infiltrate auf; die Plasmazellen lassen sich hier strangartig oder gruppenweise nachweisen. Nastzellen trifft man verschiedentlich an.

Media: Enthält zahlreiche erweiterte Gefäße, um einige gruppieren sich Plasmazellen.

Adventitia: In der Adventitia sieht man hier und da umfangreiche Infiltrate, besonders an dem Grenzgebiet. Die Infiltrationen bestehen zumeist aus Plasmazellen, die an einer Stelle die Kapillaren rosettenartig umkränzen. Um Nerven bestehen umfangreiche, aus vielen Lymphozyten zusammengesetzte Infiltrationen. In diesen Nerven sieht man viele Mastzellen, die überhanut in der Adventitia massenhaft erkennbar sind.

Präparate II (Pars ascendens). Intima: Die Veränderungen in der Intima und Media sind fast die gleichen wie die in den Präparaten $I$, nur sind in den Präparaten II Plasmazellen nicht so zahlreich vorhanden. In der Adventitia sieht man einige schon makroskopisch sichtbare Iynphknötchenartige Zellanhäufungen aus Lymphozyten, in deren Peripherie sich Gruppen von Plasmazellen finden. An manchen. Stellen bemerkt man groRe Nervendurchschnitte, die viele Mastzellen enthalten; teilweise finden sich Plasmazellen in dem Perineurium. Mastzellen sind in der Adventitia zahlreich vorhanden.

Fall 58. F. P., Rittergutsbesitzer, 50 Jahre.

Klinische Diagnose: Herzklappenfehler und Herzmuskelentzündung.

Wassermannsche Reaktion $+t+$.

S.-Nr. 1141; 1911. Obduktion 25. Oktober ( $\mathrm{K} \mathrm{o} \mathrm{c} \mathrm{h} \mathrm{).}$

Pathologisch-anatomische Diagnose: Schwere Aortitis syphilitica (Skleratheromatose:) Diffuses Aneurysma der Pars ascendens und des Arcus aortae. Starke Retraktion und Verdickungder Aortenklappen. Aorteninsuffizienz; starke Dilatation und Hypertrophie des linken Ventrikels, starke Verfettung und Schwielenbildung im Myokard. Staumgsorgane; groBer schiefriger Indurationsherd in der rechten, kleinerer in der linken Lungenspitze; pleuritische Adhäsionen rechts oben, alveoläres Randemphysem. Cholecystitis chron. mit großen und mehreren kleinen Gallensteinen. Alte Ulkusnarbe in der Gegend des Pyloras. Dystopie and starke Hyperplasie beider Hoden, Ulkusnarbe an der Corona glandis penis. Beginnende eitrige Peritonitis, multiple kleine Schleimpolypen und Geschwüre an zirkumskripter Stelle im Anfangsteil des Colon transversum. Muskatmußleber. Pfröpfe in den Tonsillen. Starke Skoliose der Lendenwirbelsäule nach links.

Präparate I sind einer zirkumskripten, grau weibichen Stelle der Pars ascendens entnommen. Präparate II vom Arcus aortae, Stelle von gleicher Beschaffenheit wie in den Präparaten I. 


\section{Mikroskopischer Befund.}

Präparate I (Pars ascendens). Intima zeigt geringe Verdickung, doch sieht man nengebildete elastische Fasern.

Media weist hier und da kieine Herde auf, in denen sich Plasmazellen and Lymphozyten tunden. Die Veränderung der elastischen Fasern ist ganz gering.

Dagegen zeigt die Adventitia mäßig starke Veränderungen. In erstex Linie fällt der Reichtum der Gefäße anf, von denen viele stark verdickt oder sogar ganz obliteriert sind. Während die kleineren Infiltrate meist nur aus Plasmazellen bestehen, sind einige makroskopisch schon sichtbare, lymphknötchenartige adventitielle Infiltrate hauptsächlich aus Lymphozyten zusammengesetzt, an ihrem Rande bemerkt man auch Gruppen von Plasmazellen. Die oben beschriebenen großen Infiltrate enthaiten viele Kapillaren. Mastzellen sind sehr viel nachweisbar. Die adventitiellen Bindegewebs- und elastischen Fasern sind mäBig stark entwickelt.

Präparate II (Arcus aortae) zeigen nikroskopische Veränderungen von gleicher Beschaffenheit.

F a 11 59. E. B., Zuschneider, 60 Jahre.

Klinische Diagnose: Taboparalyse. Gebinnerweichung.

Infektion: Lues positiv.

Wassermannsche Reaktion fehlt. Exitus letalis am 6. Dezember 1911.

S.-Nr. 1321; 1911. Obduktion 7. Dezember ( Ka is e r ling).

Pathologisch-anatomische Diagnose: Syphilitische Aortitis und Arteriitis cerebri. Thrombose der rechten Karotis und Art. foss. Sylvii. Großer Erweichungsherd in den Ganglien. Chronische Leptomeningitis mit starkem Ödem; Exostosen am äußeren Schädeldach. Hypertrophie und Dilatation des Herzens, stark braune Muskulatur. Polysarcie und Fettdurchwachsung, besonders rechts. Mesaortitis bis zum Abzweigen der Abdominalgefäße. Verengerung der oberen Interkostalarterien. Bronchopneumonie im rechten Unterlappen, starke Hyperämie und Ödem der Lungen, chronisehe Bronchitis. Adhäsion der rechten Pleura, Randemphysem der linken Lunge. Geringe Granulation der Nieren, starke Hyperämie, diffuse bämorrhagische Färbung der Rinde. Frischer Infarkt der linken Niere mit gelblichweißem, scharfem Rande. Geringe Prostatahypertrophie mit Konkrementbildung, starke Dilatation der Blase mit $650 \mathrm{cem}$ Urin, chronische Gastritis. Leichte Hyperplasie der Milzpulpa, Verwachsung der Milzkapsel. Hämorrhagischer Milzinfarkt.

Präparate I entstammen einer gerunzelten, zum Teil leicht verdickten Stelle der Pars ascendens mit der A. pulmonalis. Präparate II sind einer stark verdickten Stelle der Pars ascendens mit linker verdickter Klappe entnommen. Präparate III sind der Aorta mit hinterer Klappe entnommen.

$$
\text { Mikroskopischer Befund. }
$$

Präparate I (Pars ascendens mit der A. pulmonalis). Intima: Sie zeigt an ihrer Innenfläche anf eine lange Strecke hin zahlreiche, verschieden tiefe Einsenkungen, daneben ist sie etwas sklerotisch verdickt mit einigen elastischen Lamellen. An einer Stelle findet sich ein großer, anch einen Teil der betreffenden Media einnehmender, gegen die Umgebung sehr scharf begrenztex nekrotischer Herd, in dem viele ovale, rundliche und unregelmäßige Kerne noch gerade erkennbar sind. An anderer Stelle, und zwar in der innersten Schicht der Intima, sieht man einige kleine Kalkablagerungen.

Media: An einer Stelle ist sie von einem makroskopisch schon kenntlichen, mehr diffusen Zellherde durchsetzt. In seinem Bereich finden sich einige Gefäße, Blutpigment und reichlich Plasmazellen, während die elastischen Fasern zerstört sind. Der übrige Teil der Media zeigt auch einige Zellherde, aber nur in geringer Zahl. Der unter den Falten der Intima liegende Teil der Media. zeigt ganz geringe Zellherde.

Adventitia: Während die adventitiellen Gefäße verhältnismäßig geringe Veränderungen zeigen, treten sehr starke Infiltrate auf. Die großen Infiltrate, die mit bloßem Auge erkennbar 
sind, bestehen aus lymphozyten, nur in der Peripherie sieht man Plasmazellen in mäßiger Menge. Dagegen sind die perivaskularen Zellherde und die anderen interstitiellen Zellanhäufungen meist fast ganz aus Plasmazellen zusammengesetzt, ja manchmal sieht man Plasmazellen, die um stark dilatierte Kapillaren radiär sich anordnen. Hier und da finden sich Plasmazellen in rosettenartiger Anordnung. An einer Stelle bemerkt man Lymphknoten, an deren Peripherie Gruppen von Plasmazellen und Blutpigment sich finden. Während Mastzellen in der Media sehr wenig vorhanden sind, sind sie in der Adventitia massenhaft nachweisbar. Die A. pulmonalis zeigt keint Veränderungen.

Präparate II (Pars ascendens mit linken Klappen). An einer Stelle der Media findet man einen großen, einen Teil der dariiber gelegenen Intina angreifenden, scharf begrenzten nekrotischen gummösen Herd mit Infiltraten aus Iymphozyten und Plasmazellen umgeben, besonders der betreffende Intimateil ist yon zahireichen Plasmazellen und Iymphozyten durehsetzt. Sonst zeigt die Intima nur eine leichte Verdickung. Der übrige Teil der Media dagegen enthält klleine Zellinfiltrationen. In der Adventitia sind Infiltrate aus Plasmazellen und Lymphozyten vorhanden. Mastzellen sind ebenfalls sehr viel nachweisbar. In den überall stark fibrös verdickten Klappen sieht man keine Infiltration. Mastzellen sind nur spärlich vorhandep. In dem Herzmuskelgewebe sind nirgends Plasmazellen nachweisbar, die Muszkelzellen zeigen Pigmentablagerung an den Polen ihrer Kerne.

Präparate III (Pars ascendens mit hinteren Klappen). In diesen Präparaten sieht man viel stärkere Veränderung der Gefäße in der Adventitia als in den Präparaten II. Sonst ist der mikroskopische Befund fast genau so wie in den Präparaten II.

Fall 60. L. A., Witwe, 52 Jahre.

Klinische Diagnose: Aortenaneurysma.

Infektion: negatur.

7 Partus; 5 KKinder starben inn Sänglingsalter, 2 Kinder ganz gesund.

Wassermannsche Realition +++ . Exitus letalis am 30. Dezember 1911.

S.-Nr. 1413; 1911. Obduktion 2. Januar 1912 ( Koch).

Pathologisch-anatomische Diagnose: Faustgroßes, sackförmiges Anenrysma. der Pars ascendens, kleines walnußgroßes des Arcus aortae. Aortitis syphilitica. Ausgedehnte Pneumonie des linken Unterlappens und von Teilen des Oberlappens. Sero-fibrinöse Pleuritis links. Mäßige Dilatation und Hypertrophie des linken Ventrikels, gexinge Hypertrophie des rechten. Gefensterte Aortenklappen, Sklerose der Koronararterien. Bronchitis, Tracheitis mit Kompressionen der Bifuration durch das Aneurysma. Struma. Kavernom und Schnürfurche der Leber. Mehrere kleine Schleimpolypen im Rektum. Taenia saginata.

Die Aorta erweitert sich oberhalb der Klappen zu einem mannsfaustgroßen Sack, der rechts Pars ascendens und Arkus cinbegreit. Bein Ubergang zur Pars descendens findet sich nach der Wirbelsäule zu gelegen nochmals eine walnußgroße Ausbuchtung, die sich in den Knochen hinein erstreckt, und mit braunen, weichen Massen erfiullt ist. Die Veränderung in den Wirbelkörpern findet sich am 4. und 5. Brustwirbel. Die Aorta zeigt an der Intima unregelmäBiges Aussehen. Neben gelblichweiben, erhabenen Flecken von derber Konsistenz, die besonders in der Nähe der Interkostalarterienabgänge sitzen, finden sich außerordentich zahlreich grauweiße, rnnzlige narbenartige Züge und Streifen. Die Veränderung wird nach unten zu geringer. Auf einem Querschnitt durch die Wand der Aorta sieht man die Media nux als unterbrochenen gelbliehen Streifen.

Präparate I sind einer glasigen, unebenen Stelle des Areus aortae entnommen. Präparate II stammen von einer leicht verdickten Stelle der Pars descendens.

Mikroskopischer Betund.

Präparate I (Areus aortae). Intima: Teilweise zeigt sie geringe Verdickung ohne Verfettung, Man sieht einige elastische Lamellen mit Infiltraten ans Iyymphozyten. 
Media: Hier und da, besonders in der adventitiawärts liegenden Partie der Media, lassen sich verschieden grobe Zellherde aus Plasmazellen und Lymphozyten nachweisen. Ein Herd enthält auch einige Mastzellen. Die Schädigung der elastischen Fasern ist gering.

Adventitia: Hier fallen die stark entwickelten, dilatierten und mit Blut strotzend gefüllten Gefäße auf. Besonders in dem Grenzgebiet zwischen Media und Adventitia sieht man solche Gefäßie von Lymphozyten und Plasmazellen umgeben. Einige Gefäße sind stark verdickt. In dem übrigen Teil finden sich einige, schon makroskopisch erkennbare, lymphknötehenartige Zellanhäufungen aus Lymphozyten. Um die Nerven bestehen auch starke Infiltrate. An einer Stelle bemerkt man stark entwickelte, lamellenartige elastisehe Fasern. Mastzellen sind vorhanden.

Präparate II (Pars descendens). Intima: Ihre Verdickung ist stärker als in den Präparaten I. außerdem zeigt sie eine kleine Kalkablagerung mit Infiltration.

Media: Ihre Breite ist sehr verschieden. An einigen Stellen, wo man mäßig starke Zellherde sieht, ist die Media bis auf ein Drittel ihrer normalen Breite verschmälert. In diesen Herden sind die elastischen Fasern stark geschädigt. Anch die übrigen Teile zeigen sie verändert. Die erwähnten Zellherde sind mit Plasmazellen, teilweise mit Schwielen durchsetzt. An anderer Stelle ist der dicht unter der Intima liegende Teil der Media auf eine lange Strecke hin schwielig verändert.

Adventitia: Die Infiltrate der Adventitia besitzen eine noch größere Ausdehnung als die in den Präparaten I. Die am meisten ins Auge springende Veränderung ist das zahlreiche Anftreten der Plasmazellen in den linsengroßen Lymphdrüsen, die in der Nähe der Adventitia liegeri. Die Plasmazellen sind hier zahlreich in den Lymphräumen und Lymphsträngen, besonders aber in der Peripherie der Lymphdrüsen vorhanden, und auch in der Kapsel sowie in den Trabekeln nachweisbar. Mastzellen läßt die Adventitia vier exkennen.

Fa 1161 . E. R., Schutzmann, 34 Jahre.

Klinische Diagnose: Aorteninsuffizienz. Lungeninfarkt.

Infektion: Tripper 1907. Lues 1903. 11/2 Kur (Schmierkur) 1904.

Wassermannsebe Reaktion positiv. Am 1. Januar 1912 Exitus letalis.

S.-Nr. 1; 1912. Obduktion 3. Januar ( $\mathrm{L}$ ö h e ).

Pathologisch-anatomische Diagnose: Rekurrierende Endocarditis aortica verrucosa mit starker Zerklüftung der linken vorderen Klappe. Aortitis syphilitica (?). Starke Verengerung der Abgangsstelle der linken Art. coron. Infarktbildung in der Muskulatur des linken Herzventrikels. Starke Hypertrophie und Dilatation beider Ventrikel. Thrombus im linken Herzohr. Thromben in den prostatischen Venen. Starke Stanungsinduration beider Lungen, Embolie und hämorrhagische Infarktbildung der rechten Lunge. Stauungsorgane (Leber, Milz, Nieren). Staungstracheobronchitis, allgemeiner Ikterus.

An der Aorta ascendens, dicht oberhalb der Aortenklappen findet sich eine zehnpfennigstückgroße, grauweibliche, glänzende derbe Erhöhung, deren Oberfläche ziemlich glatt ist, und von feinen Fältchen, gleichlaufend der Aorta, umgeben ist.

An den Präparaten aus der obenerwähnten Erhöhung findet sich mikroskopisch: Die Intima ist stark sklerotisch, hügelförmig verdickt, erscheint bei $\mathrm{v}$ a n $\mathrm{G}$ i e s on - Färbung überall rosarot; man sieht spindelförmige ovale Kerme. Diese verdickte Intima zeigt keine Zerfallserscheinungen, doch sind an eimigen Stellen geringe Mengen Fett abgelagert. Die Intimaerhöhung hat an ihren Übergangsstellen neugebildete, lamellenartige elastische Fasern. In der innersten Schicht der Intima befinden sieh stellenweise geringgradige Infiltrationen aus Lymphozyten.

Media: Die an die obenerwähnten verdickten Intimateile angrenzende Media zeigt zu ein Fünftel fast keine Veränderung, bis auf einige Infiltrationen aus Plasmazellen und Zerstörungen elastischer Fasern, die bei der W e ig e $\mathbf{t}$ schen Elastika-(blau und rot)färbung dentlich zu sehen sind. Der übrige Mediateil ist stark durchwuchert von Granulationsgewebe und derben Bindegewebsfasern von narbenartigem Aussehen, so daß die normale Muskelschicht stark zerstört und von getrennten klumpigen. Muskelgewebsstücken gebildet erscheint. Die Elastikafärbung zeigt 
die hochgradige Zerstörung der elastischen Fasem in fleckweise auftretende und scharf durchschnittene Büschel. Hier und da sieht man deutlich die Spaltungen der einzelnen elastischen Fasern. Diejenigen herdartigen Partien, wo die elastischen Fasern ganz zerstört und verschwunden sind, zeigen zahlreiche neugebildete, stark dilatierte und mit Blut gefüllte Gefäße. Dieselben Herde weisen, besonders in der Nähe der scharf durchschnittenen elastischen Faserbüschel, starle Infiltrationen, Vasa vasorum und neugebildete Getäbe auf, umgeben von Zellanhäufungen. Diese Infiltration besteht größtenteils aus Plasmazellen und nur in geringerer Menge ans Lymphozyten. Die Plasmazellen treten bisweilen vereinzelt, doch meist gruppenweise auf, oder zeigen, wenn in den Lymphspalten und Lymphkapillaren befindlich, die Form eines kürzeren oder längeren einreihigen Stranges. In den erkrankten Partien, besonders in der Ungebung der neugebildeten Gefäße; sieht man zahlreiches Blutpigment. Der dem unveründerten Intimateil entsprechende Mediateil zeigt fast gar keine krankhafte Veränderung, doch an dem adventitiawärts gelegenen Mediateil findet sich eine Zerstörung von elastisehen Fasern und Iokalisierte Infiltrationen, die fast alle aus Plasmazellen zusammengesetzt sind; besonders einige Stellen im Grenzgebiet zwischen Media. und Adventitia sind bei 70 facher Vergrößerung dureh das ganze Gesichtsfeld strangförmig mit Plasmazellen durchsetzt. In diesem Plasmazellenstrang sind hier und da stark gefüllte Gefăße. Der diesem entgegengesetzte, dem oben beschriebenen erkrankten angrenzende Mediateil weist noch stärkere krankhafte Veränderung auf, als dieser selbst. Mastzellen finden sich überall in den exkxankten Teilen, besonders in den Gebieten starker Infiltration; in einem Gesichtsfeld zählt man dayon etwa 20. Diese Mastzellen haben meistens kokkenartige Fortsätze.

Adventitia: Die Adventitia ist im allgemeinen weniger als die Media erkrankt. Die Yasa vasorum sind stark entwickelt; einige zeigen eine Intimaverdickung. Hier und da, besonders in der Umgebmng von kleinen Nährgefäßen, bemerkt man starke zellige Infiltrationen aus Plasma zellen und Lymphozyten; zum Teil sind Plasmazellen in überwiegender Mehrzahl vorhanden, an anderen Stellen dafür wieder spärlicher. In einem kleinen Lymphknötchen der Adventitia sieht man ebenfalls viele Plasmazellen, die sich vor allem am Rande befinden. Mastzellen sind überall, meist zerstreut vorhanden; man zählt in jedem Gesichtsfeld bei 100 facher VergröBerung durchschnittich 20--30. Hier und da sind anch mehrere Mastzellen dicht beieinander gelegen. Nanchmal sind einige Mastzellen mit Gruppen von Plasmazellen verbunden. Das Bindegewebe ist kernarm and zeigt zum Teil ein glasiges Aussehen.

Fal1 62. J. H., T'oilettenwärter, 43 Jahre.

Kinische Diagnose: Myodegeneratio cordis. Aszites.

Alkohol : früher viel Bier (12-15 Glas) und $1 / 2$ Iiter Schnaps, in letzter Zeit etwas weniger.

Nikotin: früher 4-ŏ Zigarren, jetzt weniger. Infektion: 1895 Tripper. 1898 Sehanker. Nicht behandelt.

Wassermannsche Reaktion fehlt. Exitus letalis an 16. Januar 1912.

S.-Nr. 75; 1912. Obduktion 18. Januar ( $\mathrm{K}$ a is e $\mathrm{l}$ in $\mathrm{g}$ ).

Pathologisch-anatomische Diagnose: Schwere Mesaortitis mit Übergreifen auf die Aortenklappen; chronische retrahierende Endocarditis aortica; fibröse Verdickungen unterhalb der Aortenklappen, geringe Verdickung der Mitralschließungsränder. Hypertrophie und starke Dilatation beider Herzkammern; fettige Entartung des Myokards und multiple schwielige Verdicknngen des Perikards, geringe Skleratherose dex Koronargefäße, $50 \mathrm{ccm}$ orangegelbes Hydroperikard. Pleuritis serosa (rechts) $300 \mathrm{ccm}$ leicht rötlicher Flüssigkeit, geringe Kompressionsatelektase am scharfen Rande. Starke Stauung. Ödem beider Lungen, chronische Bronchitis beiderseits. Spitzenadhäsionen rechts, mäBige Lipoidosis der Pulmonalarterien, chronische Induration. Staumgsmilz $(16: 10: 6$ ), multiple fibröse Knoten in der Milzkapsel, indurierte Stauungsnieren mäßigen Grades, deutliche Reste der renkulären Zeichnung; Aszites 3 I gelber, leicht trüber Flüssig. keit. Leberzirhose; allgemeine VergröBerung der Leber; chronische Stauungsgastritis, starke 
saure Erweichung des Magens, starkes Ödem der unteren Bauchdecken und des Penis, chronische Leptomeningitis fibrosa; Sinus occipitalis rechts reichlich von der Weite eines Gänsekiels.

Präparate I wurden einer unebenen, grauweißlichen Verdickungsstelle der Pars ascendens entnommen. Präparate II stammen von einer verdickten, zum Teil gerunzelten Stelle der Pars descendens.

$$
\text { Mikroskopischer Befund. }
$$

Präparate $\mathrm{I}$ (Pars ascendens). Intima zeigt überall leichte Verdickung. Sie enthält an einigen Stellen ganz scharf begrenzte, aber auch mehr diffuse Zellherde aus Plasmazellen und Lymphozyten, von denen einige mit gleichen Zellherden in der Media kommunizieren.

Media: Während kleine perivaskuläre Zellherde überall reichlich vorhanden sind, fallen drei makroskopisch sichtbare, an dem intimawärts gelegenen Teil dex Media befindliche, große Erkrankungsherde auf, von denen einer ausgedehnte Schwielenbildung mit zum Teil gefäßhaltigem frischen Granulationsgewebe und Zellinfiltration aus Lymphozyten und Plasmazellen zeigt. Dieser Herd hat einen großen Defekt der elastischen Fasern bewirkt. Die zwei anderen Herde sind aus großen Mengen von Plasmazellen und nur wenigen Lymphozyten zusammengesetzt und enthalten anch Gefäße. Eines dieser Herde ist gegen die Ungebung ganz scharf abgegrenzt und ihm feblen die elastischen Fasern, ebenso die Muskelfasern. Der andere Herd ist mehr diffus und zeigt vor allem am Rande eine starke Zertrümmerung der elastischen Fasern, aber auch in dem Herde selbst. Die zwischen den zwei letztgenannten groBen Herden liegenden elastischen Fasern sind autgelockert, auch stückweise zerstört, dazwischen finden sich kleine Zellherdchen aus Plasmazellen.

Adventitia: Die mikroskopische Vexänderung in der Adventitia ist nicht so stark wie die in der Media, doch lassen sich hier und da zahlreiche verdickte Vasa vasorum mit geringen perivaskulären Infiltrationen aus Plasmazellen und Lymphozyten erkennen. Um die Nerven besteht ebenfalls ein Infiltrat und man sieht auch Plasmazellen in dem Perineurium. Ein Lymphknoten ist vorhanden, in dessen Peripherie sich Gruppen von Plasmazellen finden. Mastzellen sind viel vorhanden, anch in dem Endoneurium. In der Adventitja bemerkt man mö̈Big starke Neubildung der Bindegewebsfasern.

Präparate II (Pars descendens). Die Intima ist stellenweise mäßig verdickt und an der Oberfläche mit zahlreichen flachen und tieferen Falten versehen. Sie enthält auch Gefäße und Plasmazellen. Auf dex Grenze von Intima und Media sieht man stellenweise derbe Schwielen mit vielen spindeligen Kernen und zahlreichen Gefäßen und Plasmazellen.

Media und Adventitia enthalten eine große Anzahl von kleinen Zellherden aus Plasmazellen und Lymphozyten. Die Vasa vasorum sind stark entwickelt, Mastzellen ebenso.

F a 1 I 63. Frau A., Arbeiterfrau, 45 Jahre.

Klinische Diagnose: Oesophagusstenose. Mitralstenose und Insuffizienz.

Infectio: negatur.

Wassermannsche Reaktion + . Exitus letalis am 4. Februar 1912.

S.-Nr. 144; 1912. Obduktion 5. Febrnar ( K 0 c h ).

Pathologisch-anatomische Diagnose: Schwere Aortitis syphilitica bei starker Retraktion und Verdickung der Aortenklappen. Verengerung der Arteria coronaria, sehr starke Dilatation and geringe Hypertrophie besonders des linken Ventrikels, schwere Myodegeneration mit Verfettung, Schwielen- und Infarktbildung. Stauungsorgane, Muskatnufleber, geringer Aszites und Hydrothorax. Geringe Bronchitis, narbenartige Veränderungen an der Portio cervicalis nteri mit starker Erweiterung des Zervilkalkanals. Corpus lutenm. Taenia saginata, geringe Urocystitis cystica.

Die Aortenklappen, besonders die rechte, sind außerordentlich stark retrahiert und zeigen besonders in der Nähe des Schließungsrandes sehr derbe, gelblich-weiße Verdickungen. Die stärkste Veränderung in jeder Beziehung findet sich in der rechten Klappe. Zwischen der rechten und mittleren findet sich ungefähr ein $3 \mathrm{~mm}$ breiter, narbenartiger Streifen. Die Koronararterien 
sind beiderseits an ibrer Abgangsstelle etwas verengt, aber im weiteren Verlauf uberall gut durchgängig, ihre Intima fast äberall spiegelnd und glatt. Oberhalb der rechten Klappe findet sich eine ungefähr hanfkorngroße, $1 \mathrm{~mm}$ tiefe Grube in der Aortenwand, die etwas unterminierte Wände aufweist.

Die Anrta zeigt in der Pars ascendens, im Arkus und im oberen Teil der Pars descendens eine grauweiße Farbe von außerordentich unregelmäßiger, höckriger Oberfäche, daneben finden sich vielfach narbenartige Züge. Die Wand erseheint in allen Schichten erheblich verdickt, die Media auf einem Querschnitt unregelmäbig. Im Bauch- und unteren Brustteil ist die Verdicknng: geringer, und es finden sich an ihrer Stelle eine große Anzahl unregelmäßig gestalteter Herde von gelblicher Farbe und verschiedener Größe, die etwas über die Oberfläche prominieren. Im allgemeinen nehmen alle Veränderungen der Aorta nach unten zu erheblich ab.

Präparate I stammen von einem vollständigen Querschnitt der Pars ascendens, an einer narbigen, leicht verdickten Stelle. Präparate II von einer gleich aussehenden Stelle des Arcus a.ortae.

\section{Mikroskopischer Befund.}

Präparate I (Pars ascendens). Intima: Sie ist an dem ganzen Querschnitt nur stellenweise leicht verdickt. In ihrem tiefsten Teil trifft man einige Plasmazellen an. Sonst zeigt sie keine Verïnderung,

Media: Stellenweise stark zerstört. Hier und dort, besonders in dem intirnawärts liegender Mediateile, finden sich derbe Schwielen mit nergebildeten Gefäßen. Dazwischen sieht man Zellanhäufungen aus Lymphozyten und Plasmazellen in mäBiger Menge; hier sind auch etwas Blutpigment und zahlreiche Mastzellen vorhanden. Die elastischen Fasern sind in den Herden stark geschädigt; sie zeigen große, scharf geschnittene, oder mehr unregelmäBig gestaltete Defekte, in denen manchmal nur noch feine Trümmer oder Reste der elastischen Fasern vorhanden sind.

Adventitia: Die Veränderung in der Adventitia ist verhältnismäßig geringer wie die in der Media. Man sieht hier und da ziemlich große perivaskuläre Infiltrate aus Lymphozyten. Während sich nur wenig Plasmazellen finden, bemerkt man viele Mastzellen. Die Vasa vasorum sind auch endarteriitisch verändert, außerdem sieht man ausgedehnte Bindegewebsneubildung in der Adventitia.

Präparate II (Arcus aortae). Intima: Sie ist teilweise etwas verdickt, enthält einige Blatgefäise, um die geringes Infiltrat liegt.

Nedia zeigt zwar in ganzen geringere mikroskopische Verändernogen als die in den Präparaten $I$, doch ist eine derselben schon makroskopisch sichtbar.

Adventitia: Die Zellherde in der Adventitia sind ausgedehnter wie in den Präparaten I; Plasmazellen sind an der Periphexie des Zellherdes reichlich vorhanden. Einige obliterierte Gefaßse sind sichtbar. Mastzellen sind sehr viel nachweisbar. Adventitielles Bindegewebe ist mäbig nelzsebildet.

F a 11 64. L. K., Plättanstaltsbesitzersfrau, 46 Jahre.

Klinische Diagnose: Myodegeneratio cordis chronica. Syphilis. Lungenödem.

Wassermannsche Reaktion fehlt. Exitus letalis am 19. März 1912.

S.-Nr. 336; 1912. Obduktion 21. März (Ce eJen).

Pathologisch-anatomische Diagnose: Aortitis syphilitica, besonders des Arkus und der Pars thoracica. Fast völliger Verschluß der Abgangsstelle der linken Koronararterie. Verengerung der Abgangsstelle der rechten Koronararterie; schwere Myodegeneratio cordis, starke Dilatation beider Ventrikel. Verdickung der Schliebungsränder der Aortenklappen, Hyperämie und starkes Ödem beider Lungen, Enteritis nodularis, geringe Milzschwellung, sauere Erweichung des Magens.

Präparate I sind einer narbigen, zum Teil gerunzelten Stelle der Pars ascendens entnommen. Präparate II stammen von einer grau-weiBlichen Verdickungsstelle des Arcus aortae. 
Mikroskopischer Befund.

Präparate I (Pars ascendens). Intima: Sie zeigt erhebliche Veränderungen. Während sie stellemweise mäßig stark sklerotisch verdickt ist, fallen an einer Stelle viele flache und tiefere Einsenkungen auf. Zwischen diesen und der darunter liegenden Media, die ganz geringe Veränderung anfweist, sind stark dilatierte Kapillaren in großer Ausdehnung reichlich entwickelt. Dazwischen sieht man viele elastische Fasern, zum Teil trümmerartig. Hier findet sich auch junges Bindegewebe. An einer anderen Stelle bemerkt man einen gleichen Herd, der aber nicht so grob ist wie der andere und dessen Gefäße nicht erweitert sind. Die am meisten ins Auge springende Veränderung in der Intima ist das Auftreten von zahlreichen Plasmazellen, die bald strang- oder kettenartig parallel der Oberfläche der Intima angeordnet, bald gruppenweise angehäuft sind. Die Plasmazellen treten teils mit Lymphozyten zusammen auf, teils liegen sie in Gruppen für sich. Die Plasmazelleninfiltration findet sich nicht nur in der verdickten Intima, sondern auch in den Räumen zwischen den oben erwähnten Kapillaren. Die verdickte Intima enthält außerdem neugebildete elastische Fasern.

Media: Sie hat im allgemeinen fast normale Breite; doch ist sie von zahlreichen Herden durehsetzt, die aus Granulationsgewebe mit Plasmazellen und Lymphozyten bestehen. Daneben finden sich anch Zellherde, die schon makroskopiseh sichtbar sind und sich nur aus reichlichen Plasmazellen zusammensetzen. Diese Erkrankungsherde haben zu mäßjig starker Schädigung der elastischen Fasern, nur stellenweise zur Zerstörung derselben geführt. In dem der Adventitia angrenzenden Mediateil sieht man viele in einer Linie aneinanderliegende erweiterte Gefäße, wodurch die elastischen Fasern auf eine lange Strecke hin zu geschlängelten Bündeln voneinander getrennt sind. Die Zwischenrüume sind mit Plasmazellen angefüllt.

Adventitia: Sie ist durchweg von Schwärmen zahlreicher Plasmazelien, weniger von Lymphozyten durchsetzt. Einige sind schon mit bloßem Auge erkennbar; einer derselben besteht aus Lymphozyten mit wenigen Plasmazellen. In den übrigen großen und kleinen Zellherden fallen die Plasmazellen hauptsächlich ins Auge. Hier und da trifft man letztere in rosettenartiger Anordnung. In der Adventitia finden sich Vasa vasorum in großer Anzahl; sie sind alle erweitert und mit Blut gefüllt; einige, schon makroskopisch sichtbar, enthalten Plasmazellen. Obliterierte Gefäße lassen sich vereinzelt feststellen. Die adventitiellen Nerven sind auch von Plasmazellen umsänmt. Mastzellen sind viel nachweisbar.

Präparate II (Arcus aortae). Intima: Sie ist ungleichmäBig verdickt, enthält einige elastische Lamellen. An einer Stelle sieht man ein gefäBreiches frisches Granulationsgewebe mit reichlichen Plasmazellen, das einem gleichen Gewebe in der Media entspricht. Der übrige Teil der Intima weist stellenweise geringfügige Infiltration auf.

Media: Sie ist am schwersten erkrankt, besonders der intimawärts liegende Teil, wo sie von einigen, schon mit bloßem Auge erkenntlichen, scharf begrenzten Erkrankungsherden durchsetzt ist. Der eine dieser Herde hat Amboßform mit nach der Adventitia zu gerichteter Basis und nimmt fast die ganze Mediabreite ein. Er besteht zum Teil aus frischem Granulationsgewebe mit reichlichen Plasmazellen und Lymphozyten; letztere liegen an einer Stelle des Herdes in Gruppen. Diesem Herde entspricht ein scharf geschnittener Defekt in den elastischen Fasern, von denen an dieser Stelle nur noch Reste enthalten sind. Daneben findet sich ein ebenso großer und gleiche Zusammensetzung zeigender Herd, der aber mehr Gefäße enthält. Die anderen makroskopisch sichtbaren Granulationsherde sind nicht so frisch wie diese; Plasmazellen sind in mäßiger Menge, daneben auch einige Mastzellen, vorbanden. In einem der Herde finden sich einzelne ganz feine Reste der elastischen Fasern, zum Teil sind auch Muskelfasern erhalten. Der übrige Mediateil enthält viele kleine Schwielen und Zellherde aus Plasmazellen und Lymphozyten.

Adventitia: In der Adventitia fallen viele verdickte und sogar ganz obliterierte Vasa vasorum auf. Besonders liegen sie im Grenzgebiet zwischen Media und Adventitia. Man sieht auch viele Gefäße mit zahlreichen Plasmazellen in dem der Adventitia angrenzenden Mediateil, wodurch 
die elastischen Fasern wie in Präparaten I getrennt sind. In der Adventitia treten allenthalben umfangreiche, teils unschriebene, teils diffuse Herde von Plasmazellen und Lymphozyten auf; die Menge dieser beiden ist ganz verschieden, durchschnittlich sind die Plasmazellen überwiegend. Die Plasmazellen umsäumen nicht nur die GefäBe, sondern finden sich auch in deren Lumen. Mastzellen lassen sich in mäßiger Menge erkennen. Die adventitiellen Bindegewebs- und kollagenen Fasern sind mäßig stark entwickelt.

F a 11 65. E. F., Portier, 41 Jahre.

Klinische Diagnose: Lungenabszesse bzw. durchgebrochenes Empyem?, Aneurysma aortae.

Infektion: harter Schanker, einmal weicher Schanker. Alkoholgenuß: früher reichlich, jetzt wenig. Nikotin: mäßrig.

Wassermannsche Reaktion fehlt. Exitns letalis an 7. Mai 1912.

S.-Nr. 547; 1912. Obduktion 9. Mai ( $\mathrm{K}$ a is e r lin $\mathrm{g}$ ).

Sektionsdiagnose: Mehrere ulzeröse Kavernen nach Erweichung tuberkulöser Pneumonie im rechten Unterlappen. Disseminierte Bronchopneamonien. Schwere Bronchitis. Bronchiektasie. Hyperämie und Ödem der linken Lange. Pleuritis sicca rechts am Unterlappen. Aneurysma. aortae im absteigenden Bogenteil mit Arrosion der Wirbelsäule. Ausgedehnte Mesaortitis an der Grenze des Sinus Valsalvae mit scharfem Rande beginnend. Hypertrophie des Herzens. Traeheitis. Walnußgroßes Rindenadenom der linken Nebenniere. Mäßige Leberzirrhose mit unregelmäßiger Heekweiser Verfettung. Kleiner dreieckiger Lappen am vorderen Rande des rechten Leberlappens, Linker Hoden klein, braun; rechter größer, grau; in beiden verbreiterte Septen.

Die Präparate I sind einer Stelle dicht oberhalb der Klappen entnommen, die zum Teil granweißliche, höckerige Erhabenheiten, zum Teil narbige Einziehungen zeigt.

\section{Mikroskopischer Befund.}

Präparate I (Aorta mit A. pulmonalis). Intima: Man sieht stellenweise mäßig stark verdickte Intima ohne degenerative Veränderungen. An einigen Stellen finden sich Rundzelleninfiltrate.

Media: Sie ist in ihrem ganzen Verlauf schwer geschädigt, sogar streckenweise vollständig zerstört, so daß die Muskelschicht bei van Gies on - Färbung stellenweise unterbrochene, gelbiche, verschieden große Streifen und Inseln darstellt. Die elastischen Fasern sind auch erheblich betroffen. An den adventitiawärts gelegenen Mediateil bleiben die elastischen Fasern in einem großen Teil ohne Unterbrechung, doch sind sie sehr locker. In den erkrankten Mediateilen fallen ausgedehnte derbe Schwielen, gefäBreiche junge Granulationsgewebe and Zellherde auf. Die letzteren bestehen in der Hauptsache aus Plasmazellen mit nur wenigen Lymphozyten. In der Media sieht man auch viele gefüllte GefäBe ohne Zellinfiltrationen. Hier und da bemerkt man Blutpigment.

Adventitia: Sie ist relativ wenig verändert, doch sieht man stellenweise Zellschwärme aus Plasmazellen und Lymphozyten, vorwiegend in der Ungebung der Vasa vasorum, deren Lumen, infolge der Wucherung dex Intima zum Teil konzentrisch stark verengt zum Teil exzentrisch verlagert ist. Die übrigen, nicht verdickten Vasa vasorum sind stark gefüllt. Einige Nerven sind sichtbar, um sie besteht keine Infiltration. Mastzellen sind viel vorhanden. Die Arteria pulmonalis, die ich gleichzeitig geschnitten und untersucht habe, zeigt absolnt keine Veränderung.

Präparate II sind dem Aneurysmahalsteil entnommen. Intima: Sie ist am Halsteil des Aneurysma mäBig stark verdickt. In der tiefsten Schicht der Intima findet sich an einigen Stellen lipoide Degeneration. Hier und da ist Rundzelleninfiltration - nux Lymphozyten - sichtbar. An der übrigen Aneurysmawand ist die Intima nicht verdickt; auf ihr lagern thrombotische Massen.

Media: Die elastischen Fasern, ebenso anch die Muskelfasern, sind erheblich geschädigt, namentlich sind sie am Halsteil des Aneurysma und zwar nach dem Aneurysma zu in fortschreitender Stärke verschmälert, stellenweise sogar unterbrochen, an der Aneurysmawand endlich ganz verschwunden. In diesen Herden ist das Gewebe meist durch derbe Schwielen ersetzt. An einigen 
Stellen des Halsteils sind kleine Zellschwärme von Plasmazellen und Lymphozyten erkennbar.

Adyentitia: Während am Halsteile nux viele Vasa vasorum stark verdickt und ihre Lumina verengt sind, sind sie in der übrigen Aneurysmawand ganz obliteriert. In der Adventitia fallen auch viele makroskopisch schon erkennbare Zellanhäufungen auf, welche aus Plasmazellen und Lymphozyten zusarnmengesetzt sind, und besonders große Zellherde, welche hauptsächlich aus Lymphozyten bestehen, aber von einem Ring von Plasmazellen umgeben sind. Mastzellen sind viel nachweisbar.

Fall 66. M. S., Werkführer, 44 Jahre.

Klinische Diagnose: Luetische Aorteninsuffizienz. Leberzirrhose, Ren granularis, Arteriosklerose.

Infektion: 1892 Schanker; angeblich ausgeheilt. Alkohol: früher 5 Flaschen Bier, 3 Schnäpse täglich. Nikotin: 5 Zigarren.

Wassermannsehe Reaktion fehit. Am 5. Juni Exitus letalis.

S.-Nr. 661; 1912. Obduktion 6. Juni ( $\mathrm{K}$ a is e $\mathrm{rling}$ ).

Sektionsdiagnose: Syphilitische Aortitis mit geringer Stenose und Retraktion der Aortenklappen; Hypertrophie und Dilatation beider Ventrikel, besonders links, teilweise fibröse Umwandlung des hinteren Papillarmuskels, multiple Schwielen in dem vorderen Papillarmuskel, hyokaxditis; Sklerose der Koronararterien; Tracheobronchitis catarrhalis. Indurierte, leicht granulierte Staungsnieren; indurierte Stauungsmilz. Unregelmäßige Stauungsatrophie, Verfettung und Ikterus der Leber. Schwere hämorrhagische, pseudomembranöse Enteritis bis zur lleozökalklappe, starke Pigmentierung des Dickdarmes. Hyperämie der Ureteren und des Blasenhalses; Lungenödem. Hoden und Nebenhoden o. B. Starke Dilatation der Karotiden mit Sklerose ind Lipoidosis, Thromben im linken Herzohr.

Die Präparate I sind einer Stelle der Pars ascendens entnommen, die grauweilliche, strahlige, narbige Einziehungen und starke Verdickung der Adventitia zeigt.

Mikroskopischer Befund.

Präparate I (Pars ascendens). Intima: Sie zeigt stellenweise leichte Verdickung. An einer längeren Strecke der Intima, die dem nachstehend beschriebenen großen Herd der Media entspricht, bemerkt man viele Gruppen von Plasmazellen und wenig Lymphozyten, auch stark dilatierte Gefäße. Im übrigen sieht man keine degenerativen Veränderungen.

Media: Sie ist erheblich geschädigt, sogar herdweise ganz zerströt. Diese Herde haben große Defekte der Muskel- sowie elastischen Fasern hervorgerufen, an ihrer Stelle findet sich hauptsächlich ganz frisches Granulationsgewebe und gruppenweise auftretende Plasmazellen und Lymphozyten. In den so veränderten Teilen sind nicht nur viele neugebildete, sondern auch stark verdickte Gefäße erkenmbar. In der Nähe dieser Herde finden sich große Blutungen, daneben viel 33lutpigment. Einige Vasa vasorum, die an der Grenzschicht der Media und Adventitia liegen, sind infolge der Wucherung der Intima ganz obliteriert. In dieser Grenzsehicht sieht man viele langgestreckte Zellanhäufungen, vorwiegend in der Umgebung der Vasa vasorum, die sich vielfach won hier mit den Gefäßen in die Media hinein erstrecken.

Adventitia: In der Adventitia fällt die Neubildung von adventitiellem Bindegewebe auf, so daß die Adventitia das vielfache (etwa das $5-6$ fache) ihrer normalen Breite erreicht. In dieser verbreiterten Adventitia finden sich anch zahlreiche verdickte und obliterierte GefäBbe, welche von so zahlreichen in getrennten Gruppen angeordneten Lymphozyten und Plasmazellen umgeben sind, daßs sie schon makroskopisch als Pünktchen sichtbar sind. Man sieht anch ein einzeines Lymphknötchen, an dessen Rand eine Gruppe von Plasmazellen liegt. Um die Nerven herum bestehen ebenfalls Infiltrate. Mastzellen sind hier und da nachweisbar. 
Fall 67. A. W., Altsitzersfrau, 62 Jahre.

Klimische Diagnose: Dementia postthrombotica. Multiple Hirnthrombose. Lungenentzündung. Partus 3, alle Kinder leben.

Wassermannsche Reaktion fehlt. Exitus letalis am 17. November 1909.

S.-Nr. 1314; 1909. Obduktion 18. November (Rheind orf).

Pathologisch-anatomische Diagnose: Geringes Himgewioht $(1140 \mathrm{~g})$. Ftat criblé an verschiedenen Stellen der weißen Hirnsubstanz, besonders im linken Schläfenlappen. Hydrocephalus internus besonders stark links mit Ependymgranulationen. In den unteren Lungenlappen, besonders den linken, Hypostase, Ödem und beginnende hypostatische Pneumonie, sehr starke Skleratherose der Aorta, besonders im Anfangsteil, wo die Wand etwa $3 \mathrm{~mm}$ dick and auf dem Querschnitt die Media nicht zu erkennen ist. Steine in der Gallenblase. Kleines Lipom in der Rinde der rechten Niere. Schwere parenchynatöse Degeneration dex Nieren.

Präparate I und II sind einer grauweißlichen Stelle mit vielen Runzeln entnommen; Präparate I sind der Pars ascendens, Präparate II der Pars descendens entnommen.

\section{Mikroskopischer Befund.}

Präparate I (Pars ascendens). Intima ist überall etwas verdiclst und man sieht auf eine lange Strecke hin viele feine flache und tiefere Einziehungen, die den makroskopisch sichtbaren Längsfurchen entsprechen. An einer Stelle tritt eine geringe kleinzellige Infiltration auf.

Media zeigt in dem ganzen Präparat ausgedehnte narbige und infiltrierte Herde, die beide die elastischen Fasern stark zerstört haben. Einige der narbigen Herde haben fast die ganze Mediaschieht ergriffen. Am Rande der Herde sind die Enden der elastischez Fasern entweder zusammengedrängt oder diese werden allmählich immer feiner und verlieren ihre Färbbarkeit. In den Herden selbst sind Reste derselben als einzelne kurze Fasern, gewundene Trümmer oder inselförmige Pakete vorhanden. An dem Grenzgebiet der Intima und Media ist teils nur ein dünner elastischer Faserstreifen sichtbar, teils sind gar keine elastischen Fasem mehr da. Dafür sieht man stark erweiterte Gefäße, von denen zwei von Infiltrationen aus Lymphozyten and Plasmazellen umgeben sind. Die Infiltrationsherde in der Media selbst bestehen aus reichlichen Plasmazellen und wenigen Lymphozyten, auch in diesen Infiltrationen finden sich viele Gefäße und Reste der elastischen Fasern. Mastzellen sind sehr selten.

Adventitia: Die Veränderungen in der Adventitia sird gering. An mehreren Stellen sieht man perivaskuläre, ziemlich starke Infiltrationen aus Lymphozyten und wenigen Plasmazellen. Zwei Vasa vasorum sind verdickt. Nerven frei von Infiltration.

Präparate II. Veränderung fast gleich wie in den Präparaten I.

F all 68. Frau H., Arbeiterswitwe, 52 Jahre.

Klinische Diagnose: Tabes incipiens mit Optikusatrophie. Vestibuläre Halluzinationen, Pleuritis. Bronchopneumonie.

S.-Nr. 1459; 1909. Obduktion 27. Dezember ( H e m m e).

Pathologisch-anatomische Diagnose: Piä̈dem. Arteriosklerose der Hirngefäße. Knochenplatten in der Dura. Rückenmark makroskopisch o. V. Bronchopneumonie im linken Unterlappen, schwere Bronchitis, geringe pleuritische Verwachsungen beiderseits. Schwere Arterioskjerose der Aorta. Stauungsorgane. Schlaffe Milz. Uterus myomatos.

Präparate I sind einer leicht verdickten Stelle der Aorta ascendens entnommen, die hier eine Kalkablagerung zeigt.

Mikraskopischer Befund.

Präparate I (Pars ascendens). Intima mäBig stark verdickt mit mehreren Vertiefungen; eine Stelle hat eine große, einige andere Stellen haben viele kleine Kalkablagerungen in Form 
kleiner Krümchen. Im tiefsten Intimateil sieht man drei atheromatöse Herde mit Einlagerung von Cholestearinkristallen. Elastische Fasern sind auch neugebildet.

Media ist in vielen Stellen durch narbiges Gewebe zerstört, und zwar meistens in dem adventitiawärts liegenden Teil. Der unter den Falten der Intima liegende Teil der Media zeigt keine Veränderung. In den Erkrankungsherden sind die elastischen Fasern zum Teil verschwunden, teilweise stark aufgelockert und geschlängelt. In einem Herde, wo narbiges Gewebe entwickelt ist, ist die Grenze zwischen Media und Adventitia ganz unkenntlich, und sind nur Reste der elastischen Fasem spärlich erkennbar. Infiltrationen relativ gering, bestehen aus Plasmazellen und Lymphozyten. Nur wenige Mastzellen. An dem dicht unter dem atheromatösen Herde liegenden Teil der Media bemerkt man mehrere ganz kleine Kalkablagerungen.

Adventitia: In der Adventitia fallen zahlreiche versehieden groBe, schon mit blo Bem Auge erkennbare perivaskuläre Infiltrate auf. Wührend die kleinen Infiltrate meistens an der Grenze zwischen Media und Adventitia dicht aneinanderliegen und fast nur aus Plasmazellen bestehen, sind zahlreiche große umschriebene Infiltrate hauptsächlich aus Lymphozyten zusammengesetzt, an deren Rande viele Plasmazellen liegen, die manchmal um die Kapillaren herum rosettenartig angeordnet sind. Die Vasa vasorum sind stark entwickelt, einjge endarteriitisch verändert. Ino allgemeinen zeigen die kollagenen Fasern der Adventitia gleichmäßig glasige Beschaffenheit. Mastzellen sind viel vorhanden.

Präparate II sind einer beetartigen Verdickung entnommen, die mit zahlreichen Falten ungeben ist.

Präparate II (Pars descendens). Intima zeigt eine große Anzahl von flachen und tieferen Falten. An einer Stelle findet sich eine sehr starke Verdickung der Intima, im Anschluß daran treten wieder die oben besehriebenen Falten auf (makroskopisch entspricht die Verdickung einer beetartigen Erhebung, die Falten den Runzeln, welche die Intima aufweist). Elastische Fasern sind lamellenartig stark entwiekelt, besonders in dem die Falten zeigenden Teil haben diese Fasern auch die gleiche Faltenform angenommen. In der innersten Sehicht der oben erwähnten beetartigen Erhebung der Intima bemerkt man einen atheromatösen Herd.

Media: An manchen Stellen sind die elastischen Fasern ebenfalls stark aufgelockert und sogar vollständig zerstört, wie diejenigen in den Präparaten I; besonders in dem der beetartigen Erhebung entsprechenden Teil der Media ist diese Veränderung ausgeprägt. Im Bereich dieser Veränderung findet sich frisches Granulationsgewebe mit vielen Gefäßen, welche von Infiltrationen umgeben sind, und zum Teil narbiges Gewebe. Die Infiltrationen aus Plasmazellen sind stärker als in den Präparaten I. Mastzellen sieht maz in den Herden der Media sehr wenig.

Adventitia: Die GefäBe der Adventitia sind viel stärker als bei den Präparaten I entwickelt, und zeigen vielfach eine Wandverdickung, sogar Verschluß des Lumens. Viele Gefäßje sind stark gefüllt und von zahleichen Zellanhäufungen umgeben. - Diese Anhäufungen sind manehmal so grob, da.B sie schon makroskopisch sichtbar sind, und bei 100 facher Vergrößerung ein Gesichtsfeld füllen. Am Rande dieser großen Infiltrationen sind nur sehr wenige Plasmazellen, doch bestehen die kleinen Infiltrate aussehliebich aus diesen. Hier und da sieht man die Plasmazellen in rosettenartiger Anordnung, Mastzellen trifft man sehr viel an.

Fall 69. R. S., Oberbahnassistent, 49 Jahre.

Klinische Diagnose: Dementia paralytica.

Wassermannsche Reaktion fehlt. Exitus letalis ana 3. April 1912.

S.-Nr. 404; 1912. Obduktion 3. April ( Ce elen).

Pathologisch-anatomische Diagnose: Dementia paralytica, Tabes dorsalis, chronische Leptomeningitis cerebrospinalis; syphilitische Aortitis besonders im Arkus und oberen Bauchteil; Sklerose der Koronararterien, chronische Endocarditis fibrosa mitralis; Hypertrophie des linken Ventrikels; Tonsillitis, starkes Odem des Zäptehens; parenchymatöse Degeneration der Leber; Enteritis 
nodularis; im unteren Teil des Riuckenmarks in den Hintersträngen reichliche Mengen Kömchenkugeln; in oberen Teil weniger.

Präparate I sind einer grauweißlichen, glasigen Stelle des Arcus aortae entnommen, während die Präparate II von einer fein gerunzelten Stelle der Pars thoracica stammen.

\section{Mikroskopiseher Befund.}

Präparate I (Arcus aortae). Intima zeigt allenthalben mäBjg starke Verdickung ohne degenerative Erscheinungen. An einigen Stellen sind Rundzelleninfiltrate aufgetreten, an einer Stelle wenige Plasmazellen.

Media: ist wenig verändext, sie enthazt hier und da kleine Zellherde und viele Gefarise. Die elastischen Fasern sind fast unverändert.

In der Adventitia fallen zahlreiche stark dilatierte, mit Blut strotzend gefüllte Vasa vasorum auf; obliterierte Gefäße sind wenig nachweisbar. Perivaskuläre Infiltrationen, die aus Plasmazellen und Lymphozyten bestehen, sind geringfügig. Mastzellen sind wenig vorhanden.

Präparate II (Pars descendens). Intima: Die mäBig stark sklerotisch veränderte Intima weist viele flache und tiefere Einsenkungen, entsprechend den makroskopisch sichtbaren Falten, anf.

Media: Während der den flachen Einsenkungen der Intima entsprechende Teil der Media einige kleine Zellherde zeigt und die Intima daselbst sich stellenweise vor der Media unter Lückenbildung ablöst, weist der unter den tieferen Einsenknngen der Intima gelegene Mediateil keine Schädigung auf, sondern zeigt nur die Wellenform, die den Falten der Intima entsprechend ist. Zwischen Intima und Media sieht man an einer Stelle viele, stark erweiterte und gefüllte Gefäßse; der diesem Herde entsprechende Intimaabschnitt zeigt eine starke Vertiefung.

Die Adventitia ist mit vielen, mäßig großen Schwärmen von Lymphozyten und Plasmazellen durchsetzt. Die Gefäßveränderungen sind dieselben wie die in den Präparaten I.

Fall 70. F. O., Schlosserfran, 40 Jahre.

Klinische Diagnose: Phthisis pulmonum.

Partus 2, Abort 4. Infektion: negiert.

Wassermannsche Reaktion noch nicht ausgefuhrt. Exitus letalis am 4. Juni 1903.

S.-Nr. 534; 1903. Obduktion 5. Juni ( David s o h n).

Pathologisch-anatomische Diagnose: Aortenaneurysma, Lungenschwindsucht, Darmtuberkulose, braume Gehimerweichung.

Der Arcus aortae zeigt am Abgang des Aneurysma eine Ausbuchtung, welche mit Speckgerinnsel gefiullt ist. Der oben erwähnte faustgrobe Tumor, der der Ansbuchtrung entspricht, hat vome eine bonzentrisch geschichtete hell und rot gestreifte bis $21 / 2 \mathrm{~cm}$ dicise Wand, ist inzerk von einem weichen geschichteten Gerimsel von ApfelgröBe eingenommen, vor den das oben erwähnte Speckgerinnsel liegt.

Aorta thoracica descendens und abdominal. glattwandig, $4 \frac{1}{2} \mathrm{~cm}$.

Präparatte I sind der faltenreichen, etwas verdickten Stelle der Aorta ascendens entnommen. Präparate II sind der Aneurysmagegend entnommen.

\section{Mikroskopischer Befund.}

Präparate I (Pars ascendens). Intima: In Anfangsteile dieses Schnittes ist die Intima ziemlich normal, nur ganz wenig verdickt, doch sehr faltenreich; in ihrem weiteren Verlaufe zeigt sie eine gleichmäBig anstejgende, immer stärker werdende Verdickrung, mit vielen kleinen unregelmäßigen Falten. Unter dem stärlksten Verdickungsteil sind die elastischen Fasem neugebildet, und seine Oberfläche sieht nicht derb aus.

Media: Der unter dem wenig verdickten, faltenreichen Intimateil liegende Mediateil ist ganz normal und zeigt keine Veränderung. Perivaskuläre Zellherde sind im übrigen Teil dex Media 
eingestreut; sie bestehen aus wenigen Iymphozyten und vielen Plasmazellen. Eine große, schon makroskopisch sichtbare Schwiele findet sich adventitiawärts gelegen onne Infiltration.

Adventitia: In der Adventitia sind Bindegewebsfasern mäBig stark entwickelt, ebenso stellenweise elastische Fasern. Obliterierte sowie verdickte GefäBe sind in gleicher Menge hier und da vorhanden, auch finden sich zahlreiche dilatierte Kapillaren. Infiltrationen sind verhältnismäßig wenig sichtbar, sie bestehen aus Plasmazellen und Lymphozyten. Die Umgebung der Nerven ist frei von Infiltration. Mastzellen nur sehr wenig.

Präparate II (Aneurysmagegend). Intima zeigt an einer Stelle eine stark höckerige Verdickung; in dem übrigen Teil ist sie ziemlich gleichmäßig verdickt bis auf eine kleine, scharf begrenzte Kalkablagerung hart an der Mediagrenze ohne degenerative Erscheinungen. An einer Stelle sind einige elastische Lamellen neugebildet.

Media: In dex dem stark höckerigen Intimateil entsprechenden Media hat sich reichliches Narbengewebe zum Teil frisches Granulationsgewebe gebildet; dort sieht man auch viele Trümmer elastischer Fasern. Die Media verschmälert sich allmählich strangartig, um weiterhin, in der Nähe der oben genannten kleinen Kalkablagerung, eine vollständige Unterbrechung zu erleiden. Hier sind die Bindegewebszüge der Intima und Adventitia direkt miteinander verbunden. Nur ein kurzer Mediateil zeigt kleine Infiltrationen.

Adventitia: Die Adventitia hat im allgemeinen wenig Infiltrationen; diese bestehen hauptsächlich aus Lymphozyten und sehr wenigen Plasmazellen. Im übrigen zeigt sie die gleichen Verhältnisse wie in den Präparaten I.

F a ll 71. Frau A., Schneiderin, 39 Jahre.

Klinische Diagnose: Aorteninsuffizienz, hypostatische Pneumonie, Embolie der linken Bracchialis.

S.-Nr. 924; 1904. Obdulktion 6. August ( W e s t e n h o e f e r).

Pathologisch-anatomische Diagnose: Endocarditis chronica fibrosa aortica retrahens. Endaortitis chronica deformans. (Syphilis?) Hyperostosis calcar. Haemorrhagia lobi occipit. sinist. Oedema flavum et Icterus eiusdem regionis. Alte und frische Infarkte der linken U. L. Braune Induration der Lunge. Hypertrophie, Dilatation und Verfettung des Herzens. Thrombose der linken Vena brachialis, femoralis und der rechten Vena saphena. Stauungsmilz, -leber, -nieren. Epithelnekrose und verkalkte Zysten der Nierenwände.

Präparate I sind der verdickten, zum Teil narbigen Stelle dicht oberhalb der Klappen entnommen. Präparate II sind der Pars descendens, von einer ebenso erkrankten Stelle wie die für die Präparate I entnommen.

\section{Mikroskopischer Befund.}

Präparate I (Pars ascendens). Intima: Sie ist stellenweise leicht verdickt mit Infiltration aus Lymphozyten und wenig Plasmazellen.

Media: Sie enthält hier und da große Erkrankungsherde, die bereits makroskopisch erkemnbar sind. Die oben genannten Herde bestehen aus großen Schwielen, zumTeil aus gefäßreichem, frischem Granulationsgewebe und Zellanhüufungen. Die am meisten ausgedehnte Schwiele liegt auf der Grenze von Intima and Media und enthält viele Reste von elastischen Fasern. Dicht oberhalb dieser Schwiele sieht man (bei roter Elastikafärbung) eine intensiv rot gefärbte elastische Lamelle, die stark geschlängelt ist und plötzlich verschwindet. Dicht unterhalb der großen Schwiele findet sich ein mäßig ausgedehnter, viele, bisweilen verdickte Gefäße enthaltender Zellherd, der mit Plasmazellen übersät ist und auch Lymphozyten in geringerer Zahl enthält. An anderen Präparaten ist dieser Herd sehr groß und makroskopisch bereits sichtbar. An einer anderen Stelle ist ein gro Ber, mit bloBem Auge erkennbarer Herd vorhanden, der zum Teil aus schwieligem und Granulationsgewebe, zum Teil aus großen Gruppen von Plasmazellen mit wenigen Lymphozyten besteht. Die hier befindlichen Gefäße sind von Plasmazellen und Lymphozyten umgeben und gehen bis an die 
Intima heran, die ihre normale Breite hier stark überschreitet. Innerhalb dieses Herdes sieht man gar keine elastischen Fasern, an seiner Grenze sind sie zum Teil bündelartig zusammengedrängt und umgeschlagen. Die oben erwähnten zwei großen Herde haben in ihrer Umgebung noch große Zellanhäufungen aus Plasmazellen mit wenigen Lymphozyten, in ihrem Bereich sind die elastischen Fasern stark zerstört. Mastzellen sind sehr spärlich vorhanden.

Adventitia: In der Adventitia fallen viele aneinanderliegende makroskopisch sichtbare Zellherde auf, die meist im Zentrum Lymphozyten, in der Peripherie reichlich Plasmazellen haben, doch sieht man auch Infiltrate, die zur Hälfte aus Plasmazellen, zur anderen aus Lymphozyten zusammengesetzt sind. Es findet sich ein adventitielles Lymphknötehen, das in seiner Umgebung Plasmazellen in mäBiger Menge aufweist. Viele Vasa vasorum zeigen starke Verdickung der Wandung, sogar totalen Verschiuß des Lumens mit Zellinfiltration. Die gesunden Gefüße sind alle stark gefüllt. Um die Nerven besteht keine Infiltration. Nastzellen sind viel nachweisbar, auch im Perineurim. In der Adventitia sind Bindegewebsfasern und elastische Fasern mäBig stark neugebildet. Die A. pulmonalis, die ich mit der Aorta zusammen geschnitten habe, zeigt gar keine Veränderung.

Präparate II (Pars descendens) wie I.

Fall 72. Frau N., Schleifersfran, 42 Jahre.

Klinische Diagnose: Herzfehler, Wassersucht.

S.-NTr. 194; 1907. Obduktion 18. Februar (Staatsprüfung).

Pathologisch-anatomische Diagnose: Allgemeine Wassersucht. Starke Vergrößerung des Herzens, besonders des linken Ventrikels, der dilatiert und hypertrophiert ist; Papillarmuskel abgeplattet, Mitralsegel wenig verdickt mit je einer zottigen, kalkigen Warze an der Vorhofseite; Aortensegel verdickt, verkürzt, verwachsen, am stärksten verändert das linke, an dessen beiden Ansatzstellen große zottige harte Hervorragungen sichtbar sind. Starke, aber fleckweise skleratheromatöse Verdickungen der Aorta; ïber der Vereinigungsstelle des linken und rechten Segels, auch an ihrex Oberfläche in einer Ausdehnung von etwa $1 \mathrm{~cm}$ Länge und $1 / 2 \mathrm{~cm}$ Breite eine stacblige, harte Hervorragung. Erweichte Thromben im rechten Herzohr, Hypertrophie der rechten Kammer, hämorrhagische Infarkte in den Iungen, besonders links; exsudative Pleuritis links, Kollaps des linken, unteren Lappens. Stauungsmilz; alte Niereninfarkte. Harnsäure- nnd Kalkabscheidungen in Nieren und Nierenbecken. Markfibrom, Phlebektasien in den Markkegeln. Kolpitis emphysema. tosa. Portio-Erosion. Alte perimetritische Narben. Fibröse Degeneration der Ovarien. Ulcus votundum des Pylorus. Zwei Schleimhantgeschwüre des Duodenum. Muskatnußleber. Darmhyperämie.

Präparate I sind einer zirkumskripten, teilweise faltigen, verdickten Stelle des Areus aortae entnommen.

Mikroskopischer Befwnd.

Präparate I (Arcus aortae). Intima stellenweise ziemlich stark verdickt und derb aussehend. Die verdickte Intima zeigt stellenweise verschieden tiefe Falten; man sieht nirgends Frweichungsherde.

Media: Der der verdickten Partie der Intima anliegende Teil der Media ist iberall stark verändert. An den Präparaten mit van Gies on - Färbung sieht man die Veränderungen sehr deutich; die gelbgefärbte Mediaschicht ist auf lange Strecken bis auf ganz feine Fäden verschmälert, teilweise sogar vollständig unterbrochen. Die elastischen Fasern sind ebenso wie die Nuskelschicht stark verschmälert oder zerstört, ihre Reste zeigen sich als ganz schmale oder feine Fäden (hier sieht man bei starker Vergrößerung, daß die Reste einiger elastischen Fasern stark geschlängelt oder ballenartig gerollt sind), die vor ihrem völigen Verschwinden streckenweise unterbrochen sind. In den oben beschriebenen ausgedehnten Herden tritt derbes Bindegewebe in großer Ausdehnung auf, zum Teil auch Granulationsgewebe und geringe Infiltrationen aus Plasmazellen und Lymphozyten. Mitunter finden sich neugebildete Gefäße mit perivaskulärer 
Infiltration. Die unter den Falten der Intima liegende Partie der Media zeigt nur mäBig starke Zerstörung der elastischen Fasern.

Adventitia: Gefäße stark entwickelt, meist von Zellinfiltrationen umgeben, die manchmal schon mit blo Bem Auge erkennbar sind und meist aus Lymphozyten, am Rande aus Plasmazellen, bestehen. Einige Vasa vasorum stark verdickt. Nerven frei von Infiltration. Mastzellen nur wenig. Das adventitielle Bindegewebe ist stark entwickelt.

F all 73. Frau B., Monteursfrau, 44 Jahre.

Klinische Diagnose: Herzsehwäche infolge HerzgefäBverkalkung (Koronarshlerose).

S.-Nr. 166; 1910. Obduktion 4. Juli (Beitzke).

Pathologisch-anatomische Diagnose: Fettherz mit starker fettiger Degeneration. Aortitis fibrosa. Lungenödem, Bronchitis. Gallensteine. Alte Ovarialzyste links. Parovarialzysten beiderseits, chronische Metritis und Endometritis, chronische Gastritis. Verkalkte Bronchialdrüsen links.

Aorta ascendens leicht ausgebuchtet, Umfang dicht äber den Klappen $8 \mathrm{~cm}$, Wand bis $5 \mathrm{~mm}$ dick. Innenfäche stark gerunzelt, hanfkorn- bis pfennigstückgroße, flache Buckeln wechseln mit tiefen vielfach verästelten und anastomosierenden Furchen.

Arcus aortae ähnlich wie Aorta ascendens. Unterhalb des Artsus und beim Übergang in die größeren Arterien der oberen Körperhälfte hört die Veränderung rasch auf.

Bauchaorta zeigt an der Intima einzelne kleine gelbe, Ieichterhabene Fleckchen.

Präparate I sind einer stark gerunzelten, flachbuckligen Partie der Aorta ascendens entnommen. Präparate II sind der Pars descendens entnommen, einer grawweiblichen, fleckigen Steile.

Mikroskopischer Befund.

Präparate I (Pars ascendens). Intima stellenweise stark sklerotisch, und ihre Oberfläche ist uneben (Falten). Man sieht in ihr mehrere ïbereinandergelegene, lamellenartige, neugebildete elastische Fasern und zerstreut Infiltrate aus Lymphozyten und Plasmazellen.

Media: Während die Zerstörung der elastischen Fasern gering ist, bemerkt man an vielen Stellen mäBig starke perivaskuläre Infiltrationen aus Plasmazellen und Lymphozyten, teilweise nur aus Plasmazellen. Hier und da finden sich diese strangartig in den Lymphräumen angeordnet. Mastzellen sind sehr wenig vorhanden.

Adventitia: Gefäße in der Adventitia sind kolossal entwickelt, viele stark verdickt; einige Gefäße zeigen deutlich starke Spaltung und Auflockerung der elastischen Lamellen der Wandung, sogar vollständige Obliteration des Lumens. Hier und da finden sich, mit bloßem Auge sichtbare lymphknotenartige zirkumskripte Infiltrate ans Lymphozyten; am Rande derselben treten auch viele Plasmazellen, zum Teil gruppenweise, zum Teil zerstreut auf; besonders bemerkt man hier die Kapillaren von einer Reihe Plasmazellen rosettenartig umkränzt. Auch die übrigen kleinєn Zellanhäufungen bestehen meist aus Plasmazellen. Adventitielle Lymphknötchen findet ran von Plasmazellen umgeben, Nerven gleiehfalls. Mastzellen sind sehr viel vorhanden. In der Adventitia bemerkt man neugebildete Bindegewebs- und elastische Fasern.

Präparate II (Pars descendens). Abgesehen von der stärkeren Veränderung der Media, besonders des intimawürts liegenden Mediateiles, zeigen Präparate II die gleichen Verhältnisce wie Präparate I, nur weist die Intima an. Stelle der Infiltrate ans PIasmazellen und Lymphozyten ausschlieBlich solche aus letzteren auf.

F all 74. Frau D., Graveursfrau, 66 Jahre.

Klinische Diagnose: Apoplexie (Thrombosen). Multiple Erweichungsherde des Gehirns. Wassermannsche Reaktion fehlt. Exitus letalis am 9. Juli 1910.

S.-Nr. 797; 1910. Obduktion 11. Juli (Orth).

Pathologisch-anatomische Diagnose: Kleine flache Blutungen in den Weichteilen des Schädels, embolische Verstopfung der linken Karotis und der A. cerebri media mit beginnender Erweichung in der Hemisphärə und den großen Ganglien. Kleine Zysten im Marklager des rechten 
Okzipitallappens, Oberflächliche Zyste am vorderen Ende des linken Temporallappens. Ödem und mäBiger Blutreichtum des Gehirns. Piaödem, umschriebene Leptomeningitis chronica fibrosa, reichliche Arachnoidalzotten, tiefe Grube im rechten Seitenwandbein, innere Exostose der Stirngegend, Pigmentierung der Pia, der Medulla oblongata. Sklerose der Aorta und Karotiden. Lungenembolien, Pneumonie, Hydrops vesicae fell. Zystikusstein, beginnende arteriosklerotische Schrumpinieren, Darmpolypen. Stenose des Orific. ext. uteri.

Aortenintima gelblich weiß, in der Gegend des Bogens ist die Oberfläche der Intima rauh, unregelmäBig; sie weist mehrere bis $5 \mathrm{~mm}$ im Durchmesser haltende, harte, gelbe Einlagerungen auf. Karotiden beiderseits frei, an der Teilungsstelle zeigt die Innenfläche ebenfalls linsengroße, gelbe, harte Einlagerungen. Koronararterien 0. V.

Präparate I sind rauhen, unregelmäBigen Stellen des Arcus aortae entnommen, Präparate II und III der Pars ascendens, von einer gleich beschaffenen Stelle wie I.

\section{Mikroskopischer Befund.}

Präparate I (Arcus aortae). Intima zeigt kleine höckerige Verdickung, zum Teil erhebliche, diffuse sklerotische Verdickungen, die die Breite der Media erreichen. An dieser Partie, und zwar an dem Grenzgebiet zwischen Media und Intima, fallen zahlreiche stark dilatierte Gefäße mit geringen Infiltraten auf. Neugebildete elastische Fasern sind sehr wenig vorhanden.

In der Media ist überall schmales, bandartiges junges Bindegewebe und Schwielen mit Zerstörung und Auflockerung der elastischen Fasern zu erkennen; besonders die Partie der Media, die unter dem gefäßreichen Grenzgebiet zwischen Intima und Media Iiegt, zeigt diese Herde. Außerdem sieht man auch viele Gefäße mit geringen Infiltrationen.

Adventitia: Viele Vasa vasorum sind kolossal dilatiert und mit Blut strotzend gefült. Perivaskuläre Infiltrationen sind sehr wenig vorhanden. Mastzellen ziemlich viel.

Präparate II (Pars descendens). Intima: AuBer geringen Kalk- und Fettablagerungen in einer Stelle der verdickten Intima zeigen alle Schichten (Intima, Media und Adventitia) ganz ähnliche Veränderungen wie diejenigen in den Präparaten 1 .

Präparate III (Pars descendens). Die mikroskopischen Veränderungen sind in allen Schichten stärker wie in den Präparaten I, II, besonders in der Media. Während die Intima an einer Stelle eine atheromatöse Veränderung zeigt, bemerkt man hier und da, besonders in den tiefsten Schichten, frisches Granulationsgewebe mit vielen, zum Teil stark dilatierten Gefäßen; einige davon sind von. der Media bis in die Intima eingedrungen. Hier lassen sich aucl Infiltrate in geringer Zahl nachweisen.

Media: Elastische Fasern sind durch starkes Granulationsgewebe und bandartige Schwielen auseinandergedrängt, zum Teil zerstört.

Adventitia: Die zahlreichen stark dilatierten Gefäße sind strotzend gefüllt. Perivaskuläre Infiltrationen sind nicht so stark vertreten. Mastzellen sind hier und da sichtbar. Die Nerven in der Adventitia sind frei von Infiltrationen.

F all 75. O. Z., Schriftsetzerswitwe, 50 Jahre.

Klinische Diagnose: Myokarditis. Embolie oder Hämorrhagie? der linken Hemisphäre. Arteriosklerose. Nephritis.

Partus: 1. Abort: vor 7 und 8 Jahren je ein Abort. Infektion: negatur.

Wassermannsche Realtion fehlt. Am 1. September 1910 Exitus letalis.

S.-Nr. 1016; 1910, Obduktion 2. September ( $\mathrm{K} \circ 0 \mathrm{~h}$ ).

Pathologisch-anatomische Diagnose: Schwere Aortitis. Thrombose der Aorta, Carot. communis, Interna cerebri media mit beginnender Erweichung des vorderen Teils der linken Hemisphäre. Starke Sklerose der basalen Hirnarterien, Leptomeningitis chron., starke Hyperostosis des Schädeldaches. Starke Hypertrophie beider Ventrikel. Dilatation 1., geringe Endocarditis chron. fibrosa mitral., Thromben in beiden Herzohren. Frische und ätere Schwielen, besonders 
im linken Ventrikel, bei starker Sklerose der A. coronar. und fast völligem VersehluB des Ramus descend. der A. coronar. sinistra. Frischer Milzinfarkt. Thrombose des Stammes und mehrerer Äste der A. mesaraica sup. mit braunroter Infarzierung des größten Teils des Dünndarms. Starkes alveoläres Emphysexn, beginnende Schluckpneumonie, besonders links. Starke chronische Bronchitis. Kleiner verkalkter Herd am unteren Rand des Oberlappens. Stanungsleber, Gallensteine, Stauungsnieren. Uterus myomatosus mit starker Stenose des Zervikalkanals.

Präparate I sind einer weißlich-gelben Erhabenheit mit Runzeln der Aorta ascendens, Präparate II einer transparenten Stelle der Aorta descendens entnommen.

\section{Mikroskopischer Befund.}

Präparate I (Pars ascendens). Intina: Man sieht überall wellenförmige Verdickung der Intima mit. wenigen elastischen Lamellen. An einer Stelle haben sich zahlreiche Schwielen mit wenigen Gefäßen entwickelt; hier besonders finden sich viele Lymphozyten und Plasmazellen, letztere auch in rosettenartiger Anordnung. Die übrigen Partien der Intima enthalten ebenfalls Plasmazellen.

Media: An dem unter den oben beschriebenen schwieligen Herden. liegenden Teil der Media bemerkt man einen derben, kernarmen, schwieligen Herd mit geringer Infiltration. Die übrige Partie der Media zeigt stark vermehrte Gefäße mit perivaskulärer Infiltration aus Plasmazellen und Lymphozyten.

Adventitia: Sie enthält an vielen Stellen verschieden große Zellherde; einige sind makroskopisch bereits sichtbar, und bestehen nur aus Lymphozyten; Plasmazellen sind sebr spärlich. Dagegen sind die Zellen in den kleinen Herden und in den interstitiellen Lymphräumen durchweg Plasmazellen. Einige verdickte oder obliterierte Gefäße sind nachweisbar. Um die Nerven besteht kein Infiltrat. Mastzellen sind ziemlich viel vorhanden.

Präparate II (Pars descendens). Intima zeigt an einer Stelle geringgradige skleratheromatöse Veränderung mit Kalkablagerung. Die mikroskopischen Veränderungen der Media und Adventitia sind weniger hochgradig als in den Präparaten $\mathrm{I}$.

F a I 76 . A. L., Maurerswitwe, 56 Jahre.

Klinische Diagnose: Arteriosklerose.

Wassermannsche Reaktion fehlt. Exitus Ietalis am 23. September 1910.

S.-Nr. 1108; 1910. Obduktion 24. September ( M a r tin).

Pathologisch-anatomische Diagnose: Arteriosklerose der Aorta mit Aneurysma am Arcus aortae, der Pulmonalarterien, Basalgefäße; Verdickung der Aortenklappen. Erweiternng des linken Ventrikels. Stauungsmilz. Beginnende Granularatrophie der Nieren. Geringe Fettleber.

In der Pulmonalis weist die Intima ausgedehnte gelbe und weiße verhärtete Flecken auf. Die Intima der Aorta zeigt dieselbe Veränderung in verstärktem Maße mit Defekten in der Oberfläche.

Die Aorta zeigt in ihrem ganzen Verlaufe gelbe bis weiße verhärtete Flächen in der Intima, an denen besonders am Aortenbogen und am Lambalteile bis linsengroße Defekte der Intima sichtbar sind.

Präparate I sind einem zirkumskripten, glasigen Teil der Pars ascendens entnommen. Präparate II sind der Aorta descendens, und zwar einer narbigen, zum Teil gelblichen Stelle entnommen.

\section{Mikroskopischer Befund.}

Präparate I (Pars ascendens). Intima ist gleichmäBig leicht verdicht mit geringer Rundzelleninfiltration.

Media zeigt ganz eigentiümliche Veränderungen, indem sie in ihrem ganzen Verlauf eine vollständige Zerstörung der elastischen Fasern aufweist. Die Reste dieser Fasern sind überall 
als kleine Trümmer oder als einzelne kurze Fäden vorhanden, dazwischen sieht man ausgedehntes frisches Granulationsgewebe, daneben fallen zahlreiche neugebildete, stark erweiterte Grefäße auf. Teilweise sind in diesen Herden die glatten Muskelfasern noch erhalten. Man sieht in der Media nur eine einzelne ganz kleine perivaskuläie Infiltration aus wenigen Plasmazellen.

Adventitia: Kernarme, bindegewebige Substanz ist mäßig stark entwickelt. Hier und dort finden sich sehr lang ausgestreckte Infiltrate aus Lymphozyten und wenigen Plasmazellen. Einige. Gefäß乃e zeigen endarteriitische Veränderung. In der Nähe der Adventitia sieht man einen linsengroßen Lymphknoten, der zahllose Plasmazellen und Kohlenpigmente enthält. Die Plasmazellen finden sich meist in den Lymphknötchen und auch in der Kapsel. In dem Lyrophsinus findet man nur wenige Plasmazellen. Mastzellen sind viel nachweisbar.

Präparate II (Pars descendens). Intima zeigt zwei hügelartige Verdickungen, zwischen. denen sich ein fast normaler Teil befindet. In den verdickten Partien finden sich geringe Kalk ablagerungen.

Media: Auch hier zeigt die Media auBerordentlich schwere Veränderungen, indem sie íast in ihrem ganzen Verlaufe Schädigungen aufweist. Es findet sich kaum eine Stelle, an welcher die elastischen. Fasern nicht unterbrochen oder zerstört sind. An der am schwersten geschädigten Stelle finden sich nur noch Trümmer von elastischen Fasern. Zwischen dieselben eingestrent sieht man reichlich zellige Infiltrationen, die sich meist aus Plasmazellen und Lymphozyten zusammensetzen, deren Zahl, wie ihr jeweiliges Auftreten, ganz verschieden ist. In allen den Herden, in denen die elastischen Fasern stark zerstört sind, treten Schwielen in verschiedenem Grade aul. GetäBe sind reichlich entwickelt, von denen viele mit Plasmazellen umgeben sind.

Adventitia: Man sieht viele verdickte Gefäße mit zahllosen Lymphozyten und Plasmazellen in mäbiger Menge umgeben. An anderen Stellen fallen die vielen, schon makroskopiseh sichtbaren lymphknötchenähnlichen. Infiltrationen auf, welche sich aus sehr vielen Lymphozyten und meist in der Peripherie befindlichen Plasmazellen zusammensetzen. Die adventitiellen Nerven sind auch mit gleichen Zellanhäufungen umgeben. Mastzellen viel vorhanden. Die adventitiellen Bindegewebsfasern sind stark vermehrt.

F a 11 77. Frau G., Schneidersfrau, 53 Jahre.

Klinische Diagnose: Herzîehler (Insufficient. valvulare Aortae. Aneurysma?).

S. -Nr. 1254; 1911. Obduktion 29. Oktober (B eitzke).

Pathologisch-anatomische Diagnose: Schwere chronische retrahierende Endocarditis aortica mit Inkontinenz des Ostium. Aortitis fibrosa. Partielle Atrophie des Zungengrundes. Kalkherde mit schiefriger Induration in beiden Spitzen. MäBiges Lungenödem. Alte Verwachsungen im Cayum rectouterinum.

Präparate I und II sind einer diffus weißlichen, transparenten Verdickung der Pars ascendens (I) und descendens (II) entnommen.

Mikroskopischer Befund.

Präparate I (Pars ascendens). Intima im allgemeinen gleichmäßig sklerotisch verdickt; man sieht nirgendwo Erweichungs- oder Degenerationsherde. An einigen Stellen sind neugebildete, lamallenartige elastische Fasern sichtbar, und eine geringe Infiltration nachweisbar (keine Plasma zollen).

Media: An vielen Stellen, besonders dem intimawärts gelegenen Mediateile, finden sich Erkrankungsherde in großer Ausdehnung. Die Muskelschicht und Elastika sind an mehreren Stellen auffällig verschmälert und hier und dort sieht man, daß die einzelnen elastischen Fasem zum Teil zerstört, zum Teil in ihrem Zusammenhang gelockert sind; stellenweise zeigen sie eine starke Verkimmpung. An diesen Stellen vorzugsweise treten Infiltrate hervor, die sich gleichmäBig aus Gruppen von Plasmazellen und einzelstehenden Lymphozyten zusammensetzen. Massen ron diesen Zellen schieben sich zwischen die Fasern hinein und drängen sie auseinander. An der 
schmalsten Stelle der Media, wo sie bis auf etwa die Hälfte ihrer normalen Breite verschr:älert ist, tritt eine außerordentlich dichte, schon mit freiem Auge sichtbare Infiltration aus Plasmazellen und Lymphozyten hervor, welche gewissermaßen den schwer geschädigten Faserresten aufliegt. Hier ist sonst narbiges Gewebe entwickelt, welches auf den Intimateil übergreift. In dem übrigen Teil der Media bemerkt man hier und da kleine Gefäße mit perivaskulären Infiltrationen. Mastzellen sehr wenig.

Adventitia: Ĺberall finden sich Infiltrationen, teils als umschriebene Herde, teils diffus; ihre Menge unterliegt sehr bedeutenden Schwankungen. Schon mit bloßem Auge sieht man einige ganz zirkumskripte lymphknotenartige Infiltrationen, welche meistens aus Lymphozyten bestehen. Plasmazellen sind spärlich am Rande vorhanden. Die übrige Partie enthält sehr viele perivaskuläre Infiltrationsherde, die teilweise nur aus Plasmazellen bestehen. Vasa vasorum finden sich sehr viel; besonders einige in der Nähe der oben erwähnten großen Infiltration liegende Vasa vasorum zeigen eine starke Verdickung der Intima. Das Interstitium des Fettgewebes enthält auch Plasmazellen. Mastzellen sind massenhaft vorhanden, meist ohne Fortsätze.

Präparate II (Pars descendens). Intima ist allgemein verdickt und sieht derb aus. Die Oberfäche der verdickten Intima zeigt längliche, nur wenig hervorragende, dicht aneinanderliegende kleine Höcker (das sind makroskopisch feine Längsfalten), daneben aber noeh bedeutend umfangreichere und viel stärker vorspringende Erhebungen. Die in der Intima neugebildeten elastischen Fasern zeigen einige sehön ausgebildete Lamellen, die in der Mitte des Präparates plötzlich verschwunden sind. In einer tiefer liegenden Stelle der Intima bemerkt man einige stark dilatierte, neugebildete Gefäße, deren Umgebung in großer Ausdehnung von einer kolossalen Menge von Plasmazellen und wenigen Lymphozyten erfüllt ist. Diese Infiltration steht in Zusammenhang mit einem ebenso beschaffenen Herde im Grenzgebiet zwischen Media und Adventitia. Der übrige Teil der Intima enthält an einer Stelle wenige Plasmazellen. Sonst keine degenerativen Vorgänge.

Madia zeigt aucl starke Veränderung wie die Media des I. Präparates. An einer Stelle der Media sieht man einige stark ausgedehnte, fast die ganze innere Mediahälite ergreifende Defekte, die zum Teil zum Verschwinden der elastischen Fasern, zum Teil nur zu deren Auflockerung geführt haben. Hier treten auch frisches Ğranulationsgewebe und zellige Infiltrationen aus Plasmazellen und Lymphozyten auf. Dieses Infiltrat ist nicht so stark wie das im I. Präparat. In dem übrigen Mediateil gibt es hier und dort kleine Herde mit kleinen Gefïßen. Die den oben beschriebenen kleinen Höckern der Intima entsprechende Partie der Media weist keine Veränderung auf. Man trifft einige deutlich sichtbare Mastzellen und Plasmazellgruppen an.

Adventitia: Überall sind reichlich die Adventitiagefäße, welche starke Erweiterung und perivaskuläre Infiltration zeigen, während die gröBeren Infiltrationen meist aus Lymphozyten und wenigen randständigen Plasmazellen bestehen, bestehen die kleinen Infiltrationen meistens nur aus Plasmazellen. Mastzellen sind überall vorhanden.

F a 11 78. W. M., Arbeiter, 58 Jahre.

Klinische Diagnose: Aneurysma aortae.' Pneumonie links. Lungensyphilis rechts.

Infektion: 1872 Tripper?

Wassermannsche Reaktion fehlt. Exitus letalis am 25. Dezember 1910.

S.-Nr. 1462; 1910. Obduktion 29. Dezember ( $\mathrm{L}$ öh e ).

Pathologiseh-anatomische Diagnose: Syphilis, geschwürige Aortitis am Arcus aortae. Perforation in die Trachea. Ausgedehnte Blutaspiration in beiden Lungen. Starkes vesikuläres Emphysem der linken Lunge und fibröse Pneumonie und chronisehe Lymphangitis des größten Teils der rechten Lunge. Bronchektasien im rechten Unterlappen. Narben in der Trachea und im Rachen. Sufiokationsstellung der Epiglottis. Frische Milzschwellung. Zystizerkus in der Pia des Gehirns. 
Der Anfangsteil der Aorta ist weit $(9-13 \mathrm{~cm})$, fühlt sich derb an. Die Innenfläche ist uneben; die Farbe an einzelnen Stellen gelbweiß, an anderen grauweiB. Brustaorta: im Anfangsteil des Bogens findet sich eine bohnengroße Öffnung, deren Rand zackig zerfressen ist; man gelangt durch diese Öffnung in eine Höhle, deren Wandung mit miBfarbenen Massen belegt ist, diese kommuniziert mit der Trachea an einer Stelle, die $3 \mathrm{~cm}$ oberhalb der Bifurkationsstelle gelegen ist. Die Öfnung zeigt auch hier einen zackigen Rand. Von dem oberen Rand dieser Öffnung erstreckt sich naeh oben eine gut markstückgroße, unregelmäBig gestaltete, von einzelnen. Strängen durchzogene narbenartige Partie, die unter dem Niveau der Schleimhaut gelegen ist; sowohl in der Trachea wie in den Bronehien finden sich große schwarze Blutgerinsel.

Präparate I sind einer narbigen Stelle der Pars ascendens, Präparate II dem Arcus aortae an einer unebenen Stelle entnommen.

Nikroskopischer Befund.

Präparate I (Pars ascendens). Intima: Intima, Media und auch Adventitia zeigen hochgradige Veränderungen. Kurzum, die ganze Wand läßt schon makroskopisch zahlreiche diffuse oder scharf begrenzte Erkrankungsherde erkennen. Intima überall ziemlich stark verdickt, mit mehreren lamellenartigen Zügen elastischer Fasern. An zwei oder drei Stellen der tiefsten Schicht der Intima finden sich atheromatöse Herde, welche Kalkmasse enthalten. Noch an anderen Partien der Intima sieht man hier und da zahlreiche kleine Kalkablagerungen. Infiltrationen treten ebenfalls fleckweise in der Intima auf; sie bestehen teilweise aus Plasmazellen. Die Grenze zwischen Intima und Media ist größtenteils ganz undeutlich, da hier an vielen Stellen bald zirkumskripte, bald diffuse Zellinfiltrationen aus Plasmazellen und Lymphozyten auftreten, die nicht nur im Grenzgebiet lokalisiert sind, sondern auch weiter in die Intima hineinreichen; die elastischen Fasern sind in diesen Herden auch stark geschädigt, zum Teil spurlos verschwunden, zum Teil sieht man noch Reste. Man findet sie dann vereinzelt oder büschelweise angeordnet, wnd zwischen diese büschelartigen Fasern sind viele Plasmazellen strangweise infiltriert, so daß sich dieser Teil an den Präparaten mit Pyronin-Methylgrünfärbung ganz hellrot färbt.

Media: Sie ist am schwersten erkrankt; an vielen Stellen ist sie von sehr verschieden groBen Zellherden aus Plasmazellen mit einigen Lymphozyten durchsetzt. Diese Herde sind schon makroskopisch deutlich sichtbar und einige, welche sich in dem intimawärts gelegenen Mediaabschnitte finden, ergreifen nicht nur die Mediahälfte, sondern gehen auch in die Intima über. Die gleichen krankhaften Verhältnisse zeigen sich in dem adventitiawärts gelegenen Mediaabschnitt. Außer diesen Zellherden finden sich zwei nekrotische Herde, von denen einer klein ist und einzelne, schlecht gefärbte Reste der elastischen Fasern enthält; der andere ist sehr groß und nimmt nicht nur die ganze Media ein, sondern greift auch auf die stark verbreiterte Adventitia über. Dieser Herd ist ein Gumma und in weitem Umkreis mit Zellanhäufungen umgeben. Diese Anhäufungen bestehen aus Plasmazellen und wexigen Lymphozyten, daneben auch jungen Bindegewebszellen. Die elastischen Fasern der Media besitzen sehr verschiedene Breite. In den oben beschriebenen Herden sieht man bis auf ganz kleine Reste keine elustischen Fasern mehr. An der Stelle, wo sich das Gumma befindet, sind die elastischen Fasern plötzlich vollständig verschwunden, um jenseits des Gumma in desto größeren Massen aufzutreten; hier aber laufen sie nicht mehr normal, sondern durcheinander, zum Teil als grobe Trümmer oder als ballenartige Klumpen. Mastzellen treten sehr wenig auf.

Adventitia: Bindegewebe und elastische Fasern in der Adventitia überall stark vermehrt; besonders an der Stelle, wo das oben erwähnte Gumma auftritt, sind in erheblicher Ausdehnung zum Teil fertiges Bindegewebe, zum Teil Granulationsgewebe mit spindeligen und ovalen Kernen gebildet. In der Peripherie des Gumma fallen Zellanhäufungen auf, die sich in der Hauptsache aus Plasmazellen mit wenigen Lymphozyten zusammensetzen, teils sogar nur aus Plasmazellen bestehen, letztere finden sich auch in rosettenartiger Anordnung. Die übrige Partie der Adventitia 
enthält hier und dort verschieden starke Zellinfiltrationen, manchmal sind sie schon makroskopiseh erkennbar und bestehen meist aus Plasmazellen und wenigen Lymphozyten. An einer Stelle befinden sich mehrere adventitielle Lymphnoutchen, die in der Peripherie mit vielen Plasmazellen infiltriert sind. Die Vasa vasorum sind mit Blut stark gefüllt und von Zellanhäufungen umgeben, einige zeigen endarteriitische Vexänderungen. In der Umgebung der gummösen Herde bemerkt man viele neugebildete Gefäße. Mastzellen sind stellenweise nachweisbar.

Präparate II (Arcus aortae). Intima: leidet ain imäRiger skleratheromatöser Veränderung. An einer Stelle, dicht an dem atheromatösen Herde ist Kalkmasse abgelagert. In der verdickten Intima finden sich neugebildete elastische Fasern. Hier und da, besonders in dem am stärksten verdickten Teil der Intima, bemerkt man ziemlich starke Infiltration, die außer aus Lymphozyten aus vielen zerstreuten oder zu Gruppen geordneten Plasmazellen besteht; die letzteren sind namentlich in der äußersten Schicht der Intima vorhanden.

Media: Versehiedentlich weist die Media Erkrankungsherde auf, in deren Bereich zum T'Tl frisches Granulationsgewebe, zum Teil Schwielen und Zellinfiltrationen auftreten; hier fehlen dann die elastischen Fasern, oder es finden sich ganz schwach gefärbte Reste. Die einem atheromatösen Herde anliegende elastische Schicht der Međia ist erheblich geschädigt und bis auf etwa ein Drittel der Normalbreite verschmälert. Die unter der am stärksten verdickten Intima liegende Media enthält viele kieine Verkalkungsherde: Hier sind die elastischen Fasern streckenweise stark zerstört und zerbröckelt. Mastzellen nicht za sehen.

Adventitia: Es lassen sich auch schwere Veränderungen nachweisen. Überall treten Infiltrationen aus Plasmazellen und Lymphozyten auf, besonders die dem oben beschriebenen kalkhaltigen Teil der Media anliegende Adventitia zeigt eine ausgedehnte, aus Plasmazellen mit wenigen Lymphozyten zusammengesetzte Infiltration, die mit blokem Auge schon deutlich zu erkennen ist und bei 100facher Vergrößerung ein ganzes Gesichtsíeld völlig einnimmt. Andere gröBere, lymphknötchenartige Infiltrationen bestehen hauptsäehlich aus Lymphozyten, doch findet man am Rande größere Gruppen von Plasmazellen. Vasa vasorum stark entwickelt und manchmal dickwandig. Zwei Nerven in der Adventitja sind mit Plasmazellen umgeben. Mastzellen vorhanden. Die adventitiellen Bindegewebs- und elastischen Fasern sind mägig stark entwickelt.

F a 11 79. H. E., Agent, 49 Jahre.

Klinische Diagnose: Stenose der Atemwege, Bronchopneumonie.

Infektion: Tripper und weicher Schanker konzediert, über Syphilis nichts bekannt.

Wassermannsche Realtion fehlt. Exitus letalis am 9. März 1911.

S.-Nr. 264; 1911. Obduktion 10. März ( M a rtin ).

Pathologisch-anatomische Diagnose: Miultiple Aneurysmen der Aorta und der Arteria anonyma. Zylindrische Erweiterung der Carotis dextra. Mesaortitis, Arteriosklerose der Aorta. Hypertrophie des linken und des rechten Ventrikels. Struma. Parenchymatöse Degeneration. beider Nieren. Gastritis chronica. Bronchopneumonie im linken Unterlappen. Bronchitis, Tracheitis.

Die Aorta ist weit ausgedehnt. Die Wand ist etwa $13 \mathrm{~cm}$ lang. Die Intima ist von lleineren und größeren Atheromen, Löchern und Vertiefungen durchsetzt und mit geraden zum Teil durchsiehtigen, strahlenartig angeordneten Flecken übersät. An der Konvexität des Aortenbogens befindet sich ein deutlich ausgeprägter Ring der Wand mit etwa Einmarkstückumfang, in welchem die Wand weit nach anßen vorgebuchtet und von dunkelbraungrauer Farbe ist. Die Wand ist hier bis über $1 \mathrm{~cm}$ verdickt und von glasig-grauroter Beschaffenheit, Nach außen hebt sich deutlich die ursprïngłich graue Wandung des Gefäßes ab. Die Arteria anonyma ist erweitert. Àn der Hinterwand befindet sich ein ebensolcher Ring mit derselben Wandbeschaffenheit der Ausbuehtung, wie oben beschrieben, nur etwa von Fünfpiennigstïckumfang. Diese Vorbuchtong wölbt sieh an der oben beschriebenen weiblichen Stelle der Trachea in die Tr. vor.

Präparate I and II entstammen dem Aneurysma der Aorta. 
Mikroskopischer Befand.

Präparate I (Aneurysmasack). Intima ist ohne Veränderung.

Media: Die ganze Media ist fabrös verändert, nirgendwo sieht man Muskel-oder elastische Fasern. Die ganze Wand erscheint, als ob sie nur aus der Adventitia besteht. In der Wand finden sich hier und da erweiterte Gefäße mit perivaskulären Infiltrationen aus Lymphozyten und wenigen Plasmazellen. Verdickte, sogar obliterierte Geläße sind auch nachweisbar. Man trifft stellenweise Blutpigment. Das tumen des Aneurysmasacks ist mit thrombotischer Masse ganz gefüllt; diese ist stellenweise organisiert.

Präparate II (Aneurysmahalsteil). Intima: Während sie am eigeatlichen Aneurysmateil keine Veränderung aufweist, bietet sie am Halsteil starke Verdickung mit vielen feinen Intimaspalten dar.

Media: Sie ist am eigentlichen Aneurysmahalsteil erheblich geschädigt, sogar stellenweise zerstört. Bei van Gies o n - Färbung sieht man eine sehr schmale, gelbgefärbte Muskelschicht, die streckenweise unterbrochen ist; an einer Stelle finden sich mehrere kleine, inselförmige Muskelstücke. Am eigentlichen Aneurysmateil bemerkt man. keine Muskelschicht. Die elastisehen Fasern zeigen bei Elastikafärbung ebenfalls starke Zerstörung, die der der Muskelfasern ganz entsprechend ist. In diesen Defekten sind viele ausgedehnte Schwielen ausgebildet, zum Teil gefäßreiches Granulationsgewebe aufgetreten.

Adventitia weist auch starke Veränderungen auf, so daß man im ganzen Verlaufe der Adventitia viele schon makroskopisch erkennbare Zellherde sehen kann. Letztere bestehen aus Plasmazellen und Lymphozyten. Die Menge und Verteilung der beiden ist ganz verschieden. An einer Stelle der eigentlichen Aneurysmawand benerkt man zahlreiche Plasmazellen, die parallel der Wand reihenweise angeordnet sind. In der Adventitia des Halsteils treten meist diffuse Infiltrationen auf; hier sind die Plasmazellen überwiegend und man findet sie auch in rosettenartiger Anordnung. Auffallend sind viele verdickte und ganz obliterierte Gefäße, die mit Infiltrationen umsäumt sind. Das Lumen des Aneurysmasacks ist auch hier mit teilweise organisierter, thrombotischer Masse ganz gefüllt. Mastzellen sind wenig vorhanden.

F a 11 80. H. S., Rentier, 72 Jahre.

Klinische Diagnose: Hydronephrose, Arteriosklerose, hypostatische Pneumonie.

Wassermannsche Reaktion fehit. Am 16. März 1911 Exitus Ietalis.

S.-Nr. 284; 1911. Obduktion 18. März (C e elen).

Pathologisch-anatomische Diagnose: Schwere Arteriosklerose, stellenweise fast völliger VerschIuß der Koronararterien. Ausgedehnte Infarkte und Schwielenbildung im. Herzen. Fibröse Endocarditis mitr. et tricusp., Hypertrophie und Dilatation beider Ventrikel. Multiple eitrige bronchopneumonische Herde in beiden Lungen. Eitrige Bronchitis beiderseits. Beginnende fibrinöse Pnenmonie beiderseits. Skleratheromatose der Aorta. Embolie eines Astes der linken Arteria renalis. Hämorchagiseher und anämischer Infarkt der linken Niere. Mächtige Hydronephrose links (faustgroße Erweiterung des Nierenbeckens infolge von spitzwinkligem Abgang und Abknickung des Ureters). Operativ hergestelite Kommunikation des Nierenbeckers mit der Außenseite der linken Bauchseite. Zirkumskripte Gangrän der Schleimhaut des Nierenbeckens. Geringe Balkenblase. (Linker Ureter nicht dilatiert.) Prostatahypertrophie. Maltiple Zysten in der linken Niere. Kleine Struma suprarenalis beider Nebennieren. Struma colloides. Parenchymatöse Trübung von Leber und Nieren. Kleiner Schleimhantpolyp im Diekdarm. Drainage der Bauchwonde durch Gummirohr. Laparatomiewunde. Geschwürsnarben im Magen.

Gehirn: Bohmengroßer alter Blutherd mit Erweichung am hinteren Ende des rechten Temporalhirrs. Mikroskopisch: Körnchenkugeln, Blutpigment. Chronische Leptomeningitis.

Präparate I und II entstammen dem Aneurysmahalsteil. 
Mikroskopischer Befind.

Präparate I (Aneurysmahalsteil). Intima: Während d'e Intima am Halsteil nur eine ganz geringfügige Verdickung zeigt, ist ihre Fürbbarkeit am übrigen Aneurysmateil teilweise sehr schlecht. Auf der Intima des eigentlichen Aneurysmateiles lagert thrombotische Masse.

Media: Sie weist starke Veränderungen auf. Bei van Gieson-Färbung sieht man, daB die Muskelfasern sich vom Halsteil an nach dem übrigen Aneurysmateil zu allmählich verschmälern, streckenweise unterbrochen sind, um dann sehlieblich ganz zu verschwinden. Bei Elastikafärbung zeigen die elastischen Fasern auch erhebliche Beschädigungen und sind ganz entsprechend den Muskelfasern zerstört. Diese Defekte sind meist durch ausgedehnte Schwielen, zum Teil frisches Granulationsgewebe ersetzt. Das Granulationsgewebe enthält Lymphozyten und wenige Plasmazellen. An einer Stelle, wo die Media ganz unterbrochen ist, finden sich zwei, schon bei bloßem Auge erkenntliche, mit Blut gefülltè Gefäße.

Adventitia enthält viele kleine und einige große Zellanhäufungen, die aus viejen Plasmazellen und Lymphozyten zusammengesetzt sind. Vasa vasorum sind vielfach endarteriitisch verändert, einige sind ganz obliteriert. Adventitielle Bindegewebsfäsern sind mäßig stark entwickelt. Mastzellen sind sehr viel vorhanden.

Präparate II (Aneurysmahalsteil). Im allgemeinen sind die Veränderungen der Aortenwand stärker als in den Präparaten I. In der Adventitia finden sich einige große Infiltrationen, eine besteht fast nur aus Lymphozyten, doch kann man auch in dieser zerstreut Plasmazellen erkennen. Hier und da sieht man Blutpigment. Um die Nerven besteht keine Infiltration. In der Adventitia sind die Bindegewebsfasern vermehrt.

F all 81. M. G., Schuhmachersfrau, 62 Jahre.

Klinische Diagnose: Carcinoma cervicis, Peritonitis nach Karzinomoperation.

6 Geburten. 3 Aborte; der letzte vor 16 Jahren.

Wassermannsche Reaktion fehlt. Exitus letalis am 14. Mai 1911.

S.-Nr. 507; 1911. Obduktion 15. Mai ( $\mathrm{I}$ öhe ).

Pathologisch-anatomische Diagnose: Karzinom des Uterus (durch Operation entfent). Bauchdeckenabszeß, breit gespalten. Peritonitis sero-fibrinosa. Schlaffes, fettdurchwachsenes, trübes Herz. Aortitis syphilitica (?). Zirkumskripte Pleuraverdickung an der linken Lunge, geringes Ödem beider Lungen. Parenchymatöse Degeneration beider Nieren und der Leber. Urocystitis nodularis. Im Peritoneum und in der Nahtstelle des kleinen Beckens: Fäulnisbakterien und Bact. coli; im Herzblut: Fäulnisbakterien, Sarzine, Staphyl. pyogen. albus; in der Milz: Fäulnisbakterien, Staphylococeus pyogenes.

Die Aorta zeigt in ihrem ganzen VerTaufe unregelmäßig gestaltete, größere und kleinere gelblichgraue, bucklige Erhabenheiten, die sich zum Teil sehr derb anfühlen. Dieselben Veränderungen in geringerem Maße in den Koronararterien.

Präparate I und II entstammen gelblichgrauen, buckligen Erhabenheiten und Runzaln der Pars ascenderis und descendens.

\section{Mikroskopischer. Befund.}

Präparate I (Pars ascendens). Intima: Während die Intima an einer Stelle viele dicht aneinanderliegende Vertiefungen von verschiedener Tiefe zeigt, sieht man man an anderer stclle einen skleratheromatösen Herd, der einige stark erweiterte Kapillaren enthält. In der obersten Schicht des skleratheromatösen Teiles bemerkt man geringe Infiltrationen aus Lymphozyten.

Media enthält hier und da kleine Zellherde. Der den Falten der Intima entsprechende Teil der Media zeigt keine Veränderung.

Adventitia: Man sieht in der Adventitia, besonders im Grenzgebiet zwischen Media und Adventitia Infiltrate aus Plasmazellen mit wenigen Lymphozyten; auch finden sich verdickte Gefäße. Mastzellen sind hier und da vorhanden. 
Präparate II (Pars descendens) verhalten sich ähnlich den Präparaten I.

F a 11 82. Frau H., Witwe, 45 Jahre.

Klinische Diagnose: Herzklappenfehler und Lungenödem (Aorteninsuffizienz).

S.-Nr. 520; 1911. Obduktion 17. Mai (Staatsprülung).

Pathologisch-anatomische Diagnose: Schwere Sklerose der Aorta mit Ubergreifen auf die Aortenklappen, die verdickt und geschrumpft sind. (Insuffizienz) Dilatation und Hypertrophie des linken Ventrikels. Doppelseitiges Lungenödem. Chronische Endometritis, Verengerung des äußeren Muttermundes. Perimetritis, Salpingitis, Oophoritis fibrosa adhaesiva. Hydrosalpinx links. Zysten in beiden Ovarien. Induration des Uterus.

Präparate I und II sind einer Stelle mit kleinen, gelblichen Flecken der Pars ascendens mit der A. pulmonalis und der Pars descendens entnommen.

\section{Mikroskopischer Befund.}

Präparate I (Pars ascendens mit der A. pulmonalis). Intima: Sie zeigt leichte Verdickung mit geringer Rundzelleninfiltration.

Während die Media geringe mikroskopische Veränderung aufweist, bemerkt man auffällige makroskopische und mikroskopische Veränderungen in der Adventitia. Man sieht in ihrem ganzen Verlaufe viele kleine sowie mehrere große, aneinanderliegende Zellherde, die letzteren mit bloßem Ange als Fleckchen bereits erkennbar; der eine erreicht nicht ganz StecknadelkopfgröBe. Diese groBen Zellherde enthalten viele, mit BIut stark gefïllte Gefäße und bestehen zumeist aus Lymphozyten mit wenigen Plasmazellen, die meist an der Peripherie des Herdes sich finden oder als Gruppen die Hälfte des Herdes einnehmen. Die kleinen, vereinzelten Infiltrate bestehen meist aus vielen Plasmazellen, die zum Teil auch in rosettenartiger Anordnung liegen. Mastzellen sind viel nachweisbar. Einige Vasa vasorum sind endarteriitisch erkrankt, sogar obliteriert. Die A. pulmonalis zeigt gar keine mikroskopische Veränderung.

Präparate II (Pars descendens). Außer Fettablagerung und geringer atheromatöser Veränderung der Intima und einer stärkeren Veränderung der Media sind die Präparate II ähnlich wie die Präparate $I$.

F all 83. P. D., Portier, 41 Jahre.

Klinische Diagnose: Urämie.

Nikotin: 1 Zigarre. Infektion: vor 12 Jahren Tripper. Potus: gar nicht:

Wassermannsche Realtion fehlt. Am 10. Juni 1911 Exitus letalis.

S.-Nr. 625; 1911. Obduktion 12. Juni ( $\mathrm{K} \circ \mathrm{ch}$ ).

Pathologiseh-anatomische Diagnose: Starke Granularatrophie der Niexen mit ausgedehnter Zystenbildung, besonders links. Starke Hypertrophie und Dilatation des linken Ventrikels. Kleines Transsudat in beiden Pleurahöhlen. MäBiges Lungenödem und alveoläres Emphysem beiderseits. Geringe pleuritische Verwachsungen am rechten Oberlappen. Starke Sklerose (Syphilis?) der Aorta. Strumaknoten beiderseits. Amygdalitis lacunaris rechts. Crocystitis nodularis. Erbsengroßer Tumor im Duodenum. Mäßiges Piaödem und Hydrocephalus internus.

Aorta im Arkus und in der Pars ascendens enthält zahlreiche, derbe, grauweiße Runzeln und Stränge. Auf dem Bauchteil hören die Veränderungen fast völlig auf.

Präparate I und II sind verdickten Stellen der Pars ascendens (I) und der Arcus aortae (II) entnommen.

Mikroskopiseher Befund.

Präparate I (Pars ascendens). Intima zeigt teilweise ganz geringe Verdickung.

In der Media bemerkt man stellenweise kleine, perivaskuläre, meist aus Plasmazellen bestehende Infiltrate. 
Gefïße in der Adventitia sind stark entwickelt und mit Blat strotzend gefült. Die unter der Media befindlichen GefäBe sind oft mit Plasmazellen und Lymphozytenanhäufungen umgeben. Mastzellen sind hier und da sichtbar.

Präparate II (Arcus aortae). Die Veränderungen sind die gleichen wie in den Präparaten I.

F a 11 84. H. S., Ingenieur, 49 Jahre.

Klinische Diagnose: Chronische Entartang des Herzmuskels.

S.-Nr. 898; 1911. Obduktion 17. August ( L ö h e ).

Pathologisch-anatomische Diagnose: Endocarditis chronica recurrens mitralis. Hypertrophie und Dilatation beider Ventrikel. Mesaortitis syphilitica, Koronarsklerose; Herzschwielen. Alte und junge Infarkte in beiden Lungen. Stauungsorgane: Stauungsleber, Milz und Stauungsgastritis und Enteritis. Kolloidstruma; Schleimhantpolyp im oberen Teil des Dünndarms. Starke Hyperämie und geringe Blutresorption der vergröBerten Zervikal- und Hilusdrüsen.

Präparate I sind gelblich kleinen Herden der Pars ascendens mit der A. pulmonalis entnommen. Präparate II einer ähnlichen stelle der Pars descendens.

Mitroskopiseher Befund.

Präparate I (Pars ascendens mit der A. pulmonalis). Intima: Sie ist an einer Stelle mäBig verdickt, hier finden sich einige Gefäße und einzelne Verfettungsherde. Der übrige Teil der Intima zeigt eine diffuse Verdickung mit Infiltration.

Media: Sie enthält hier und dort viele Gefäße mit perivaskulärer Infiltration. An einer Partie sieht man einen makroskopisch schon sichtbaren, etwas scharf begrenzten Herd, in welchem die elastischen Fasern zwar verschwunden sind, die Muskelfasern aber ihre normale Struktur behalten haben. Sonst zeigen die elastischen Fasem wenig Veränderung.

Adventitia: Außer einer makroskopisch sichtbaren perivaskulären Infiltration aus Lymphozyten und Plasmazellen sind die Infiltrate meist klein und setzen sich gleichmäßig aus Lymphozyten und Plasmazellen zusammen. Man trifft die Plasmazellen bisweilen in rosettenartiger Anordnung. Einige Nerven sind von starken Zellanhäufungen umgeben; die Plasmazellen finden sich in dem Perineurium. Obliterierte und verdickte GefäBe sind wenig vorhanden. Während Mastzellen nur spärlich in der Media nachweisbar sind, bemerkt man sie in der Adventitia sehr reichlich. Die A. pulmonalis zeigt gar keine mikroskopische Veränderung.

Präparate II (Pars descendens). Sie zeigen mit den Präparaten I übereinstimmende mikroskopische Veränderungen.

F all 85. A. W., Maler, 55 Jahre.

Klinische Diagnose: Hautleukämie. Herzfehler.

Wassermannsche Reaktion fehlt. Exitus letalis am 28. August 1911.

S.-NTr. 937; 1911. Obduktion 28. August ( S e h u m).

Pathologisch-anatomisehe Diagnose: Schwere Arteriosklerose mit diffuser Erweiterung des Anfangsteils der Aorta. Dilatation und Hypertrophie beider Vorhöfe und Ventrikel (besonders linker Ventrikel und rechter Vorhof). Schlaffe, fettdurchwachsene Herzmuskulatur. Thrombus im rechten Herzohr, rechts in den Vorhof hineinragend. GroBe hämorrhagische Infarkte beider Langen. Fydrothorax rechts. Pleuritische Verwachsungen links. Stauungslungen, Bronchitis cyanot. Atrophie der Leber. Stauungsmilz mit vergröBerten Lymphknoten. Stauungsgastritis und -enteritis. Stauungsnieren mit beg. Granularatrophie. Prostatahypertrophie, mäBige Balkenblase. Hämorrhoiden. Vielfache Verwachsungen der Bauchein geweide und Gallenblase. Schwellung der Axillaren, tracheobronchialen, retroperitonealen Drüsen. Rotes Knochenmark $(1 / 3$ der Femur).

Präparate I und II entstammen einer grawweißlichen, geringen Erhabenheit der Pars ascendens und descendens. 
Nikroskopiseher Befund.

Präparate I (Pars ascendens). Intima: An einer Stelle findet sich eine atheromatöse Veränderung und Fettablagerung.

Media: ist nur ganz gering verändert.

Adventitia: zeigt hier und da viele verdickte Gefäße mit perivaskulären Infiltraten aus Lymphozyten und Plasmazellen. Man trifft versehiedentlich viele Mastzellen. Die adventitiellen Bindegewebstasern sind mäßig stark entwickelt.

Präparate II (Pars descendens). Die mikroskopischen Veränderungen sind ein wenig stärker als in den Präparaten $I$.

Fall 86. G. A., Fuhrmann, 51 Jahre.

Klinische Diagnose: Lungentuberkulose.

S.-Nr. 53; 1912. Obduktion 15. Januar (C e el en ).

Pathologisch-anatomische Diagnose: Chronische doppelseitige Lungentuberkulose, besonders links. Käsige Pneumonie, Bronchitis und Peribronchitis links mit Kavernenbildung, besonders im Oberlappen. Retrahierende Pleuritis mit teilweiser Schwartenbildung aul der linken Seite. Taberkulöse Geschwüre im lleum. Kleine Zysten und Narbenbildung der linken Niere, kirschgroße Zyste der rechten. Nephritis parenchymat. Große Leber mit fleckweiser Verfettung. Sklerose der Aorta. Ödem und partielles vesicul. Emphysem der linken Lunge. Hydroperikard.

Die Innenfläche der Aorta ist unregelmäßig gerunzelt, mit narbigen Vertiefungen und regellosen, gelblichweißen, derben Verdickungen.

Präparate I stammen von einer unregelmäBig gerunzeiten Ste]le der Pars ascendens. Präparate II sind einer grauen, flachen Verdickungsstelle des Arcus acrtae entnommen.

\section{Mikroskopischer Befund.}

Präparate I (Pars ascendens). Intima: Hier und da sieht man an den Stellen starker, höckeriger Verdickung kernarmes, derbes Bindegewebe mit wenigen Rundzelleninfitrationen (keine Plasmazellen). In der innersten Schicht der höckerig verdickten Teile sind Verfettungen und Fettnadeh.

Media: Media enthält an verschiedenen Stellen kleine Defekte der Muskelschicht und der elastischen Fasern, die von Plasmazellen erfüllt sind. Verschiedentlich trifft man einige stark erweiterte Gefäße mit geringfïgigen perivaskulären Infiltrationen an. Mlastzellen sind ganz wenige in Plasmazellengruppen vorhanden.

Adventitia: Die in der Adventitia sichtbaren erkrankten Stellen lokalisieren sich häufg im Grenzgebiet zwischen Media und Adventitia; diese Herde bestehen fast alle aus Plasmazellenanhäufungen. Hier in diesem Grenzgebiet hat sich auch ein bei 70facher VergröBerung dureh das ganze Gesichtsfeld hindurchzieliender Plasmazellenstrang (mit wenigen Lymphozyten) entwickelt, und hier sieht man viele erweiterte, blutgefüllte Gefube mit Infiltration. Einige Vasa vasorum sind endarteriitisch erkrankt. Die übrigen Partien zeigen zwei aus Lymphozyten gebildete lymphknötchenartige Zellanhäufungen, deren Peripherie jedoch Plasmazelleninfiltration auiweist. Mastzellen sind viele vorhanden, bei 100 facher Vergrößerung etwa 10-20 in einem Gesichtsield.

Präparate II (Areus aortae). Intima ist teilweise stark sklerotiseh mit geringer Verkalkung, ohne Verfettung. Die verdickte Intima hat dieselbe Breite wie die Yedia.

Media: Media zeigt einige ganz schwache Infiltrationen mit geringer Kalkablagerung, ist sonst intalst.

Adventitia: Hier bemerkt man im Gegensatz anr Media ganz charakteristische syphilitisehe Veränderungen, und zwar Erweiterung und Vermehrung der Geiäße mit starker perivaskulärer Infiltration aus Lymphozyten und Plasmazellen. Diese GefäBe sind mit Blut stark gefiullt. Mastzellen hier und da vorhanden. 
F all 87. Frau M., Arbeiterwitwe, 70 Jahre.

Klinische Diagnose: Hernia cruralis dextra incarcerata phlegmonosa. Peritonitis. Pneumonia.

Wassermannsche Reaktion fehlt. Am 13. Januar 1912 Exitus letalis.

S.-Nr. 63; 1912. Obduktion 15. Januar ( C e e l en).

Pathologisch-anatomische Diagnose: Operierte Brucheinklemmung mit Resektion eines Dünndarmstüickes. Enteroanastomose. Umschriebene eitrige peritonitische Herde in der Umgebung der Operationswunde. Geschwüre im Dickdarm und unteren Dünndarm. Faustgroßes, sackförmiges Aneurysma der Pars descendens aortae. Spindelförmiges Aneurysma im unteren Brustteil der Aorta. Diffuse Erweiterung der Pars ascendens aortae. Retraktion der Aortenklappen. Mesaortitis mit kleinen thrombotischen Auflagerungen. Pneumonie der linken C. L. mit umschriebener Pleuritis. Urocystitis cystica und ulcerosa. Doppeltes Nierenbecken und doppelter Ureter links, Geschwüre im unteren Ösophagus. Kompression des linken Hauptbronchus. Kleiner Polyp in der Cervix. Schrumpfnieren. Fettleber. Kleines Magengeschwür am Pylorus. Abgeheilte Ulcera cruris. Pachymeningitis fibrosa adhaesiva.

Die Aortenklappen sind etwas verkürzt. In der hinteren und der rechten vorderen Klappe findet sich in der Aorta eine derbe, bueklige, narbenartig aussehende Verdickung, an der die beiden Klappen verdickt inserieren und ebenfalls narbenartiges Aussehen haben. Die Aorta ascendens ist auf der Innenseite normal, in dem hinteren Teil glatt und spiegelnd, auch im ganzen ziemlich elastisch, während man im vordersten Abschnitt Verdiekungen findet, die von unregelmäßig verlaufenden Faltungen durchsetzt sind; nach dem Konus hin nehmen die Veränderungen ziemlich an Intensität zu, hier findet man auf der Innenfläche vielfach feinste, den Verdickungen aufsitzende, einen samtartigen Überzug bildende Wärzchen. Die hintere Seite des oberen Lappens wie der untere Rand des unteren Lappens der linken Lunge ist mit einer der linken Wirbelsäulenwand aufsitzenden, faustgroßen Geschwulst ziemlich fest verwachsen. Beim Betasten hat letztere derbelastische Konsistenz und, wie sich bei genauerer Untersuchung feststellen läBt, gehört sie der Pars descendens der Aorta an. Bei Betrachtung von der Abtrennungsstelle des Herzens an der Pars descendens der Aorta her erkennt man, daß die oben genannte Erweiterung der Aorta descendens an einer Einsehnürung im Arkus wieder ihre normale Weite erlangt, an der Übergangsstelle des Arkus in die Pars descendens jedoch eine grobe sackförmige Erweiterung erfährt, deren Wandungen mit dieken, hellroten; oberfächlich geriffelten, festsitzenden, aus Blutmasse bestehenden Belägen ausgekleidet ist. Dieselben haben feste Konsistenz und ziemlich trockene Besehaffenheit. Die Länge des Aneurysma beträgt etwa $11 \mathrm{~cm}$, die Breite 7, die Höhe $4 \frac{1}{2} \mathrm{~cm}$, der unterste Pol schneidet mit der Eintrittsstelle der linken großen Bronchus in die Lunge gerade ab, während der obere Pol an der Abgangsstelle der linken Art. subclavia liegt. Durch den aneurysmatischen Sack ist sowohl der unterste Teil der 'Trachea wie der linke Flauptbronchus stark komprimiert. Die Aorta ist in ihrem untersten, abdominalen Teil elastiseh, dünnwandig und auf der Innenfläche obne Veränderungen, an der Tripusstelle $4 \frac{1}{2} \mathrm{em}$ breit; in der Höhe der I. Sakralarterien erweitert sie sich ziemlich unvermutet zu einem spindelförmigen Rohr, das aufgeschnitten im Durchmesser $9 \mathrm{~cm}$ hat. Im Gegensatz zu dem beschriebenen untersten Teil sieht man hier zahllose narbenartige Erhebungen und Einziehungen, durch die die Wand verdickt und vollständig unelastisch erscheint. Von den Abgangsstellen der Interkostalarterien ist mit Sicherheit nichts zu erkennen. Vielfach sitzen den Wandveränderungen auf der Innenseite kleine rötliche Wärzehen aut.

Präparate I sind einer grauweiBlichen, narbigen Stelle der Pars ascendens entnommen. Präparate II entstammen einer derben, buckligen, narbenartig aussehenden Verdickung der Pars ascendens mit den Klappen. Präparate IXI und IV stammen vom Aneurysmahalsteil der Pars descendens. Präparate V sind einer narbig geschrumpften Stelle der Pars descendens entnommen. 
Mikroskopiseher Befund.

Präparate I (Pars ascendens). Intima: Sie ist stellenweise verdickt. In der tiefsten Schicht der verdickten Intima sieht man Infiltration aus Lymphozyten und Plasmazelien. Besonders an der Stelle, wo eine Infiltration der Media bis in die Intima hineinreicht, findet sich ein schon makroskopisch erkembarer Schwarm von Plismazellen mit wenigen Lymphozyten. Ejnige elastische Lamellen sind neugebildet.

Media: Sie ist von vielen schon makroskopisch erkennbaren frischen Granulationsgeweben, Zellherden und Sehwielen durchsetzt. In einem Granulationsherde bemerkt man viele epitheloide Zellen, auch Riesenzellen. An einem anderen finden sich viele Lymphozyten und einige Plasmazellen; hier sieht man auch ein stark verdicktes GefäB. Diese Erkrankungsherde haben vielfache Unterbrechungen der Media hervorgerufen. Die elastischen Fasern sind durch die Herde stark geschädigt, sogar stellenweise ganz versehwunden.

Adventitia enthält viele, mit bloßem Auge schon sichtbare, umschriebene Zellanhäufungen, die meist aus Lymphozyten mit wenigen Plasmazellen bestehen. Dagegen sind die kleinen Infiltrate aus Plasmazellen zusammengesetzt. Die adventitiellen Nerven sind von Infiltrationen umsäumt. Verdickte und obliterierte Gefäße sind hier und da zu sehen. Blutpigment ist stellenweise vorhanden. Die adventitiellen Bindegewebs- und elastischen Fasern sind ziemlich stark vermehrt. Während in der Media nur einige wenige Mastzellen nachweisbar sind, treten sie in der Adventitia sehr stark auf.

Präparate II (Pars ascendens mit den Klappen). Intima: Dicht am Anfangsteil der Aorta ascendens ist die Intima im Sinus plötzlich auf eine lange Strecke hin stark verdickt, um dann wieder zur normalen Stärke überzngehen. In der änßersten Schicht der verdickten Intima treten viele Lymphozyten auf, während der übrige Intimateil nur hier und da Plasmazellen enthält. An dem Grenzgebiet der Intima und Media sieht man ausgedehnte Granulationsherde, die gleichen Herden in der Media entsprechen.

Media zeigt starke Veränderungen. Besonders in der intimawärts gelegenen Mediahälfite sind Muskel- sowie elastische Fasern nur wenig zu sehen, dafür sind hier ausgedehnte Schwielen, zum Teil Granulationsgewebe ausgebildet. In letzterem bemerkt man stark erweiterte oder sogar obliterierte GefäBe. Daneben fallen große Schwärme von Plasmazellen auf; diese liegen teils in geschlossenen Gruppen, teils anch in rosettenartiger Anordnung. In den Herden trifit man Blutpigment. Die adventitiawärts gelegene Mediapartie zeigt wenig Veränderung.

Adventitia: Adventitielle Bindegewebs- und elastische Fasern sind stark vermehrt, sonst weist sie nur geringfügige mikroskopische Veränderungen auf. Man sieht ein Lymphknötchen, in dessen Peripherie Plasmazellen angehäuft sind. Mastzellen sind reichlich vorhanden. Die Klappe zeigt keine Veränderung. Die Herzmuskulatur zeigt Pigmentablagerung an den Polen ihrer Kerne.

Präparate III (Aneurysmahalsteil). Intima: Sie ist am Aneurysmahalsteil stellenweise etwas sklerotisch verdickt. An einer Stelle sieht man eine Schar von Plasmazellen. An zwei anderen Stellen in dem Grenzgebiet zwischen Intima und Media finden sich zwei kleine Kalkplatten. Am übrigen Aneurysmateil zeigt die Intima nur an einer Stelle ziemlich starke Verdiekung. Auf der Intima des Aneurysmateils lagert thrombotische Masse, die teilweise organisiert ist.

Media zeigt erhebliche Schädigung bis zur Zerstörung der Muskelschicht und der elastischen Fasern. Bei y an Gi i s o n - Färbung kann man sehen, wie die Muskelfasern sich rom Halsteil an nach dem übrigen Aneurysmateil zu allmählich verschmälern, streckenweise unterbrochen sind, um dann am Aneurysmateil plötzlieh ganz zu verschwinden. Bei Elastikafärbung (rot und blau) zeigen auch die elastischen Fasern starke Beschädigung, sogar Zerstörung, ganz entsprechend der der Muskelfasern. Diese Defekte sind durch viele umfangreiche Schwielen, zum Teil durch Granulationsgexiebe exsetzt. Zellherde sind sehr wenig sichtbar.

Adventitia: Die weitaus am meisten anffallende Veränderung besteht in zahireichen versehieden großen Zellherden. Einer dieser Zellherde ist makroskopisch als linsengroß sichtbar; 
er ist zusammengesetzt aus zahlreichen kleineren, ebenfalls makroskopisch schon sichtbaren Zellherden aus Lymphozyten und aus verdickten und obliterierten Gefäßen nebst einigen Nerven. Zwischen diesen kleinen Zellherden sind Lymphozyten und Plasmazellen angehäuft. Die sonstigen Zellherde bestehen auch aus Lymphozyten und Plasmazellen, manchmal liegen anch letztere in Gruppen für sich. In der dem eigentlichen Aneurysmateil entsprechenden Partie der Adventitia finden sich viele Nerven von Plasmazellen umsäumt. Hier und da sieht man Blutpigment. Die adventitiellen Bindegewebs- und elastischen Fasern sind mäßig vermehrt. Mastzellen sind in mäBiger Menge nachweisbar.

Präparate IV (Aneurysmahalsteil). Intima ist fast normal. Die Intima des eigentlichen Aneurysmateils hat thrombotische Masse aufgelagert.

Media zeigt noch stärkere Veränderungen als in den Präparaten III, sieht man doch im eigentlichen Aneurysmateil fast nur noch Trümmer elastischer Fasern. Während sich ausgedehnte Sch wielenbildungen allenthalben erkennen lassen, hat eine Stelle, dicht am eigentlichen Aneurysmateil frisches, ausgebildetes, stark erweiterte Kapillaren enthaltendes Granulationsgewebe. In der Media sind Zellherde kaum erkennbar.

Adventitia: ist von zahlreichen umsehriebenen Zellanhäufungen durehsetzt. An einer Stelle fällt eine etwa $1 \mathrm{~cm}$ langgestreckte Zellanhäufung auf, die hauptsächlich aus Lymphozyten besteht; doch haben sich auch gruppenweise Plasmazellen angesammelt. In diesen Herden finden sich einige stark erweiterte, mit Blut gefüllte Gefäße. Die übrigen Zellherde sind auch aus Lymphozyten zusammengesetzt. Teilweise liegen Plasmazellen in Gruppen für sich, teilweise in rosettenartiger Anordnung. Ein adventitielles Lymphknötchen ist zu sehen, das in der Pexipherie Plasmazellen in mäßiger Menge enthält. An einer Stelle finden sich zahlreiche gefüllte Gefäße ohne perivaskuläre Infiltration. Mastzellen viel vorhanden.

Präparate V (Pars descendens). Intima: ist stellenweise etwas verdickt. An einer Stelle sieht man Infiltration aus Lymphozytea und Plasmazellen.

Media: Sie ist in ihrem ganzen Verlaufe stark verschmälert, sogar durch Zellherde unterbrochen. Diese groBen Zellherde bestehen meist aus Plasmazellen, während andere, etwas diffuse Zellinfiltrationen aus reichlichen Lymphozyten zusammengesetzt sind. Außer diesen Zellherden treten umfangreiche Schwielen auf. Hier und da sind Blutpigmente vorhanden.

In der Adventitia fallen zahlreiche gefüllte Vasa vasorum auf; perivaskuläre Infiltrationen bestehen wenig.

F a 11 88. Frau R., Arbeiterfrau, 63 Jahre.

Klinische Diagnose: Carcinoma ventriculi, Anämia gravis. Schrumpinieren. Herzinsuffizienz.

Infektion: negatur.

Wassermannsche Realktion fehlt. Exitus letalis am 24. Januar 1912.

S.-Nr. 99; 1912. Obduktion 24. Januar ( K och).

Patho广ogisch-anatomische Diagnose: Starke Granularatrophie beider Nieren mit starker Hydronephrose links, geringer rechts, Nierensteine links. Sehr starke Hypertrophie und Dilatation beider Ventrikel bei starker Verfettung des Myokards. Perikarditische Verwachsungen. Starke, allgemeine Anämie, rotes Knochenmark. Hydrothorax und sehr starkes Ödem. Kompression (Kollaps) beider unteren Lappen und des Mittellappens rechts. Alte Spitzeninduration links, pleuritische Verwachsungen beiderseits. Tracheobronchitis. Stauungsinduration von Leber und Milz. Pịädem. Endometritis haemorrhagica. Variköse Schlängelung der Arteria renalis. Skleratheromatose der Aorta.

Aorta zeigt im Arkus und im Brustteil neben gran weiBlichen, teils runzlich, teils mehr narbenartig aussehenden Stellen im unteren Teil sehr zahIreiche gelblich weiße Verdickungen der Intima, die sich auch stark in den Schenkelgefäßen finden. Basale Hirnarterien zeigen vereinzelte gelbliche Verdickungen. Augenhintergrund o. V. 
Präparate I stammen von einer grau weißlichen, narbenartigen, leichten Verdiekungsstelle des Brustteils, Präparate II von einer gleichen des Arcus aortae.

\section{Mikroskopischer Befund.}

Präparat I (Pars descendens). Intima zeigt nur eine schwache Verdickung, trotzdem sieht man einige neugebildete elastische Fasern und geringe Rundzelleninfiltrationen.

Media: An der adventitiawärts gelegenen Mediahälfte bemerkt man viele Gefäße mit schwacher Infiltration aus Lymphozyten und Plasmazellen. Diese perivaskulären Infiltrationen gehen stellenweise kontinuierlich in die Adventitia über. Die elastischen Fasern der Media sind stellenweise zerstört. weisbar.

Adventitia zeigt die gleichen Veränderungen wie die Media. Mastzellen sind wenig nach-

Präparat II (Arcus aortae). Die Veränderungen sind ganz genau so, wie diejenigen in den Präparaten 1 .

F all 89. A. Z., Portier, 62 Jahre.

Klinische Diagnose: Lungenbluten oder Magenbluten?, sterbend eingeliefert.

S.-Nr. 157; 1912. Obduktion 9. Februar (Martin).

Pathologisch-anatomische Diagnose: Magenulkus mit Arrosion eines Gefäßes und Verblutung aus demselben. Aortitis syphilitica, Aortenaneurysma. Hypertrophie und Dilatation des linken und rechten Ventrikels. Schrumpfnieren beiderseits. Leberzirrhose. Wandständige Thromben in der Aorta. Prostatahypertrophie, Zyste der Milz. Adhäsive, chronische Pleuritis an beiden Spitzen. Alveoläres Emphysem beider Lungen, chronische Perihepatitis" und Perisplenitis, chronischer Magenkatarrh, rotes Knochenmark, chronische Bronchitis, Hypertrophie der Lymphdrüsen am Zungengrund. Nierenherde.

Die Aorta zeigt in der Pars ascendens eine starke Erweiterung ihres Lumens. Die Intima ist schwielig verdickt und von grau gelblicher, gefleckter Farbe. An der Wand der Aorta sitzen zahlreiche kleine, warzen förmige Hervorragungen.

Präparate I entstammen dem Arcus aortae, und zwar einer sehwielig verdickten Stelle von graugelblicher, gefleckter Farbe. Präparate II wurden von einer fast gleichen Stelle der Pars descendens genommen.

Mikroskopischer Befund.

Präparate I (Areus aortae). Intima: Sie zeigt überall sklerotische Veränderung, auch an einer Stelle das Bild eines beginnenden atheromatösen Prozesses. An einigen Stellen sieht man große, unregelmäßig gestaltete Zellherde, die aus einer großen Menge von Plasmazellen bestehen und Zusammenhang mit den großen, ebenso beschaffenen Herden in der Media haben. Die übrige Partie der Intima läBt einzeIne Plasmazellen und Lymphozyten erkennen.

Media: Sie ist auf der ganzen Strecke verschmälert, und zwar durch die in dem Grenzgebiet sowie in dem unter der Intima liegenden Mediateil vorhandenen; ansgedehnten Schwielen. Besonders anffällig finden sich in diesem schwieligen Teil, bald diffuse, bald scharf begrenzte Zellherde in großer Zahl, die fast alle nur aus Plasmazellen bestehen. Einige Herde enthalten auch Gefäße, während an einem Herde eine Riesenzelle, die im Zentrum viele Kerne enthält, sich findet. An einer Stelle fällt auch ein sehr großer, scharf begrenzter Zellherd auf, der nicht nur die ganze Breite der Media einnimmt, sondern auch die Intima sowie Adventitia ergriffen hat. Dieser Zellherd ist mit Plasmazellen übersät, man sieht sogar einige vielkernige Riesenzellen (nicht L a n $g$ ha an s scher Typus) und Gefäße. In dem Herde sind die elastischen Fasern zerstört; am Rande sieht man sie nur büschelweise angeordnet, zum Teil mit wie scharł abgeschnittenen Enden. Mastzellen sind wenig vorhanden.

Adventitia: An dem unter dem oben beschriebenen größten Herde liegenden Teil der Adventitia bemerkt man eine ausgedehnte makroskopisch und mikroskopisch auffallende Zellanhäufung, 
die zumeist aus Plasmazellen besteht, zum Teil in rosettenartiger Anordnung. An vielen anderen Stellen finden sich verschieden große Zellherde mit vielen verdickten, zum Teil ganz obliterierten GefäBen. Stellenweise - besonders an dem oben erwähnten Zellherde - ist viel Hämosiderin nachweisbar, hier und dort trifft man Mastzellen in mäßiger Menge.

Präparate II (Pars descendens). Intima: Stellenweise ist sie stark sklerotisch, während sie in ihrer tiefsten Schicht eine Fettablagerung aufweist. Der dem Lumen am nächsten liegende Teil der Intima ist stellenweise mit zahlreichen Plasmazellen und Lymphozyten durchsetzt; die ersteren sind meist strangartig angeordnet. An einer Stelle finden sich viele neugebildete Gefäße mit geringen Infiltraten.

Media: Während sie hier und da von einer Mehrzahl meist kleiner, aus Plasmazellen sich zusammensetzender Zellherde eingenommen ist, fällt an einer Stelle ein großer, schon mit bloßem Auge sichtbarer Zellherd mit Gefäßen auf, der sich hauptsächlich aus Plasmazellen zusammensetzt; nur in der Mitte dieses Herdes findet sich eine kleine Gruppe von Lymphozyten. Diese Zellanhäufung setzt sich in die Intima fort. Bei der Pyronin-Methylgrünfärbung kann man schon makroskopisch diesen Zellherd als roten Fleck erkennen. In dem Herde sieht man gar keine elastisehen Fasern; ihre Enden haben die gleiche Beschaffenheit wie bei dem größten Herde in den Präparaten I. In dem Grenzgebiet zwisehen Media und Adventitia sind streckenweise ausgedehnte Schwielen vorhanden.

Adventitia: Die in ihr befindlichen Zellherde sind dadurch ansgezeichnet, daß sich in einigen nur Plasmazellen, in anderen hauptsächlich Lymphozyten vorfinden. Die Adventitia enthält kein Blutpigment. Mastzellen sind viel nachweisbar.

Sonst wie Präparate I.

F all 90. A. B., Restaurateur, 52 Jahre.

Klinische Diagnose: Peniscarcinom:

Vor 5 Jahren hatte er einen Pickel am Glied, der sich vergrößerte und zu einem Geschwïr wurde.

Wassermannsche Reaktion fehlt. Am 22. Februar 1912 Exitus letalis.

S.-Nr. 223; 1912. Obduktion 23. Februar (Martin ).

Pathologisch-anatomische Diagnose: Karzinom des Penis mit Drüsenmetastasen der rechten Leistenbeuge und in den retroperitonealen Lymphdrüsen. Eitrige Zystitis. Ausgedehnter Dekubitus, subkutane Geschwü̈rsbildungen in beiden Leistenbeugen. Braunes Herz, Aneurysma der Aorta ascendens. Aortitis syphilitica, Schrumpfherde in beiden Nieren, Ulcera rotunda im Magen, chronische Bronchitis.

Die Aorta ascendens zeigt eine ausgedehnt schwielig und streifig verdickte Wand. In diesem Teil zeigt sie eine deutliche Erweiterung ihres Lumens. Im weiteren Verlauf nimmt diese Veränderung der Aortenwand nach unten zu langsam ab.

Präparate I sind einer schwielig und streifig verdickten Stelle der Pars ascendens, Präparate II der Aneurysmawand der Pars ascendens entnommen.

Mikroskopischer Befund.

Präparate I (Pars ascendens). Intima etwas verdickt, mit einigen verschieden stasken. Einziehungen. Die Verdickung ist ungleichmäßig, die tiefe Schicht der Intima zeigt stellenweise lipoide Degeneration und an einer Stelle einen atheromatösen Herd mittleren Grades; in ihm finden sich viele Cholestearinnadeln.

Media: Der unter dem atheromatösen. Herde liegende Medjaabschnitt enthält einige sehr lang gestreckte, bandartige Narben, in denen die elastischen Fasern zerstört sind; hier findet sich manchmal Infiltration aus Plasmazellen und Lymphozyten. Direkt unter der stärksten Einziehung der Intima, an dem Grenzgebiet der Intima und Media, sieht man einen Granulationsherd mit Blutpigment. Auch hier sind die elastischen Fasern geschädigt. An einer anderen Stelle bemerkt 
man einen mäBig großen Herd, in dem sich viele Gefäße, epitheloide Zellen, Lymphozyten und viele Plasmazellen, zum. Teil auch schwieliges Gewebe, finden. An dieser Stelle ist die Media viel schmäler als sonst.

Adventitia: An einem Teil der Adventitia sind Bindegewebs- und elastische Fasern mäBig stark vermehrt, Schwärme von Lymphozyten und Plasmazellen, beide meist gruppenweise angeordnet, sind zerstreut sichtbar. Verdickte und obliterierte Gefäße lassen sich erkennen. Um Nerven besteht keine Infiltration, Mastzellen sind sehr wenig sichtbar.

Präparate II (Aneurysmawand). Unregelmäßige, leichte Verdickung der Intjma. Während die verschmälerte Media, viele bandartige Schwielenbildungen enthält, ist eine Infiltration kaum erkennbar. Die Adventitia ist von einer großen Zellanhäufung durchsetzt, die im Zentrum viele Lymphozyten, in der Peripherie Plasmazellen enthält. Die anderen, kleinen Infiltrate sind n.eist reich an Plasmazellen. Die Vasa vasorum sind wenig verändert. Mastzellen sehr wenig erkennbar.

Fall 91. M. E., Arbeiterwitwe, 66 Jahre.

Klinische Diagnose: Syphilis, Amyloidniere.

Wassermannsche Realktion fehlt. Am 24. Februar 1912 Exitus letalis.

S.-Nr. 231. Obduktion 26. Februar (Orth).

Pathologisch-anatomische Diagnose: Syphilis, Aneurysma der aufsteigenden Aorta und des Bogens, organisierter Pfropf in der linken Karotis, weite rechte, kleine linke Vena femoralis. Amyloidmilz-, -nieren, pankreas, -darm, Induration des Pankreas. Verwachsung des Stranges mit der Umgebung, ausgedehnte Fettgewebsnekrose im Pankreas und in der ganzen Umgebung zum Darm und zum Becken hin. Eiterung im Pankreas?, Hydrops, Bronchitis und Kollaps in den rechten unteren Lappen, Ödem in der linken Lunge; kleines, bräunliches Herz, verruköse Endocarditis aortica, leichte chronische Endocarditis mitralis, Pigmentierungen im Magen, Arrosion der Mammar. intern. durch eine besondere Aussackung des Aneurysma.

Oberhalb der Klappen Erweiterung der Aorta über den ganzen Arkus. An der Erweiterung sitzt nach oben und rechts gerichtet eine apfelgroße, besondere Ausbuchtung, welche bei der Entfernung des Sternum eröffnet wurde, ganz mit Thrombusmasse erfüllt - zur Hauptaorta hineinragend, wo sich Speckhaut- und Kurorgerinnsel ihr angelagert haben; in der Entfernung sieht die Oberfläehe des Thrombus geriffelt aus; soweit die Ausbuchtung reicht, ist die Aortenwand von Kalkplatten durchsetzt, in deren Umgebung das Gewebe weich ist, so daß beim Auseinanderbiegen die Ränder der Kalkplatten sich abheben, zeigt zerfallenes Gewebe und plötzliches Aufhören der Veränderung. Nur in der Abgangstelle der oberen Interkostalartt. noch leichte Verdickungen, anßerdem hier und da ein paar gelbe Fleckchen; die seitlich durch den Thrombus verschlossene Ausbuchtung hat nur eine ganz düzne Wand. Karotis und Subclavia descendens liegen lateral vor diesem Sack, sind aber nach dem Aneurysma zu durch einen Thrombus verlegt, so daß man mit der Sonde nicht in die Aorta hineingelangen kann. Anch von der linken Karotis aus kann man mit einer Sonde nicht in das Aneurysma hineingelangen.

Präparate I stammen von einer beetartigen Verdickungsstelle des Pars ascendens. Präparate II wurden der Aneurysmagegend entnommen.

\section{Wikroskopiseher Befund.}

Präparate I (Pars ascendens). Intima: Sie zeigt allenthalben leichte Verdickung mit zerstreuter, kleinzelliger Infiltration; sonst sieht man keine degenerativen Erseheinungen.

Media: weist stellenweise starke Veränderungen auf. An einer Stelle des intimawärts gelegenen Teiles fuden sich zwei nebeneinanderliegende, makroskopisch schon sichtbare Herde. Einer davon besteht hauptsächlich aus vielen, stark erweiterten, mit blobem Auge bereits erkennbaren Kapillaren und einigen verdickten Gefäßen (ein Gefäß ist hyalin degeneriert). Einige Kapillaren reichen von hier in den betreffenden Teil der Intima hinein. Zwischen den GefäBen findet man viele ovale und spindelige Kerne, Rundzellen und Plasmazellen in mäßiger Menge. 
Der andere Herd hat fast gleichen Bau wie der vorige, aber hier ist nur ein Gefäß verdiekt. In beiden Herden sind die elastischen Fasern total zerstört, am Rande der Herde sind die Enden der elastischen Fasern zusammengedrängt, zum Teil scheinen sie wie glatt abgeschnitten. An einer Seite dieser Herde ist die Media mit zahlreichen verschieden großen Narben gleichmäßig durchsetzt, so daß die Narben nor kurze Stücke gesunder Media zwischen sich lassen. An der anderen Seite enthält die Media wenige, aber große Narben und GefäBe mit geringer Infiltration aus Plasmazellen und Lymphozyten. In diesen Narben sieht man keine muskulären oder elastisehen Elemente. An einer Stelle des der Adventitia angrenzenden Mediaabsehnittes sind die elastischen Fasern stark aufgelockert.

Adventitia: In der Adventitia bemerkt man nur einen lang gestreckten, aus vielen Lymphozyten zusammengesetzten Zellherd und viele kleine Infiltrationen ans Plasmazellen und Lymphozyten. Sonst finden sich hier und da verdickte, sogar obliterierte Gefäße, Mastzellen sind viel nachweisbar.

Präparate II (Aneurysmagegend). In der mäßig stark verdickten Intima finden sich zerstreut Plasmazellen und Lymphozyten. In der Adventitia fallen viele Schwärme von Lymphozyten auf, an deren Peripherie reichlich Plasmazellen angehäuft sind. Sonstiger mikroskopischer Befund ist sehr ähnlich wie in den Präparaten $\mathbf{I}$.

F all 92. M. G., Musiker, 53 Jahre.

Klinische Diagnose: Herzklappenfehler.

Alkohol und Nikotin: mälig. Infektion: zweimal Gonorrhoe. - In der Ehe 5 Fehlgeburten. Wassermannsche Reaktion fehlt. Am 9. Juni 1912 Exitus letalis.

S.-Nr. 677; 1912. Obduktion 10. Juni (Ceelen).

Sektionsdiagnose: Chronische retrahierende Endocarditis aortica fibrosa. Aortitis syphilitica et sklerathermatosa der Aorta, Verdickung am Mitralsegel. Hypertrophie and Dilatation beider Ventrikel. Verengerung der Abgangsstelle der rechten Koronararterie. Fettige Degeneration der rechten Ventrikelmnskulatur: Allgemeine Stauung, insbesondere schwere Stauungsbronchitis und -gastritis. Icterus catarrhalis. Pneumonie in beiden Unterlappen. Iungenödem beiderseits. Frische fibrinöse Pleuritis rechts. Perisplenitis fibrosa. Hydrothorax links. Sklerose der Pulmonalarterie. Schleimhautverdickungen in der Magenwand. Geringe Skoliose dex Wirbelsäale. Ödem beider Beine.

Die linke Koronararterie ist intakt, während die Abgangsstelle der rechten verlegt ist dadurch, daß dér aufsteigende Teil der Aorta zahlreiche Platten und narbenartige Verdickungen aufweist. Die Pulmonalarterie hat gelbgraue Farbe und läßt auf der Innenseite leicht erhabene Verdickungen erkennen.

Die absteigende Aorta ist auf der Innenfläche gebröekelt, dazwischen finden sich längsverlaufende Rinnen, stellenweise sind die gelben Erhebungen erweicht und zerfallen. Auf dem Vorderteil, im Suleus coronarius des Penis alte Schankernarbe.

Die Präparate I sind einer Stelle der Pars ascendens mit der Pulmonalarterie entnommen, die grauweißliche narbenartige Verdickungen mit dazwischenliegenden Falten aufweist. Die Präparate II sind einer vertieften Stelle der Pars ascendens mit verdickter Aortenklappe entnommen.

Die Präparate III sind einer Stelle der Aorta thoracalis entnommen, die dieselben Veränderungen wie die Präparate I zeigt.

\section{Mikroskopischer Befund.}

Präparate I (Pars ascendens). Intima: Sie ist im allgemeinen ziemlich stark verdickt und zeigt in ihrem ganzen Verlauf viele wellenförmige Falten. Dicht an der Oberfäche der Intima sieht man an einigen. Stellen kleine Kalkablagerungen und lipoide Metamorphose. In der tiefsten 
Schicht der Intima treten hier und da Rundzelleninfiltrationen auf. In der Grenzschicht der Intima und Media liegen nebeneinander zwei kleine nekrotische Herde.

Media: An einigen Stellen finden sich mäßig große, ganz unregelrräbige Herde, in denen man junges Granulationsgewebe and Gruppen von Plasmazellen und Lyn:phozyten sieht. Die letzteren erstrecken sich von hier aus in die Intima hinein. In den oben erwähnten Herden bencerkt man keine normalen elastiselien und NGuskelfasern mehr, sondern nur zahlreiche Trümmer vox elastischen Fasern. Man trifft in der Media auch Blutpigment, besonders in den Herden und ihrer Umgebung. Die Abschnitte der Intima, die den Herden in der Media entsprechen, zeigen nicht die oben beschriebenen, wellenförmigen Falten, sondern im Gegenteil gerade diejenigen Partien, welche über wohlerhaltenenen elastischen und Muskelfasern liegen.

Adventitia: In der Adventitia fallen große stark verdickte oder sogar ganz obliterierte Geläße mit perivaskulären Infiltraten auf. Zellherde sind sehr viel vorhanden, einige von ihnen makroskopisch schon erkennbar. Sie bestehen aus Gruppen von Plasmazellen und Lymphozyten. Die kleinen perivaskulären Infiltrate und die in den interstitiellen Räumen befindlichen Zellen bestehen bisweilen nur aus Plasmazellen. Um die Nerven besteht keine Infiltration. Mastzellen sind sehr wenig vorhanden. Die linke Pulmonalis zeigt keine Veränderungen.

Präparate II (Pars ascendens mit der Klappe). Trotz der starken fibrösen Verdickung der Klappe sieht man keine Zellinfiltration.

Präparate III (Pars descendens) fast genau wie I.

Betrachten wir die in der Gruppe B vereinigten 70 Fälle, so ergibt sich folgendes:

Nach Lebensalter und Geschlecht geordnet:

\begin{tabular}{|c|c|c|c|c|c|}
\hline Jahre ........... & $31--40$ & $41-50$ & $51-60$ & $61-70$ & $71-80$ \\
\hline$\cdots, \ldots, \ldots, \ldots, \ldots, \cdots$, & 11 & 26 & 24 & 8 & 1 \\
\hline männliches Geschlecht $\ldots \ldots \ldots \ldots$ & 7 & 19 & 14 & 3 & 1 \\
\hline weibliches Geschlecht . . & 4 & 7 & 10 & 5 & 0 \\
\hline
\end{tabular}

Syphilitische Aneurysmen sind in 27 Fällen vertreten.

A n e urysma (27 Fälle). Davon mit anderen anatomischen Befunden, die für Syphilis sprechen:

(12 Fälle)
23. (186/11.)
25. ( 477/11.)
26. ( $629 / 11$.)
28. (1171/11.)
29. (1176/11.)
31. $(1416 / 11$.
32. ( 78/12.)
34. ( 124/12.)
36. ( 251/12.)
37. ( 303/12.)
39. ( 425/12.)
40. ( 637/12.)

Fälle, in denen, abgesehen von den vorgenannten, Syphilis anamnestisch und klinisch vorhanden:

$$
\text { ( } 7 \text { Fälle) }
$$
43. $(134 / 10$.
48. ( $926 / 10$.
50. $(1180 / 10$.
56. $(563 / 11$.
58. (1141/11.)
60. $(1413 / 11$.
65. (547/12.)

(nur W. R. 2 Fälle: 43, 60).

Hochgradige Stenose oder Obliteration der A. coronaria fand sich in 13 Fällen. Makroskopische Veränderungen der Aortenklappen fanden sich $30 \mathrm{mal}$. 
Der Sitz der Aortenveränderung ist meist die Aorta ascendens besonders ïber den Klappen, der Arcus aortae und der Anfangsteil der Aorta descendens. Der Abdominalteil der Aorta ist viel weniger an dieser Veränderung beteiligt. Von größeren Ästen der Aorta waren in einem Falle (89) die A. gastrica und A. lienalis syphilitisch verändert. Ein vorhandenes großes Magengeschwür konnte auf die Veränderung einer A. coronaria superior zurückgeführt werden.

Das makroskopische gemeinschaftliche Charakteristikum der Veränderung war das eigentümlich höckerig-runzelige oder strahlig-narbige Aussehen der Innenfläche der Aorta. Diese höckerigen Erhabenheiten, die ganz verschiedene Größe zeigen, sind meist grauweißlich, manchmal transparent, und diese Farbe sticht scharf von der normalen etwas gelblichen Färbung der Aorta ab. Die beetartigen großen Verdickungen erreichen manchmal die Größe eines Markstückes und haben meist keine glatte Oberfläche, sondern sind kleinhöckerig oder fein runzelig. Häufig fand ich längsgestellte und parallel verlaufende ganz feine Falten der Intima, die hauptsächlich zwischen Intimaverdickungen und um sie herum sitzen, jedoch auch auf ihnen vorkommen können. Ebenso trifft man an vielen, scheinbar von den Verdickungen ganz freien Stellen zahlreiche solche Intimafalten. Die Aortenwand, die die oben erwähnten Veränderungen zeigt, ist meist bis zur Durchsichtigkeit verdünnt, doch manchmal auch stark verdickt. In einem Falle war sie mehrfach so dick wie normal (Fall 66).

\section{Mikroskopi sehe Veränderungen.}

In keinem der Fälle ist es mir gelungen, Spirochäten aufzufinden. Das mikroskopische Charakteristikum war das Vorkommen eigenartiger Herde in der Media und Adventitia. Diese Herde, besonders die in der Media, waren in ihrer Zusammensetzung ganz verschieden: zellreich, manchmal nur aus kleinen und großen rundlichen oder ovalen Zellen bestehend und so umfangreich, daß sie schon makroskopisch als Pünktchen oder Flecken sichtbar waren und fast die ganze Mediaund Adventitiabreite einnahmen; oft aus Plasmazellen und Lymphozyten zusammengesetzt, deren Menge bedeutenden Schwankungen unterlag; oft nur aus Plasmazellen, seltener nur aus Lymphozyten. Letztere traten meist in der Adventitia auf. Die Plasmazellen und Lymphozyten traf man fast immer in bestimmter Anordnung an. Im allgemeinen traten sie nicht unregelmäßig miteinander vermischt, sondern in Gruppen beieinanderstehend, auf. Namentlich die Plasmazellen sind besonders gruppiert (Fälle 23-26, 28-30, 32, 33, 36-41, 44, 47, 48, $50-52,54,57-61,63-69,71,73,75-80,82,84,86,87,89-92$ = 50 Fälle).

Außer diesen Plasmazellen und Lymphozyten fanden sich oft vereinzelte polynukleäre Leukozyten.

In den Fällen $23,30,32-34,39,40,43,44,50,57,59,61,62,64,65,67,78$, $80,86,89$, also in 21 Fällen fand ich in der Media sowie in der Adventitia Zellinfiltrate, tells aus zahlreichen Plasmazellen und ganz wenigen Lymphozyten, 
teils fast nur aus Plasmazellen bestehend. Überhaupt fanden sich in einzelnen Präparaten viel mehr Plasmazellen als Lymphozyten.

Dagegen fand ich in einzelnen Präparaten viel mehr Lymphozyteninfiltrate als Plasmazellen (in den Fällen 24, 35, 38, 42, 45, 48, 53, 56, 58, 70, 74-76, 83, 87, 91, also in 16 Fällen).

- Die in der Adventitia befindlichen großen Zellinfiltrate, welche teils um verdickte, sogar obliterierte Vasa vasorum herumlagen, teils sich unabhängig von den Gefäßen lymphknötchenartig anhäuften, bestanden in den Fällen 24-26, $28,29,32,34,36,37,39,41,42,44,48-52,54,55,57,59,60,63-68,71-73$, $75-77,79,82,84,87,91$, also in 40 Fällen hauptsächlich aus Lymphozyten. Dabei sind die Plasmazellen mehr oder weniger in der Peripherie derselben ringförmig angehäuft oder manchmal jan beiden Seiten der Lymphozythenanhäufungen gruppiert; nur sehr selten fanden sich Plasmazellen yanz zerstreut in diesen Lymphozytenschwärmen.

Die Plasmazellen traten einerseits in den perivaskulären Lymphräumen, mehr noch um die Gefäße herum in vielen konzentrischen Kreisen auf, oder sie ordneten sich um stark dilatierte Kapillaren radiär an, teilweise mit bloßem Auge schon erkenntlich. Andererseits lagen sie in den interstitiellen Räumen ganz zirkumskript oder waren kettenartig angeordnet. Manchmal waren die Räume zwischen naheliegenden Vasa vasorum mit Plasmazellen angefüllt. Sehr oft infiltrierten die Plasmazellen massenhaft das Interstitium des adventitiellen Fettgewebes. Die um die Kapillaren und Lymphgefäße herumliegenden einschichtigen Plasmazellen zeigten die Form von Rosetten in den Fällen 23, 26, 28, 29, 31--34. $36-38,44,48-52,57,59,64,68,71,73,77-79,82,84,87,89$, also in 30 Fällen.

Außer den oben beschriebenen hauptsächlich aus Plasmazellen und Lymphozyten zusammengesetzten Zellherden fand ich sehr oft in der Media ganz frische und etwas ältere Granulationsherde, welche sich oft erheblich ausdehnten, so daß sie schon makroskopisch sichtbar waren. Es war nicht selten, daß diese Herde in die Intima hineinragten, andererseits mit gleichen Herden der Adventitia in Verbindung standen. Im Innern der meisten dieser Herde sind Kapillaren oder auch größere Gefäße neugebildet, welche sehr oft stark dilatiert und strotzend gefiullt sind, auch bis in die verdickte Intima hineinreichen. In manchen Fällen lagen um diese Gefäße herum zahlreiche Plasmazellen, die sich auch an anderen Stellen dieser Granulationsherde anhäuften. In den Herden und ihrer Umgebung fand sich manchmal Blutpigment. Neben diesen frischen Herden sah ich in vielen Fällen zellärmere Bindegewebswucherung, teils ganz narbige Stellen in der Media, die manchmal bis in die Intima wucherten. Verschiedentlich dehnten sich diese Wucherungen fast über die ganze Wand aus; infolge Schrumpfung dieses neugebildeten Bindegewebes verschmälerte sich die Aortenwand. Nur in einem Falle (Fall 89) waren einige Riesenzellen vorhanden, die sich in zwei Zellherden der Media befanden; sie hatten nicht den Langhansschen Typus. 
In fünf Fällen $(37,44,51,59,78)$ fand ich verschieden große schon makroskopisch sichtbare scharf abgegrenzte gummöse Herde in der Media, zum Teil in der Adventitia, zum Teil an der Grenze der Intima und Media. Davon waren in zwei Fällen diese Herde so ausgedehnt, daß man sie schon bei der Sektion bemerkte.

In den oben erwähnten versehiedenen Herden selbst waren die elastischen Fasern meist ganz zerstört, manchmal waren nur noch feine Trümmer oder Reste von ihnen vorhanden. Die durch diesen Defekt hervorgerufenen Bilder waren verschieden. Meist hatte man den Eindruck, als ob die elastischen Fasern in einem umschriebenen Bezirk durch die Granulationsgewebe oder Zellherde zerstört oder auf einmal abgeschnitten wären. Hier waren oft die Enden der erhaltenen elastisehen Fasern kolbig verdickt, zum Teil korkzieherartig geschlängelt oder büschelförmig zur Seite gebogen, als ob sie durch die zunehmende Ausdehnung der Zellen oder Granulationsgewebe seitwärts auseinander gedrängt wären. Solche Herde waren manchmal so zahlreich, daß sie nur kurze Stücke gesunder Media zwischen sich ließen. In manchen Fällen konnte ich feststellen, daß, wenn auch die elastischen Fasern in der Media nicht zerstört waren, sie doch herdweise oder ausgedehnter ihre Färbbarkeit für die rote und blaue Elastikafärbung verloren hatten, so daß sie teilweise kaum sichtbar als durchscheinende Fäden imponierten.

Die muskulären Elemente in der Media waren meist wie die elastischen Fasern durch Zellwucherungen geschädigt oder sogar zerstört, doch fand ich bisweilen Herde, in denen die muskulären Elemente gut erhalten waren und hier sah man keine Zellinfiltrate oder Granulationen, während innerhalb dieser Herde die elastischen Fasern völlig zerstört waren.

Es schien mir, als ob die Mediaherde in ihrer Lokalisation eine Vorliebe für bestimmte Mediaschichten hätten. In meinen Fällen 24, 29, 33, 35, 37, 43-48, $50,52-54,56,60,62-64,71,73,75,77,87-92$, also in 29 Fällen lagen die Herde hauptsächlich in dem intimawärts gelegenen Mediateile, während sie sich nur in 3 Fällen $(38,39,68)$ in den Adventitiahälften der Media befanden. Die uibrigen 38 Fälle zeigten gleichmäßig über die ganze Mediaschicht verteilte Herde.

Die Bestandteile und Anordnung der in der Adventitia befindlichen Herde habe ich schon besprochen. Nun muß ich noch erwähnen, daß sie meist zahlreicher und größer als die in der Media waren. In vielen Fällen befanden sie sich gleichmäßig in der Adventitia, doch öfter entwickelten sie sich mehr in dem peripherischen Teil.

Besonders aufgefallen ist mir das Vorkommen von obliterierender Endarteriitis der Vasa vasorum in der Adventitia (in den Fällen 23-26, 28, 29, 31, 34, 35, 37, $39,41,42,44,47-52,54-56,58,63-66,68-71,73,75,79,80,82,84,87,89-92$, $=43$ Fälle).

Bisweilen bildeten sich keine Zellanhäufungen um die obliterierten Vasa vasorum. In weiteren 19 Fällen $27,30,32,33,36,38,40,46,53,60-62,67,72$, 
$77,78,81,85,86$ (auch in obigen 43 Fällen) fand ich viele Vasa vasorum, die eine durch Auflockerung und Spaltung der elastischen Lamellen und Wucherung der Endothelzellen hervorgerufene starke Verdickung der Wand zeigten.

In den Fällen 23-25, 28, 32-34, 37, 40, 43, 44, 52, 55, 62-64, 66, 72, 76, $79,80,85$ (auch in den später beschriebenen 14 Fällen) sah ich diffuse oder ziemlich ausgedehnte Bindegewebswucherung in der Adventitia. Besonders in dem Falle 28 erreichte die Adventitia etwa das 6 - -7fache ihrer normalen Breite. Dieses gewucherte Bindegewebe war immer zellarm und derb, zum Teil glasig.

In den Fällen 26, 38, 41, 42, 48, 49, 56 , 58, 70, 71, 73, 78, 87, 90, also in 14 Fällen, fanden sich Neubildungen der elastischen Fasern in der Adventitia mit gleichzeitiger Wucherung des Bindegewebes. Sie traten hauptsächlich in der der Media nächstliegenden Schicht auf, auch entwickelten die elastischen Fasern sich zuweilen in dem peripherischen Teil der verdickten Adventitia, Diese elastischen Fasern waren manchmal mächtig entwickelt und präsentierten sich in einigen Fällen als Fortsetzungen der elastischen Fasern der Media. Sie färbten sich meist gut mit roter und blauer Elastikafärbung und zeigten bei dieser Färbung stellenweise ganz feine in Reihen angeordnete Körnchen.

Häufig beobachtete ich, daß sich die Plasmazellen um die in der Adventitia befindlichen Lymphknötchen herum gruppenweise oder diffus anhäuften oder netzförmig anordneten, auch ab und $\mathrm{zu}$ in diese ganz vereinzelt übertretend (Fälle $24,25,30,33,37,39,42,48,56,59,62,66,71,73,76-78,87)$.

In den Fällen 34, 60, 76 fanden sich kleine dicht an der Adventitia gelegene Lymphdrüsen, die alle reichlich Plasmazellen enthielten, und zwar in den Lymphsträngen und in den Trabekeln, auch in der Kapsel, vorzüglich aber in den Lymphräumen.

In etwa 40 Fällen bemerkte ich verschiedene Schnittfläche zeigende Nerven in der Adventitia, von denen ich in 21 Fällen $(23,26,29,32,34,37,41,42,48$, $54,56,57,60,62,64,66,73,76,78,84,87$ ) feststellte, daß Plasmazellén mit Lymphozyten diese Nerven umgaben, ja die Plasmazellen gingen manchmal in das Periund Endoneurium über.

Die Intima war in fast allen Fällen mehr oder weniger erkrankt. Die gemeinsame Veränderung war eine verschiedengradige Verdickung der Intima. Abgesehen von skleratheromatösen Veränderungen, welche ich in den Fällen 26, 29, $36,38,40,43,45,46,48-50,53,55,59,60,68,74-76,78,81,82,85,86,90$ (in 25 Fällen) sah, zeigte die Intima auch gleichzeitig entzündliche Prozesse, wie die Media und Adventitia. Diese entzündlichen Veränderungen waren oft sehr erheblich und die Intima zeigte sich hier meist mehr oder weniger verdickt ohne degenerative Veränderung. In diesen Stellen fand ich auch fast immer Plasmazellen, die meist gruppenweise auftraten oder sich parallel der Intimaschicht in mehreren Reihen anordneten. Trotz des geringfügigen entzündlichen Prozesses traten die Plasmazellen manchmal massenhaft auf. Ich stellte das Vorhandensein von Plasma- 
zellen in der Intima fest bei den Fällen 23, 24, 28-30, 32, 33, 36, 40, 41, 44, 46, $47,49-52,54,56,57,59,62-64,66,67,69,71,73,75,77,78,87,89,91$ (35 Fälle).

In dem verdickten Teil der Intima fanden sich sehr häufig neugebildete elastische Lamellen, die zuweilen am Rande der verdickten Stelle mit den elastischen Fasern der Media im Zusammenhang standen. In vielen Fällen untersuchte ich mikroskopisch die Aortenwand an Stellen, wo ich an der Intima, und zwar zwischen und in der Umgebung starker Verdickungen, zahlreiche feine meist längstgestellte und parallel verlaufende Fältchen sah, die ich bereits erwähnt habe. Ich konnte mit Sicherheit beobachten, daß fast immer die Intima selbst diese feinen Fältchen vorgebracht hat, und daß sie nicht immer über den Herden in der Media lagen, sondern häufig auch über dem Mediateil, welcher gar keine Veränderungen zeigte, es zeigten: längstgestellte Falten der Intima über der große Herde zeigenden Media die Fälle $32,39,41,55,67,72,90$, Falten über der ganz wenig veränderten Media die Fälle 38, 45, 62, 64, solche über der ganz unveränderten Media die Fälle 38 [andere Stelle], 39 [andere Stelle], 44, 48, 59, 69, 70, 73, 77, 81, 92.

Mastzellen traten in den meisten Fällen massenhaft und unregelmäßig in der Aortenwand, und zwar in der Adventitia auf; in 46 Fällen fanden sich auch vereinzelte Mastzellen in den herdförmig erkrankten Stellen. Bei 2 Fällen $(44,57)$ fanden sich Mastzellen in der verdickten Intima. Manchmal bemerkte ich das Auftreten von Mastzellen in den Nerven (Fälle 23, 26, 34, 48, 57, 62, 70, 87).

Die makroskopisch erheblich veränderten Aortenklappen, die ich in vielen Fällen mit der Aorta im Zusammenhang geschnitten und untersucht habe, zeigten alle nur derbes, faseriges Bindegewebe, und keine zellige Infiltration. Dagegen fielen mir in der die Sinus Valsalvae bildenden Aortenwand starke Zellherde auf (Fälle 33, 34, 44, ว̌2, 59, 87, 92).

Häufig habe ich die Pulmonalarterie mit der Aorta im Zusammenhang mikroskopiert. Trotz der hochgradigen Zerstörungen der Aortenwand waren die Pulmonalarterien immer ganz intakt (Fälle 24, 26, 29, 39, 48, 49, 54, 56, 59, 65, 71, 82, 84, 92).

Um zunächst zu konstatieren, daßi es sich in meinen Fällen (23-92) überhaupt um Mesaortitis syphilitica handelt, führe ich zum Vergleich kurz die Resultate anderer Autoren an.

M a $1 \mathrm{msten}$ sah eine höckerig-runzlige Beschaffenheit der Innenfläche der Intjma neben strahlig-narbigen Einziehungen. Mijkroskopisch fand er Infiltrationen in der Media und Adventitia. Er nannte diese Veränderungen sklerogummöse Aortitis.

Pup p e schrieb über zwei Fälle von Aneurysma mit nachgewiesener Syphilis. Er bemerkte hauptsächlich Veränderung der Media und Adventitia, die im Auftreten der perivaskulären Infiltrate bestanden. Er fand einige Riesenzellen in dem Mediaherde und die elastischen Fasern der Media durch Granulationsherde und narbiges Bindegewebe zerstört. Vasa vasorum waren verdickt, sogar obliteriert. Die dem erkrankten Teil entsprechende Intima war verdickt.

In seiner zweiten Arbeit beschrieb Do e hle im Jahre 1895 in der Aorta ascendens und dem Areus aortae eigenartige Veränderungen bei syphilitischen Personen, die aus zahlreichen strahlig-narbigen Einziehungen, flachen grubenförmigen Vertiefungen und auch spaltförmigen 
oder strickförmigen Falten an der Innenfläche der Aorta bestanden. Die Aortenwand war stellenweise stark verdünnt, so daß sie bei Betrachtung im durchfallenden Licht durchscheinend war. In zwei von seinen drei Fällen war die Intima verdickt, ohne atheromatöse Veränderungen; mikroskopisch wies die Media die stärksten Veränderungen auf. In der Media fanden sich entzündliche Zellinfiltrate, Granulationsherde und schrumpfendes Bindegewebe, wodurch die Media stellenweise zerstört war. Die Adventitia war auch stark erkranlst und Zellanhäufungen bildeten sieh um die Vasa vasorum, die bisweilen durch eine Wucherung der Intima verschlossen waren. Fr fand in den zwei Fällen nekrotische Herde in der Media. In einigen Infiltraten fanden sich in einem Fall Riesenzellen. Da in allen drei beschriebenen Fällen durch verschiedene Momente Syphilis sicher zu konstatieren und Tuberkulose auszuschließen ist, so muBte Do e hl e als Ursache für die genannten Veränderungen die Syphilis geiten lassen.

$\mathrm{J}$ a $\mathrm{k} 0 \mathrm{~b}$ beobachtete starke gefäßführende Granulationswucherungen um die Vasa vasorum in der Adventitia der Aorta eines 18 jährigen Mannes. Die entzündlichen Herde fanden sich auch in der Media und Intima. Die Herde wurden als Gummata aufgefaßt. Die Intima selbst war verdickt.

$\mathrm{B}$ a c khaus kennzeichnete die syphilitische Erkrankung der Aorta dahin, dab meist auf der Innenfläche der Aorta ascendens Furchen oder Einziehungen entstehen, die man als Gruben aussprechen kann. Die Intima war gewöhnlich glatt und wies kaum eine Spur einer Verdickung, Verfettung oder Verkalkung auf. Mikroskopisch fand er Zellinfiltrationen mit zentraler Erweichung und Zerfall, auch narbige Herde in der Media. Gleichfalls bemerkte er in der Adventitia die entzündlichen Veränderungen mit Ausnahme der Nekrose, besonders fiel ihm obliterierende Endarteriitis der Vasa vasorum auf. In der Adventitia war das Bindegewebe vermehrt.

$\mathrm{Str}$ a u b fand schwielige ausgedehnte Intimaverdickungen mit fleckweiser Ausbreitung, und zwar traten diese Verdickungen als runzelige, kleinhöekerige wazzenähnliche, dicht gedrängte Erhabenheiten auf. Auch sah er manchmal strahlige, narbige Einziehungen der Aortenwand, wo letztere bis zum Durchscheinendwerden verdünnt war. Mikroskopisch bemerkte er Zellinfiltrationen um die verdickten und obliterierten Vasa vasorum der Adventitia. Diese Zellherde und Bindegewebswucherungen drangen in die Media vor, hier die elastischen Fasern zerstörend. In einzelnen Fällen fand er auch Riesenzellen in den Zellherden. S t r a u b hält die Erkrankung, die er nur bei sicheren Syphilitikern fand, auf Grund dieses histologischen Befundes für eine gummöse Aortitis.

Heller stellte das Bild der syphilitischen Aortitis dahin fest, daß sich makroskopisch mehr oder weniger ausgedehnte Verdickung und Runzelung der Intima finden, während die Aortenwand gegen das Licht gehalten, stellenweise starke Verdünnung zeigt. Mikroskopisch fand er Zellinfiltrationen und Gramulationen hauptsächlich in der Media, auch manchmal Riesenzellen und umschrieben Nekrose, die ex als miliare Gummata deutete. Die Adventitia zeigte Verengerung resp. völlige Obliteration der Vasa vasorum und mehr oder weniger starke Verdickung und Sklerosierung des Bindegewebes. Der chronischen Endarteriitis zukommende Veränderungen fanden sich nicht in der erkrankten Intima.

He in e bemerkte bei drei Syphilitikern im Anfangsteil der Aorta runzelige, narbige Einziehungen der Intima. Mikroskopisch fand er in der Media aus Rund- und Plasmazellen sich zusammensetzende Zellinfiltrate, die zuweilen Riesenzellen enthielten. Die elastisehen Fasem waren hier ganz zerstört. Die Zellherde zeigten manchmal bindegewebige Umwandlung. In der Adventitia bestanden Zellinfiltrate um die obliterierten Vasa vasorum. Die Intima war unregelmälig verdickt und zeigte stellenweise kleinzellige Infiltration. Da Tuberkulose im Körper nicht nachzuweisen, Syphilis aber sicher bewiesen war, sah er diese als Ursache der Veränderungen an.

$\mathrm{Ch}$ i a ri sah Furchen und kleine Ausbuchtungen an der Innenfläche der Aorta. Mikroskopisch fielen ihm die teils aus Rundzellen, teils aus Granulations- oder faserigem Bindegewebe bestehenden Entzündungsherde in der Media auf. Zưeilen waren Riesenzellen von dem Typus 
der L anghan s schen oder Fremdkörperzellen und nekrotische Herde vorhanden. Das aus den Herden hervorgegangene faserige Bindegewebe zeigte eine große Neigung zur Schrumpfung. In der Adventitia bemerkte er auch Entzündungsherde um die Vasa vasorum, die manchmal Endarteriitis proliferans zeigten. Das dichte faserige Bindegewebe war neugebildet. Die Intima war intakt oder mehr oder weniger verdickt und zeigte nur zuweilen regressive Metamorphosen geringen Grades. Er nannte diese Aortenveränderungen Mesaortitis productiva.

$\mathrm{B}$ e c k fand bei zwei Syphilitikern zackige, grubige Einziehungen und flache eingesunkene, narbige Stellen auf der Innenfläche der Aorta. Mikroskopisch fanden sich in der Media verschieden grobe aus epitheloiden Zellen, spindeligen und Rundzellen sich zusammensetzende Herde, die manchmal Riesenzellen, oft vom $\mathrm{L}$ a $\mathrm{n} \mathrm{g} \mathrm{h}$ a $\mathrm{n}$ s schen Typus enthielten. In einem Herde bemerkte er zentrale Nekrose. Auch fand er viele kernarme Bindegewebswucherungen und kleinzellige Infiltrate, die meist um die Gefäße bestanden. Die elastischen Fasern fehlten vollständig im Bereich der Herde. Die Adventitia war verdickt und enthielt zahlreiche, meist perivaskuläre Lymphozyteninfiltrate. Die Vasa vasorum waren verengt, sogar völlig obliteriert. Die Intima war stark verdickt, zeigte aber nur wenig regressive Veränderungen. B e ck faßt den Prozeßs als gummöse Aortitis auf, da die charakteristischen Stellen in der Media typischen gummösen Bau zeigten und sonstige sichere Zeichen von Syphilis vorhanden waren. Tuberkulose hält er für ausgeschlossen, da sich nirgends im Körper ein Herd vorfand.

Eich faßte die Ergebnisse seiner Untersuchungen folgendermaßen zusammen: Die Doehle-Hellersche Aortitis manifestiert sich makroskopisch an der Aorta ascendens, dem Arkus, der Aorta descendens bis zu den A. renales durch narbige Falten, Furchen, grübchenartige Einziehungen und Dellen, in deren Bereich die Gefäßwand bis zum Durchscheinendwerden verdünnt sein kann; neben solchen durch Intimaverdickungen, die sich von den atherosklerotischen durch ihre weißliche Farbe und das Fehlen von Verkalkung auszeichnen. Mikroskopiseh sieht man eine nach Umfang und Dauer der Krankheit zu verschieden starken Schädigungen der Gefäßwand führende, zur Bildung stark schrumpfender Narben neigende, herdweise Entzündung, die in den meisten Fällen nur. Media und Adventitia ergreift, aber auch die Intima nicht verschont. Der Infiltratbildung scheint in der Media fleckenweise Zerstörung der elastischen Fasern voranzugehen. Die Herde können gummösen Charakter tragen.

Orth, Kaufmann, Asehoff und $\mathrm{Schmaus}$ berichten auch in ihren Lehrbüchern über gleiche Ergebnisse.

Nach den Befunden obiger Autoren und ihren Ausführungen kann man bezüglich der Aortenveränderung auf syphilitische Erkrankung mit großer Wahrscheinlichkeit schließen. Die Ergebnisse meiner 70 Fälle (23-92) sind mit den Befunden dieser Autoren übereinstimmend, folglich müssen die Aortenveränderungen in meinen 70 Fällen durch syphilitische Erkrankung hervorgerufen sein.

Die Fälle der Gruppe IV zeigen mit den übrigen eine so vollkommene Utbereinstimmung, auch im mikroskopischen Bilde, daß man eine Syphilis nur nach diesem histologischen Befund auch ohne syphilitische Befunde an anderen Organen oder syphilitische Anamnese wird annehmen dürfen. Was hier im Allgemeinen gesagt ist, gilt für die Aneurysmen auch im Speziellen.

Es gestatten aber weiter meine 70 Untersuchungen einige Schlüsse, die teilweise zu bisherigen Ergebnissen im Gegensatz stehen, teilweise einen neuen Befund ergeben.

Trotz des Studiums vieler berufener Autoren konnte ich genauere Angaben über die Plasmazellen bei Aortitis syphilitica nicht finden; nur einige Autoren 
schenkten ihrem Vorkommen geringe Beachtung, so daß es mir scheint, daß auf das Vorkommen von Plasmazellen bei Aortitis syphilitica bisher wenig geachtet worden ist, im Gegensatz zu anderen syphilitischen Entzündungsherden. Ei c h, der noch neuerdings über 63 Fälle von $\mathrm{D}$ o e hle - $\mathrm{Helle}$ scher Aortitis berichtete, erwähnt in dieser Abhandlung nur einige Fälle mit Plasmazellen. Dagegen konnte ich in jedem einzelnen meiner vorerwähnten 70 Fälle Plasmazellen finden. Ja, unter diesen 70 Fällen waren, wie ich bereits oben anführte, 21 Fälle, in denen viel mehr Plasmazellen als Lymphozyten in den Media- und Adventitiaherden vorhanden waren. Im Gegensatz dazu fand ich vielmehr Lymphozyteninfiltrationen als Plasmazellen in den Präparaten von 16 Fällen. Ich konnte nicht nur in der Media und Adventitia, sondern auch in der mehr oder weniger veränderten Intima in 35 Fällen Plasmazellen finden. Wie schon bemerkt, fand ich die Plasmazellen in ganz eigenartiger Anordnung, und zwar waren sie nicht unregelmäßig mit Lymphozyten in den Zellherden vermischt, sondern meist in Gruppen beieinander stehend (50 Fälle), oder sie häuften sich in der Peripherie der großen adventitiellen Zellherde ringförmig an (40 Fälle), oder umgaben in ähnlicher Weise die Lymphknötchen in der Adventitia (18 Fälle). Manchmal waren die Plasmazellen reichlich auBerhalb und innerhalb der periadventitiellen Lymphdrüsen und der adventitiellen Nerven vorhanden. Mitunter bestand ein ganzer Zellherd nur aus Plasmazellen, die um Gefäße herum in vielen konzentrischen Kreisen auftraten.

In strengem Gegensatz dazu habe ich bei den zahlreichen verschieden starken Graden der Skleratherose der Aorta, die ich zur Kontrolle untersuchte (Gruppe A), und zwar mitunter in der Adventitia, äußerst selten auch in der Nedia, kleine Zellinfiltrate beobachtet, die immer nur aus Lymphozyten, manchmal mit ganz wenigen polymorphkernigen Leukozyten bestanden, in keinem Falle aber konnte ich aus Plasmazellen bestehende Herde finden, nur in einem Fall sah ich einzelne Plasmazellen in der Adventitia. Also die Tatsache, daß, wie ich bereits anfuhrte, die Plasmazellen bei Aortitis syphilitica in reichlicher Menge in der Aortenwand auftreten und daß sie im Gegensatz dazu bei Skleratherose der Aorta nicht vorkommen, muß eine ganz besondere Bedeutung für die Differentialdiagnose dieser beiden Aortenveränderungen haben. Natürlich kann man, wie bereits erwähnt, zwischen Aortitis syphilitica und Skleratherose unschwer unterscheiden, wenn beide Veränderungen ganz typiseh sind. Aber bei geringfügiger Aortitis syphilitica ist die Entscheidung manchmal schwieriger, da auch bei schwerer Skleratherose ab und zu Zellherde, wenn auch in geringerem Grade, in der Adventitia, seltener Media auftreten, die große Ähnlichkeit miteinander haben. Man kann dann, abgesehen von Komplikation beider Prozesse, nach dem Vorkommen von Plasmazellen in der Aortenwand resp. in der Media und Adventitia oder in der wenig veränderten Intima eine Diagnose stellen, und zwar wird man bei ihrem Vorhandensein mindestens einen starken Verdacht auf Syphilis aussprechen können. 
Vorsicht ist insofern geboten, als sich bei der Färbung der Plasmazellen mit Pappenheim-Unnas Pyronin-Methylgrün manchmal Protoplasma der Intimazellen und Bindegewebszellen auch rot färbt und dann wie das von Plasmazellen erscheint; bei genauerer Beobachtung kann man die Zellen jedoch leicht durch die Kerne und sonstige Beschaffenheit unterscheiden.

Mo $\mathrm{l}$ i n a r $\mathbf{i}$ beobachtete in seinen Fällen fleckweise Zerstörung der elastischen Fasern der Media ohne Infiltrate. Er faßte diese Veränderung als Initialstadien einer Mesaortitis productiva auf. Es sollte das syphilitische Virus nicht erst durch Störung der Blutversorgung. wirken, sondern direkt elektiv schädigend auf die elastischen Fasern einwirken, diese in ihrer Widerstandskraft so schädigend, daß sie unter der Einwirkung des Blutdrucks einreißen. Erst nach eingetretener Schädigung träten dann Infiltrationen auf. Er glaubt, daß die von $\mathrm{B} \mathrm{a} \mathrm{ck} \mathrm{h}$ a $u \mathrm{~s}$ als Frühsymptom bezeichnete Obliteration der Vasa vasorum erst bei fortgeschrittenen Veränderungen auftreten (ich werde noch später auf diesen Punkt näher eingehen). $\mathrm{Ei} \mathrm{ch}$ hat bei eigenen Beobachtungen diese Ansicht bestätigt gefunderi.

Ich habe, wie ich bereits anführte, selten Mediadefekte ohne Infiltrationen gefunden, in diesen aber waren die muskulösen Elemente gut erhalten. Nach meinen Erfahrungen und Beobachtungen kann ich mit M o li n a ri nicht völlig übereinstimmen aus folgenden Gründen:

1. Trotz meines zahlreichẹn Materials fand ich diese Veränderungen, d. h. die Zerstörung der elastischen Fasern, der Media ohne Infiltrationen äuBerst selten.

2. In seltenen Fällen fand ich Stellen, wo viele Infiltrate vorhanden, jedoch die elastischen und Muskelfasern erhalten waren.

3. Es scheint mir unmöglich, daß, wie Molin ari meint, zuerst nur die elastischen Fasern direkt elektiv durch das syphilitische Virus zerstört werden, da in den meisten Herden die elastischen und Muskelfasern zusammen zerstört sind. Es zeigt sich auch an anderer Stelle z. B. am Hoden, daß die Syphilis die elastischen Fasern weniger zerstört als die Tuberkulose.

Scagli o si möchte durch seine Untersuchungen beweisen, dab in der Media bei säntlichen Entzündungen zuerst die Muskelelemente und dann erst die elastischen Elemente betroffen werden. Die elastischen Bestandteile ändern sich dann infolge der Zerstörung der Muskelbestandteile.

Diese Auffassung steht in direktem. Widerspruch zu Molinaris oben zitierten Ausführungen, doch kann ich mich auch S c a gli o sis Meinung nicht völlig anschließen, denn, wie bereits erwähnt, fand ich Stellen in der Media mit vollständiger Zerstörung der elastischen Fasern und gut erhaltenen Muskelfasern.

Einzelne neuere Autoren halten das Verhalten der Vasa vasorum für sehr beachtenswert und von ihnen nimmt ihrer Meinung nach die ganze Erkrankung der Aortenwand ihren Ausgang, eine Meinung, die bereits Backhaus im 
Jahre 1897 äußerte, nachdem zuerst $\mathrm{K}$ öst er die von ihm beschriebene Mesaortitis fibrosa auf eine Veränderung der Vasa vasorum bezogen hatte.

$\mathrm{Backhaus}$ meint, das syphilitische Gift erzeuge zuerst Reizung und Wucherung der Vasa vasorum, die dadurch teilweise oder ganz obliterieren könnten. Infolgedessen entstehe in den zugehörigen GefäBgebieten eine Ernährungsstörung, weiterhin Nekrosen. Lenkozytenein wanderung in die geschädigten Teile; lokale Zellwucherung erzeuge dann kleine, meist umschriebene Knoten in der Media, die als Gummata anzusprechen sind. S a a thof $f$ hat das Verhalten der Vasa vasorum eingehend studiert und kommt zu denselben Ergebnissen wie Backhaus. H e in e ist ebenfalls der Ansicht, daß die Endarteriitis der Vasa vasorum für Syphilis spreche. Auch andere Autoren haben die Obliteration der Vasa nutritia beobachtet und ebenso aufgefaßt.

Hierzu im Widerspruch stehen die Angaben von $B$ a u $m$ garten und Eic h. Ersterer weist darauf hin, daß die Endarteriitis obliterans der Vasa vasorum auch bei ehronischen Entzündungen aller Art vorkommt und deshalb für die Annahme des syphilitischen Charakters dex Mesaortitis productiva nicht verwertbar sei. E i c h hat unter 63 Fällen nur 4 mal diese obliterierende Endarteriitis der Vasa nutritia gefunden, bestreitet deshalb die Riehtigkeit der angeführten $\mathrm{B} \mathrm{a} \mathrm{ckh}$ a u s schen Erklärung.

Von meinen 70 Fällen weisen 43 vollkommenen Verschluß der Vasa vasorum auf, 21 zeigen starke Verengerung des Lumens derselben und nur 6 Fälle sind ohne erkennbare Veränderung der Vasa vasorum.

Zudem habe ich, wie schon in meinen mikroskopischen Befunden gesagt ist, beobachtet, daß sich in 29 Fällen die relativ frischen Herde in der intimawärts gelegenen Mediahälfte finden und dagegen nur 3 Fälle - ein Fall mit einer ganz geringen Veränderung - in dem adventitiawärts gelegenen Mediateile. Der intimawärts gelegene Mediateil wird nun aber gerade von den feinsten Verzweigungen der Vasa vasorum versorgt, welche durch eine Arteriitis obliterans schneller verschlossen werden als ihre größeren Stammgefäße. Ich kann also, unterstützt durch diese besondere Beobachtung, nur durchaus $\mathrm{B}$ a $\mathrm{ckh}$ a us beipflichten.

Bindegewebsneubildung in der Adventitia bemerkten schon einige Autoren $\mathrm{Backhaus,} \mathrm{Heller}, \mathrm{Chi} a \mathrm{ri}$ und Beck. Ich habe, wie ich schon anführte, in 22 Fällen diese Veränderungen gefunden, manchmal so stark, daß der Querschnitt schon makroskopisch leicht erkennen ließ, wie stark die Verdickung der Adventitia vorgeschritten war.

Ich konnte anch viele neugebildete elastische Fasern in dieser stark verbreiterten Adventitia beobachten, und zwar in 14 Fällen. Bezüglich des Ursprungs dieser neugebildeten elastischen Fasern meine ich, daß sie hauptsächlich aus den alten elastischen Fasern der Media, zum Teil auch von diesen unabhängig, nämlich von Bindegewebszellen entstanden sind. Die bereits beschriebenen, ganz feinen, in Reihen angeordneten Körnchen, die sich bei roter und blauer Elastikafärbung zeigen, scheinen mir Querschnitte neugebildeter elastischer Fasern zu sein.

Die Intima wies, wie schon erwähnt, in meinen Fällen zwei Arten von Falten auf, die einen runzelig oder strahlignarbig, die fast in allen Füllen auftraten, während die andere Art meist längsgestellte und parallel verlaufende ganz feine Falten hatte. Erstere Art wurde fast von allen Autoren beobachtet. Dabei kann ich nur $\mathrm{C}$ h i a $\mathrm{r}$ is 
Meinung bestätigen, daß die Schrumpfung der neugebildeten Bindegewebsfasern in den Mediaherden mehr oder weniger tiefe Furchen und kleine Ausbuchtungen in der darïber liegenden Intima hervorruft. Dagegen wird von der anderen Art sehr wenig berichtet. In 11 Fällen habe ich, meist in der Umgebung von Intimaverdickungen, derartige Falten auch ohne darunter befindliche Veränderung der Media beobachtet und glaube deshalb, daß bei ihrer Entstehung teils die Zusammenziehung der elastisch-muskulösen Elemente der Media, teils auch der Seitendruck der Intimaverdickungen eine Rolle spielt, um so mehr, als die Falten besonders deutlich zwischen zwei Intimawucherungen hervortreten.

Intimaverdickungen, die sich von Skleratherose durch das Fehlen von Verfettung, Verkalkung und ihre mehr weilgraue, speckig durchscheinende Färbung unterscheiden, fanden sich meist über solcher Media, die entweder ganz frische oder ältere Herde enthielt, besonders über den am stärksten veränderten Teilen der Media. Deshalb meine ich, daß der Einfluß der Mesaortitis auf die Intima ein unmittelbarer ist, doch sind diese Verdickungen, wie auch $\mathrm{Backhaus}$ und H eller annehmen, als sekundäre Veränderungen anzusprechen. Diese Erscheinung ist, wie ich glaube, ziemlich charakteristisch für Aortitis syphilitica, wenn auch das runzelige, strahlig-narbige Aussehen der Intima im Vordergrund steht. $\mathrm{E}$ i c h sagt ,schlieBlich würde ja auch, wenn sich stets über Mediadefekten entsprechende Intimaverdickungen entwickelten, kaum die tatsächlich zu beobachtende Abnahme der Gesamtdicke der Gefäßwand erklärbar sein, wie sie tatsächlich sich einstellt und die ja makroskopisch an durchseheinenden Flecken kenntlich ist". Ich muß dieser Erklärung $\mathrm{E}$ i $\mathrm{ch}$ s widersprechen, denn ich habe in vielen Präparaten meiner Fälle beobachtet, daß die Intima verdickt, die Media jedoch durch Narbenbildung so stark verschmälert war, daß die Aortenwand in ihrer Gesamtheit dennoch sehr dünn, ja bisweilen durchsichtig erschien.

Ob die Aortitis syphilitica sekundär eine Skleratherose herbeiführt, oder $o b$ die letztere bei einer Aortitis syphilitica unabhängig von ihr als Komplikation möglich ist, ist schwer zu entscheiden. Ich habe auch bei jüngeren Individuen Skleratherose beobachtet und bin der Meinung, daß es bei längerer Krankheitsdauer noch zu skleratheromatösen Veränderungen der Intima gekommen wäre.

Aortenaneurysmen haben hauptsächlich Syphilis als Erkrankungsursache, doch können manchmal auch Aortitis chronica deformans, seltener Infektionskrankheiten in Betracht kommen. Wel ch führt $60 \%$ der Aortenaneurysmen auf Syphilis zurück, P u p p e $80 \%$, von L e y d e n $50 \%$. B a e r beobachtete 17 Fälle sicheren syphilitischen Ursprungs unter 26 von Aortenaneurysma.

Berücksichtigt man die Anwendung der Wassermannschen Reaktion so ist der Prozentsatz der syphilitischen Aneurysmen ständig in der Zunahme begriffen, K a 1 o f f z. B. fand bei 30 Fällen 26 mal positiven Ausfall der Wassermannschen Reaktion. Unter meinen Fällen stellten sich alle 27 Aneurysmen als syphilitisch heraus, wobei die hohe Zahl der Aneurysmen unter der Aortitis syphilitiea auf- 
fällt (27 unter 70) [E $\mathrm{i} \mathrm{ch}$ fand 10 Fälle von ausgebildetem syphilitischen Aneurysma unter 63 Fällen von Aortitis syphilitica].

Über Fälle von Syphilis der Pulmonalarteria haben Brooks und B arth Nitteilungen gemacht. Auch fand $\mathrm{H}$ art bei Aortensyphilis in der Wand der Pulmonalarterie einen ziemlich großen Gummiknoten. Raeh und Wiesner beobachteten syphilitische Veränderungen in der Aorta und Pulmonalis bei kongenitaler Syphilis.

Wie ich jedoch bereits anführte und für bemerkenswert halte, konnte ich trotz vieler Untersuchungen der Pulmonalarterie zusammen mit der stark zerstörten Aorta, niemals eine krankhaft veränderte Pulmonalarterie finden.

Bezüglich des Vorkommens der Spirochaeta pallida in der Aortenwand muß ich noch einmal sagen, daß ich trotz meiner sorgfältigen Untersuchungen, die sich auf ältere wie auch frische Herde erstreckten, dort niemals einwandfreie Spirochäten gefunden habe, während ein jedesmal genau korrespondierend behandeltes Kontrollstück einer und derselben kongenitalsyphilitischen Leber i m m er die Spirochäten zweifelsfrei zeigte. Verdächtige Gebilde, die man für Spirochäten hätte halten können, erschienen bei genauer Betrachtung als Niederschläge und als Trümmer von Fasern elastischen und anderen Gewebes. Ihre Schlängelung war nicht so typisch wie bei den von $\mathrm{Sch}$ a u in $\mathrm{n}$ und $\mathrm{H}$ offman $\mathrm{n}$ beschriebenen Formen, auch waren sie oft fragmentiert.

Der Syphiliserreger wurde überhaupt, wie ich schon erwähnte, bisher nur in wenigen Fällen in der veränderten Aortenwand gefunden. Einige Autoren erklärten dazu, daß es sich meist um Veränderungen in späteren Stadien der Entzündung handele, in denen die Spirochaeta pallida nicht mehr vorhanden ist.

Re u ter fand den Erreger in dem frischen, neugebildeten Bindegewebe, welches noch keine regressiven Prozesse aufwies, entweder zwischen den Fibrillen eingelagert oder in den Lymphspalten zu mehreren gelagert. Fra en kel zweifelt $R$ e u ters Behauptungen an, indem er es für mindestens auffällig hält, wenn man in diesen narbigen, den Endausgang einer vorangegangenen syphilitischen Affektion vorstellenden Krankheitsherden noch den Krankheitserreger würde nachweisen können. Vers é meint, daß die Syphiliserreger frühreitig in den entzündlichen Reaktionsgebieten infolge toxischer Wirkung der Zellen untergehen, oder daß ihr Verschwinden auf Phagozytose beruht. Vanzetti implantierte um die Karotis eines Kaninchens herum Stücke eines Syphiloms, das er in der Inguinalgegend eines anderen Kaninchens durch Impfung mit Spiroehätae pallidae erzeugt hatte. Bei späterer Untersuchung fand sich an der Karotis ein Aneurysma, in dessen Wand keine Spirochäten nachzuweisen waren.

Bestimmt durch die Tatsache, daß in diesen älteren und frischen Herden trotz sorgfältigster Untersuchungen keine einwandfreien Spirochäten zu finden waren, bin ich zu der Überzeugung gekommen, daß nur ganz frisch entstandene Herde diese Erreger enthalten und erkennen lassen. Soweit sich bei meinen Fällen der Zeitpunkt der Infektion feststellen läßt, handelt es sich durchweg um sehr alte Fälle. Von 18 Angaben liegt nur zweimal der Beginn der Erkrankung weniger als 
10 Jahre zurück (Fall 56, 8 und Fall 61, 9 Jahre), 7 Fälle $(46,44,54,49,52,47,30$ ) sind 20-30 Jahre alt, 2 (51 und 37) mit 33 und 39 Jahren noch weit älter.

Die Ergebnisse meiner Arbeit sind zusammengefaßt folgende:

1. Die Aortitis syphilitica kennzeichnet sich makroskopisch an der Aorta ascendens besonders ïber den Klappen, an dem Arcus aortae und der Aorta descendens bis zu der A. gastrica durch höckerig-runzeliges oder strahlig-narbiges Aussehen mit oft vorkommenden längsgestellten und parallel verlaufenden ganz feinen Falten, in deren Bereich die Gefäßwand bis zur Durchsichtigkeit verdünnt sein kann, auch durch Intimaverdickungen, welche sich von der Skleratherose durch ihre weißgraue, speckig durchscheinende Farbe und das Fehlen von Verfettung und Verkalkung unterscheiden.

2. Mikroskopisch finden sich in der Media und Adventitia, auch oft in der Intima ganz verschieden starke, zur Bildung sehrumpfender Narben neigende Entzüindungsherde, die auch gummösen Charakter tragen können. Die Zellinfiltration in der Media scheint der fleckweisen Zerstörung der elastisch-muskulösen Elemente voranzugehen, doch sieht man sehr selten auch Herde, in denen die muskulösen Elemente gut erhalten und die elastischen Fasern völlig zerstört sind, auch solche, in denen weder Zellinfiltrationen noch Gramulationen vorhanden sind.

3. Plasmazellen kommen nicht nur reichlich in den Zellherden der Media und Adventitia vor, sondern auch sehr oft in der Intima. Sie zeigen eine eigenartige Lokalisation in der Wand und eine bestimmte Anordnung, und zwar treten sie im allgemeinen nicht unregelmäßig mit Lymphozyten vermischt auf, sondern sie sind besonders gruppiert. Bei den in der Adventitia befindlichen großen Zellherden und Lymphknötchen häufen sich die Plasmazellen meist massenhaft in der Peripherie derselben ringförmig an. Sie treten sehr oft in einzelnen Präparaten stärker als Lymphozyten auf, manche Infiltrate bestehen sogar nur aus Plasmazellen. Letztere umgeben auch oft in vielen konzentrischen Kreisen die Vasa vasorum oder sie ordnen sich um dieselben radiär an. Man sieht manchmal Plasmazellen in dem Endo- und Perineurium der adventitiellen Nerven oder in den periadventitiellen Lymphdrüsen.

4. Bei der Skleratherose kommen ebenfalls geringfügige Zellherde in der Media und Adventitia vor, die fast gar keine Plasmazellen enthalten. Deshalb haben letztere differential-diagnostische Bedeutung.

5. Bei Aortitis syphilitica sieht man reichliches Auftreten von Mastzellen in der Aortenwand.

6. Die in der Media gelegenen Erkrankungsherde lokalisieren sich bei der Aorta syphilitica mit Vorliebe in der intimawärts gelegenen Mediahälfte.

7. Die Verdickung und Obliteration der Vasa vasorum spielt bei Aortitis syphilitica eine ganz bedeutende Rolle.

8. In der Adventitia wuchert bei Aortitis syphilitica nicht nar das kollagene Bindegewebe, sondern es entwickeln sich auch häufig elastische Fasern. 
9. Die längsgestellten und parallel verlaufenden ganz feinen Falten der Intima entstehen nicht nur durch den Narbenzug der Mediaherde, sondern auch durch die Zusammenziehung der elastisch-muskulösen Elemente der Media, und durch Seitendruck der Intimaverdickungen, um so mehr, als die Falten besonders deutlich zwischen zwei Intimawucherungen hervortreten.

10. Die Pulmonalarterie, die ich in einer Reihe yon Fällen stärkster Aortenveränderung untersuchte, fand ich immer intakt.

11. Die Aortitis syphilitica kann bei längerer Dauer sekundär Skleratherose erzeugen.

12. $32,8 \%$ (23 Fälle unter 70) meiner Fälle mit sicherer Aortitis syphilitica zeigten keine klinisch oder an den übrigen Organen anatomisch nachweisbare Syphilis, noch metasyphilitische Erkrankungen, noch positive Wassermannsche Reaktion. In solchen Fällen, wo also die Syphilis nur anatomisch und nur an der Aorta anftritt, muß man sich besonders vor Verwechselungen mit Arteriosklerose hüten.

13. Die Untersuchung der Aneurysmenwand ergab in 100\% der Fälle die syphilitische Natur der Erkrankung.

14. Die Spirochaeta pallida scheint nur in ganz frisch entstandenen Herden vorzukommen.

\section{Literatur.}

1. A bram ow, U̇ber die Veränderung der Aorta bei Syphilis. Virch. Arch. Bd. 178. 2. A mend a, D., Uber den Zusammenhang von Lues und Aortenerkrankang. Diss. Mïnchen 1903. - 3. As choff, Pathologische Anatomie. - 4. Arnsperger, Die Atiologie und Pathogenese der Aortenaneurysmen. Hab.-Sohr. f. Heidelberg. Naumburg 1903. - 5. B a c k$\mathrm{h}$ a $\mathrm{u}$, Ủber Mesarteriitis syphilitica und deren Beziehung zur Aneurysmenbildung der Aorta. Diss, Kiel 1897. - 6. B e it z ke, Ủber knötchenförmige syphilitische Leptomeningitis und iber Arteriitis syphilitica. Virch. Arch. Bd. 204, 1911. - 7. B en d a, Das Arterienaneurysma. Lubarsch und Ostertags Ergebnisse: Jahrg. VIII. Aneurysma und Syphilis. Referat. Verh. $d$. D. Path. Ges. Kassel 1903. Berl. klin. Wschr. 1906, 1910. - 8. B r u b n s, Utber Aortenerkrankung bei kongenitaler Syphilis. Berl. klin. Wschr. 1906, Nr. 8/9. - 9. B ro oks, H., Zit. Ztlbl. f. Path. 1908. - 10. B arth, H., Ein Fall von Mesarteriitis der Arteria pulmonalis mit Aneurysmabildung. Ztschr. f. Path. V. 1910. - 11. B oll i n g e r, Über Arteriosklerose. Münch. med. Wschr. 1902, Nr. 15. - 12. B ardachzi, Fr., Uber zwei Fälle von Aortitis syphilitica mit Koronarostienverschließung. Ztsehr. f. Heilk. XXIV. - 13. B a er, Utber die Todesursache beim Aortenaneurysma. Frankf. Ztschr. f. Path. Bd. 10, H. 1. - 14. B e c k, Úber Mesaortitis gummosa. Diss. Basel 1903. - 15. B a u m g r t e n, Diskussionsbemerkungen. Verh. d. D. Path. Ges. Kassel 1903. - 16. Ohi a $x^{i}$, Über die syphilitischen Aortenerkrankungen. Verh. d. D. Path. Ges. Kassel 1903. - 17. Citron, Berl klin. Wschr. 1908, Bd. 48. 18. D o e h $1 \mathrm{e}$, Ùber Aortenerkrankung bei Syphilitischen und deren Beziehung zur Aneurysmabildung. D. Arch. f. klin. Med. Bd. 55, 1895 und Diss. Kiel 1885. - 19. E i ch, Beiträge zux pathologischen Histologie, Genese nnd Ätiologie der Doehle-Hellerschen Aortitis. Frankf. Ztschr. f. Path. Bd. 7, H. 3, 1911. - 20. F a h r, Zur Frage der Aortitis syphilitica. Virch. Arch. Bd. 177 und Münch. med. Wschr. 1906. - 21. F r a enkel, E., und Mue h, Die Wassermannsche Reaktion an der Leiche. Nünch. med. Wschr. 1908, Nr. 12. - 22. F o à, P., Lubarsch-Ostertags Ergebnisse der allgemeinen Pathologie und pathologischen Anatomie. Jahrg. XII, 1908. 23. Gins b urg, S., Die makroskopisch-luetischen Veränderungen der Aortenwand bei der progressiven Paralyse. I.-Diss. Jena 1910. - 24. H e in e, Beiträge zur Kasuistik der Mesaortitis gummosa. Virch. Arch. Bd. 170, 1902. - 25. H a r t, C., Beiträge zur Pathologie des GefäBsystems. Virch. Arch. Bd. 177. - 26. Has sel ba ch, Beiträge zur Syphilis der Blut- 
曹
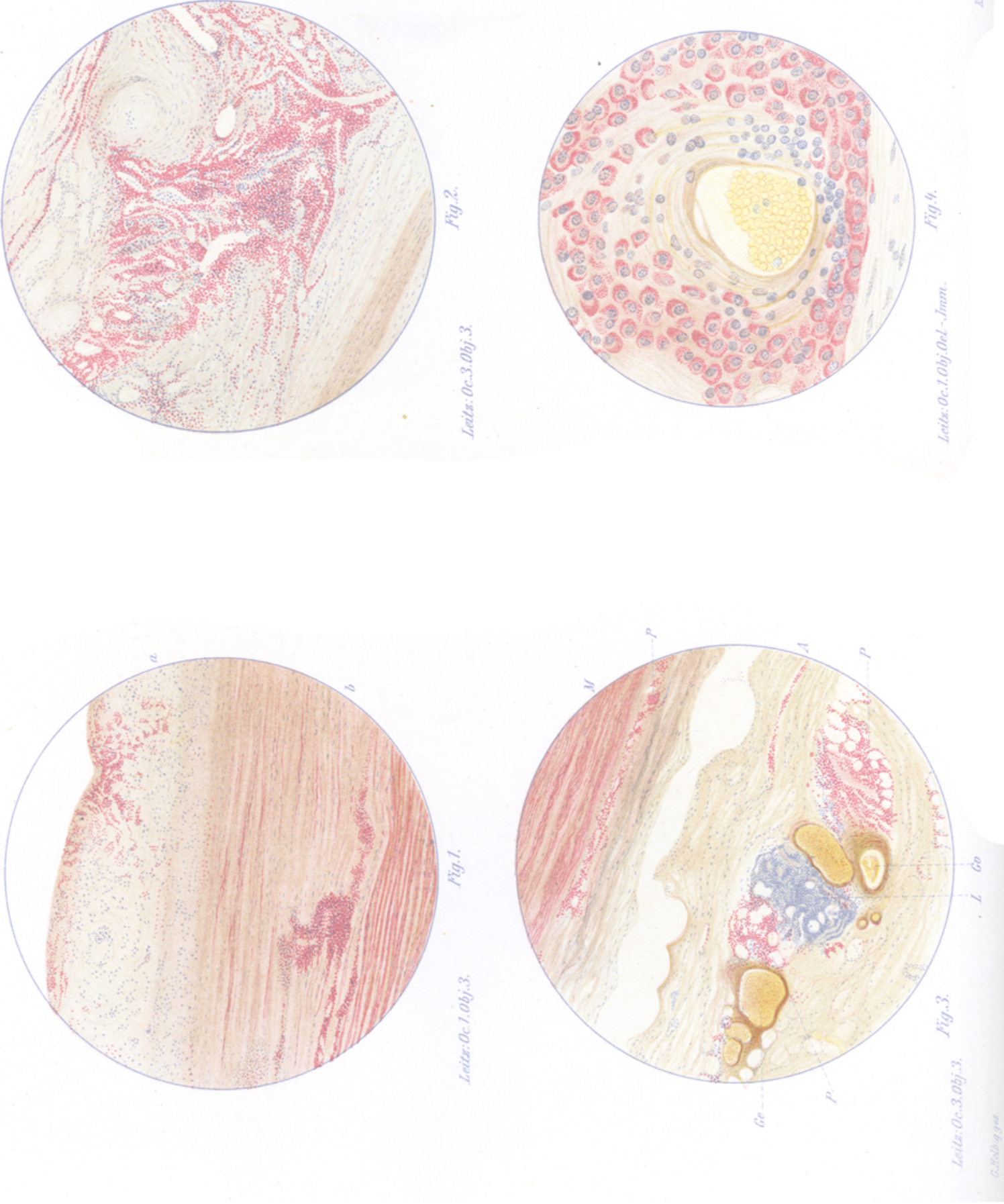
gefäße. Diss. Greifswald 1905. - 27. H ell e r, Die Aortensyphilis als Ursache von Aneurysmen. Verh. d. D. Path. Ges. München 1899. Aortenaneurysma und Syphilis. Virch. Arch. Bd. 171. Diskussionsbemerkungen. Verh. d. D. Path. Ges. Kassel 1903. - 28. H a n s e m a n n, Diskussionsbemerkungen. Verh. d. D. Path. Ges. München 1899 und Kassel 1903. - 29. J a k o b , zitiert nach Doehle. - 30. Kal eff, Über Lues und Aneurysma der Aorta. I.-Diss. Berlin 1910. - 31. K a u f $\mathrm{man} n$, Lehrbuch der speziellen pathologischen Anatomie. - 32. K ö $\mathrm{s}$ te $\mathrm{r}$, Über Endarteriitis und Arteriitis. Sitzungsberichte der niederrheinischen Gesellschaft. Bonn, Dezember 1875. - Û́ber die Entstehung der spontanen Aneurysmen und die chronisehe Mesarteriitis. Sitzungsbericht der niederrheinischen Gesellschaft. Bonn, I. 1875. - 33. v. Le y d e n, D. med. Wschr. 1894. - 34. L u b a $\mathrm{s} \mathrm{ch}$, Jahreskurse f. ärztliche Fortbildung. Jahrg. 1911, H. 1. - 35. Le dermann, Über die Bedeutung der Wassermannschen Serumreaktion für die Diagnostik und Behandlung der Syphilis. Med. Klinik 1909, Nr. 12. - 36. M a l m s te $\mathrm{n}$, Aorta Aneurysmens Ätiologie. Stockholm 1888. Zitiert nach Doehle und Backhaus. - 37. M ar chand, Über das Verhältnis der Syphilis und Arteriosklerose zur Entstehung der Aortenaneurysmen. Verh. d. VI. D. Path. Ges. Kassel 1903. - 38. Moli n a r i, zitiert nach Eich. 39. Meirowski und Jesionek, Die praktische Bedeutung der Wassermann-Neisser Brucksehen Syphilisreaktion. Münch. med. Wschr. 1909, Nr. 45. - 40. P u p p e, Untersuchungen über das Aneurysma der Brustaorta. D. med. Wschr. 1894, Nr. 45 u. 46. -. 41. P i c k, Diskussionsbemerkungen in der Berliner med. Gesellschaft. Berl. klin. Wschr. 1909, Nr. 24. 42. Re u te r, Über Spirochaete pallida in der Aortenwand bei Hellerscher Aortitis. Münch. med. Wschr. 1906, Nr. 16 u. 34 und Ztschr. f. Hygiene 54, 1, 1906. - 43. R e i t t e r. Ein Beitrag zu den syphilitischen Erkrankungen des Herzens und der Aorta unter besonderer Berücksichtigung der Ergebnisse der W. Reaktion. I.-Diss. Freiburg 1911. - 44. R a v e n n a, E., Zur syphilitischen Aortitis. - 45. Rosen berger, Statistische Untersuchungen der pathologischanatomischen Luesbefunde am Berliner städtischen Krankenhanse am Urban. Diss. Freiburg 1904. - 46. S tr a u b, U̇ber die Veränderung der Aortenwand bei progressiver Paralyse. Verh. d. D. Path. Ges. München 1899. - 47. S c h ma u s, Grundriß der pathologischen Anatomie. 48. S a a th of $f$, Das Aortenaneurysma auf syphilitischer Grundlage und seine Frühdiagnose. Münch. med. Wschr. Nr. 42. - 49. S o a gli o s i, G., Sulla aortite sifilitica. Zitiert nach Ztlbl. f. allg. Path. u. path. Anat. - 50. S te in me ier Aneurysma spurinm bei Aortitis syphilitica. Frankf. Ztsohr. 1. Path. Bd. 10, H. 2, 1912. - 51. S i m o n, Ein Fall von Aorteninsuffizienz bei Tabes dorsalis. Diss. Kiel 1900. - 52. S c h m ol, Münch. med. Wschr. 1908. - 53. Th or el, Lubarsch-Ostertags Ergebnisse. IX, XI. Jahrg. - 54. Takigu c h i, Drei Fälle von Aortitis syphilitica. Diss. München 1908. -55 . V e rs é, Periarteriitis nodosa und Arteriitis syphilitica. Zieglers Beitr. Bd. 40, 1907. - 56. V a n zetti, Ricerche sperimentali Sull' arterite e Sull' aneurisma sifilitici. Archi. per le Scienze mediche. Vol. XXXV, No. 24, 1911. - 57. W i e de m a n n, Über Aortitis syphilitica. Diss. Leipzig 1905. - 58. W right und Rich ar d s o n, Treponema and Syphilitic Aortitis, Five cases, one with Aneurisma. Boston medic and Surg. Journ. 1909, No. 17. - 59. W i e s n e r, R, Über Erkrankung der großen Gefäße bei Lues congenita. Ztlbl. f. path. Anat. 1905, Nr. 20. - 60. W e le h, Med. chir. Tr. Bd. 59.

\section{Erklärungder Abbildungen a f Taf. VIII.}

Die Abbildungen sollen das Vorkommen der Plasmazellen veranschaulichen. Sie sind nach Präparaten angefertigt, die mit $P$ appenheim-Unnas Methylgrün-Pyronin gefärbt sind (Plasmazellen rot).

Fig. 1. Plasmazellen in der verdickten Intima (Fall 64). a Intima. $b$ Media.

Fig. 2. Plasmazellen in einem. Mediaherde (Fall 34).

Fig. 3. Plasmazellen in der Adventitia (Fall 64). M. Media. L. Lymphozytenanhäufung. Gv. verdicktes Gefäß. Ge. erweiterte Gefäße. P. Plasmazellen.

Fig. 4. Plasmazellen in der Umgebung eines GefäBes (Fall 40). 